AUTARQUIA ASSOCIADA À UNIVERSIDADE DE SÃO PAULO

\title{
AVALIAÇÃO DA ECOTOXICIDADE DO RESVERATROL NO ESTÁGIO EMBRIOLARVAL DE PEIXES DA ESPÉCIE Danio rerio
}

\author{
ADRIANA KUCHINSKI CAVALCANTE
}

Dissertação apresentada como parte dos
requisitos para obtenção do Grau de
Mestre em Ciências na Área
de Tecnologia Nuclear-Materiais

Orientador:

Prof. Dr. José Roberto Rogero 
INSTITUTO DE PESQUISAS ENERGÉTICAS E NUCLEARES

Autarquia associada à Universidade de São Paulo

AVALIAÇÃO DA ECOTOXICIDADE DO RESVERATROL NO ESTÁGIO EMBRIOLARVAL DE PEIXES DA ESPÉCIE Danio rerio

ADRIANA KUCHINSKI CAVALCANTE

Dissertação apresentada como parte dos requisitos para obtenção do Grau de

Mestre em Ciências na Área

de Tecnologia Nuclear - Materiais

Orientador:

Prof. Dr. José Roberto Rogero

Versão Corrigida

Versão Original disponível no IPEN

São Paulo

2017 
Dedico este trabalho aos meus pais que sempre me incentivaram, amo vocês! 


\section{AGRADECIMENTOS}

Agradeço a Deus pela minha existência e pela oportunidade de aprender sempre nessa escola que é a vida.

Aos meus pais que sempre estiveram ao meu lado, me incentivado, torcendo por mim em todos os momentos, e que se não fosse por eles não teria chegado até aqui.

Ao Dr. José Roberto Rogero pela oportunidade, pelo acolhimento, pela orientação, pelos conselhos, pelo apoio, pela confiança, paciência e amizade. Muito obrigada por tudo.

À Ms. Sizue Ota Rogero por sempre estar ao meu lado em todos os momentos, principalmente os difíceis, me dando apoio sempre. Obrigada pela sua amizade que quero levar para a vida.

À Dra. Mônica Lopes Ferreira, do Laboratório Especial de Toxinologia Aplicada (LETA), do Instituto Butantan, pela amizade, pelo fornecimento dos embriões para o estudo, pelos ensinamentos e pelo incentivo.

Ao Dra. Ademar Benévolo Lugão pelo acolhimento, atenção, apoio, conselhos e por proporcionar condições laboratoriais para a conclusão deste trabalho.

Ao Dr. Cesar Koppe Grisolia e ao Dr. Rhaul de Oliveira, do Laboratório de Genética Toxicológica (G-Tox), da Universidade de Brasília, pela parceria, pela ajuda na parte experimental e pelos ensinamentos.

A Dra. Tamara Mieco Fucase pela amizade, pelo apoio, pelos conhecimentos transmitidos e pela ajuda na parte experimental. 
Ao meu amigo, namorado e companheiro de todas as horas, Williams Camilo Junior, por sempre estar ao meu lado, me ajudando em tudo, pela força, pelo incentivo, pelos conselhos, pelos abraços quando achava que nada ia dar certo. Obrigada por tudo.

Ao meus amigos do Laboratório de Ecotoxicologia do Centro de Química e Meio Ambiente: Joana, Gisela, Matheus, Fernanda e Kelme por toda ajuda ao decorrer do trabalho, pelas risadas, pela parceria e pela amizade.

À minha amiga Gleide Sanges, do Laboratório Especial de Toxinologia Aplicada (LETA), do Instituto Butantan, pela ajuda, parceria e amizade.

Ao Instituto de Pesquisas Energéticas e Nucleares, em especial ao Centro de Química e Meio Ambiente (CQMA) e ao Centro de Biotecnologia (CB) pela oportunidade de desenvolver este projeto.

À Capes pelo apoio financeiro para o desenvolvimento deste trabalho. 


\title{
AVALIAÇÃO DA ECOTOXICIDADE DO RESVERATROL NO ESTÁGIO EMBRIOLARVAL DE PEIXES DA ESPÉCIE DANIO RERIO
}

\author{
Adriana Kuchinski Cavalcante
}

\section{RESUMO}

A busca pelo homem por uma vida saudável tem impulsionado pesquisas por novas substâncias capazes de atender tal desejo. O composto fenólico resveratrol (3, 4', 5- trihidroxiestilbeno) é uma dessas substâncias que apresenta uma variedade de ações farmacológicas, como potencial antioxidante, capacidade antiinflamatória, proteção contra doenças cardíacas e câncer. Apesar dos inúmeros estudos sobre os benefícios do resveratrol à saúde, há poucos dados na literatura sobre sua toxicidade em organismos aquáticos, e principalmente sua concentração no ambiente, tornando o presente estudo fundamental para a contribuição de informações sobre a ecotoxicidade do resveratrol no ambiente aquático. O presente estudo avaliou a toxicidade do resveratrol em embriões e larvas de Danio rerio (zebrafish). Para isso foi realizado o ensaio in vitro de citotoxicidade do resveratrol, ensaios de ecotoxicidade e ensaio de biomarcadores enzimáticos. A avaliação do resveratrol por cromatografia líquida de alta pressão (HPLC) também foi realizada. De acordo com os resultados obtidos, o índice de citotoxicidade ( $\left(\mathrm{C}_{50}\right)$, concentração do resveratrol que causou a morte de $50 \%$ das células da linhagem NCTC-L929 foi de $39 \mathrm{mg} \mathrm{L}^{-1}$. A concentração de resveratrol que causa mortalidade em $50 \%$ dos organismos expostos (CL50), nos ensaios de ecotoxicidade crônica de curta duração com larvas do peixe Danio rerio foi de $51,37 \mathrm{mg} \mathrm{L}^{-1}$. A CL50 obtida no ensaio de ecotoxicidade aguda no estágio embriolarval do peixe Danio rerio com $96 \mathrm{~h}$ de duração foi de $75,33 \mathrm{mg} \mathrm{L}^{-1}$ e a CL50 obtida no ensaio de ecotoxicidade aguda no estágio embriolarval do peixe Danio rerio com $168 \mathrm{~h}$ de duração foi de $50,87 \mathrm{mg} \mathrm{L}^{-1}$. Nas concentrações mais elevadas de resveratrol foram observadas deformidades em embriões e larvas. $\mathrm{O}$ resveratrol alterou as atividades das enzimas LDH e ChE no estágio embriolarval de Danio rerio. $\mathrm{Na}$ análise do resveratrol por HPLC não foi observado degradação do composto. 


\title{
EVALUATION OF RESVERATROL ECOTOXICITY IN THE EMBRYOLARVAL STAGE OF FISHES OF THE SPECIES DANIO RERIO
}

\author{
Adriana Kuchinski Cavalcante
}

\begin{abstract}
The concern about human being healthy life has driven researchers to study new compounds capable of reaching that desire. Resveratrol (3, 4, 5 trihydroxystilbene) a phenolic compound, is one of these substances which presents a variety of pharmacological actions, as antioxidant potential, antiinflammatory capacity, protection against heart and cancer diseases. Despite the numerous studies on the benefits of resveratrol to health, there is little evidence in the literature of its toxicity to aquatic organisms, and especially its concentration in the environment, making the present study fundamental for the contribution of information on the ecotoxicity of resveratrol in the aquatic environment. The present study evaluated the toxicity of resveratrol in embryos and larvae of Danio rerio (zebrafish). For this purpose the in vitro cytotoxicity of resveratrol assay, ecotoxicity assays and enzyme biomarker assay were performed. The evaluation of resveratrol by high pressure liquid chromatography (HPLC) was also performed. According to the results, the cytotoxicity index (IC50), concentration of resveratrol that caused the death of $50 \%$ of the cells of the NCTC-L929 lineage was $39 \mathrm{mg} \mathrm{L}^{-1}$. The concentration of resveratrol that causes mortality in $50 \%$ of exposed organisms (LC50) in the short-lived chronic ecotoxicity assays with larvae of the Danio rerio fish was $51.37 \mathrm{mg} \mathrm{L}^{-1}$. The LC50 obtained in the embryo-active acute ecotoxicity test of the Danio rerio fish with $96 \mathrm{~h}$ duration was $75.33 \mathrm{mg} \mathrm{L}^{-1}$ and the LC50 obtained in the embryo-active acute ecotoxicity assay of the Danio rerio fish with $168 \mathrm{~h}$ duration was $50.87 \mathrm{mg} \mathrm{L}^{-1}$. At higher concentrations of resveratrol deformities were observed in embryos and larvae. Resveratrol altered the activities of LDH and ChE enzymes in the embryonal stage of Danio rerio. No degradation of resveratrol was observed in the HPLC analysis of compound.
\end{abstract}




\section{SUMÁRIO}

Página

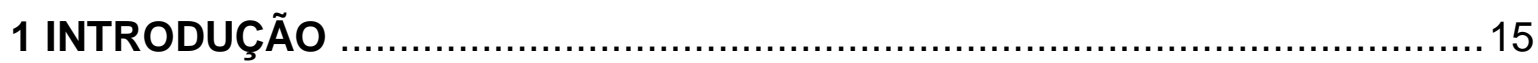

2 OBJETIVO

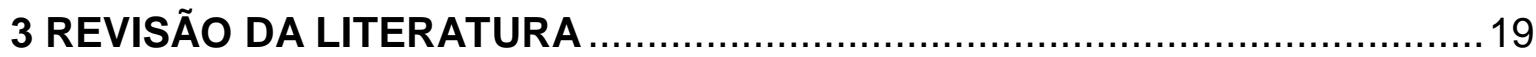

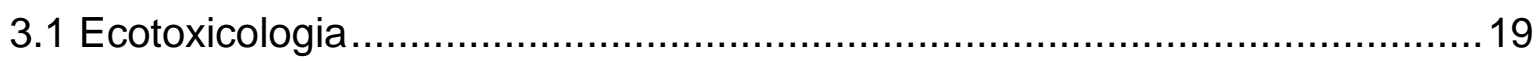

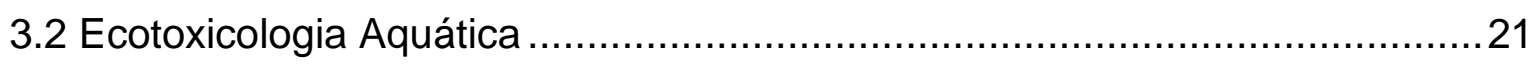

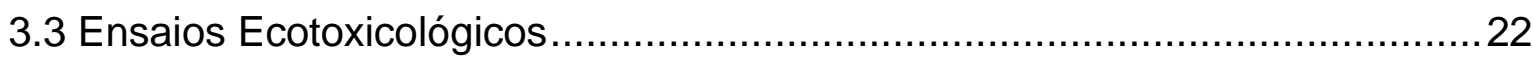

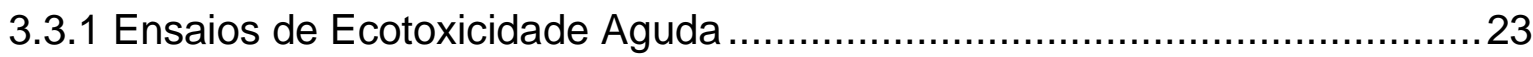

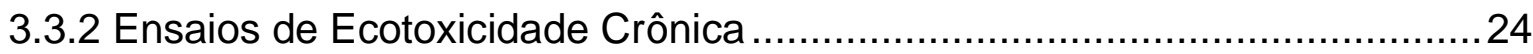

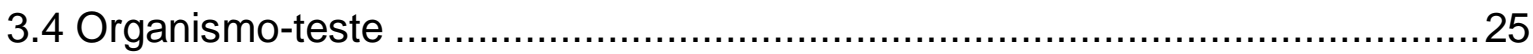

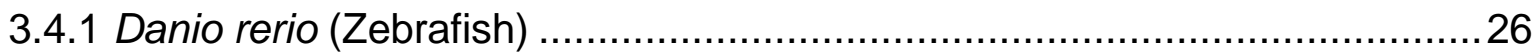

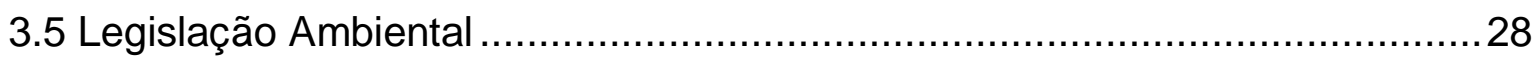

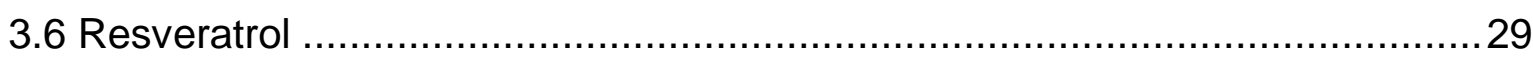

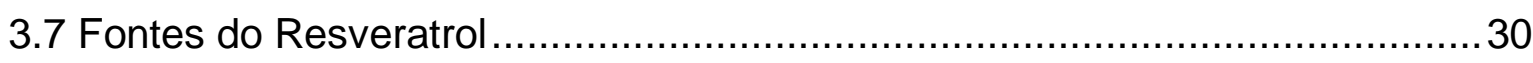

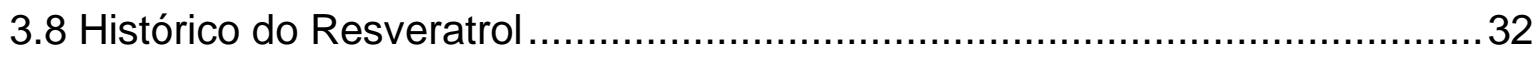

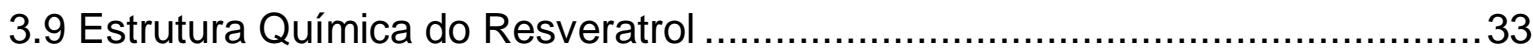

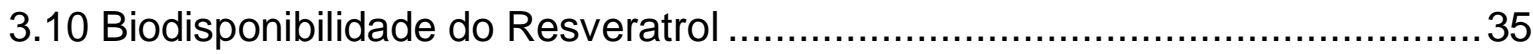

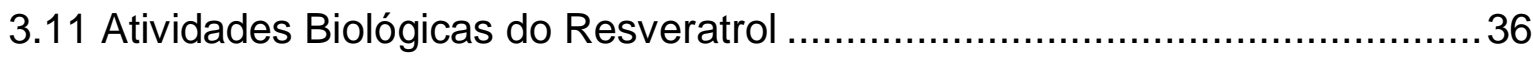

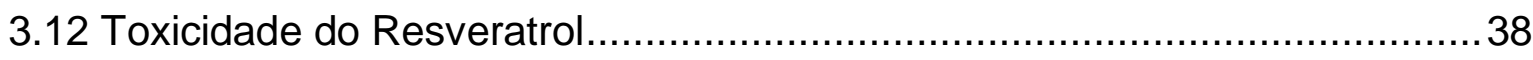

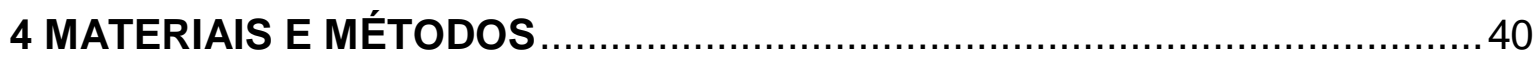

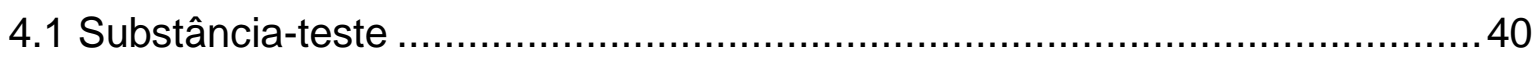

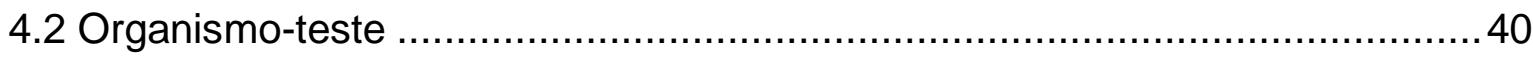

4.3 Análise do resveratrol por cromatografia líquida de alta pressão (HPLC) ......44

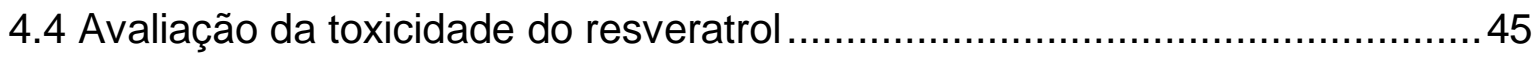

4.4.1 Ensaio in vitro de citotoxicidade do resveratrol.........................................45

4.4.2 Ensaio de ecotoxicidade crônica de curta duração com larvas do peixe Danio rerio

4.4.3 Ensaio de sensibilidade com larvas do peixe Danio rerio e obtenção da carta- controle

4.4.4 Ensaio de ecotoxicidade aguda no estágio embriolarval do peixe Danio rerio (96 h de duração) 
4.4.5 Ensaio de ecotoxicidade aguda no estágio embriolarval do peixe Danio rerio (168 $\mathrm{h}$ de duração)

4.4.6 Ensaio de biomarcadores enzimáticos de Danio rerio no estágio embriolarval .53

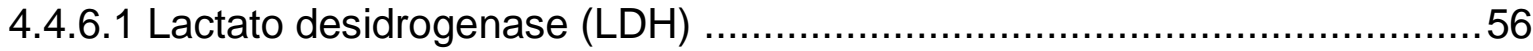

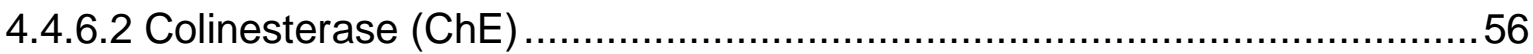

5 RESULTADOS E DISCUSSÃO

5.1 Análise do resveratrol por cromatografia líquida de alta pressão (HPLC) …...57

5.2 Ensaio in vitro de citotoxicidade do resveratrol .............................................. 61

5.3 Ensaio de ecotoxicidade crônica de curta duração com larvas do peixe Danio rerio 64

5.4 Ensaio de sensibilidade com larvas de Danio rerio e obtenção da carta controle 68

5.5 Ensaio de ecotoxicidade aguda no estágio embriolarval do peixe Danio rerio (96 h de duração) 71

5.6 Ensaio de ecotoxicidade aguda no estágio embriolarval do peixe Danio rerio (168 $\mathrm{h}$ de duração).

5.7 Ensaio de biomarcadores enzimáticos de Danio rerio no estágio embriolarval

5.7.1 Quantificação de proteínas .83

5.7.2 Atividade da enzima lactato desidrogenase (LDH) .................................... 84

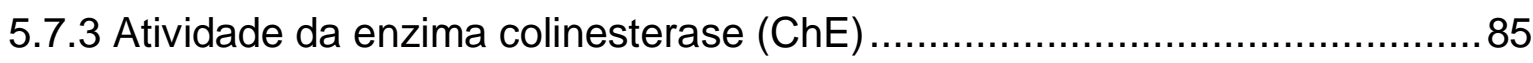

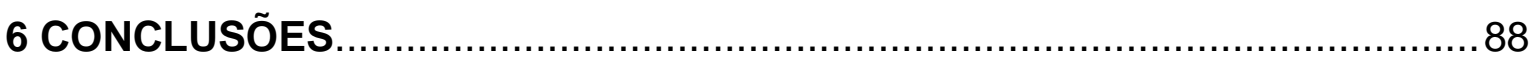

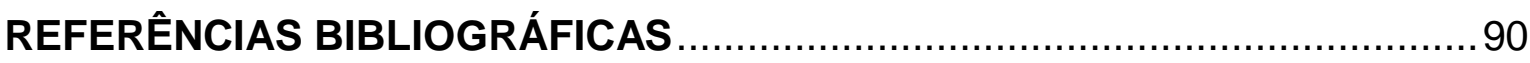




\section{LISTA DE TABELAS}

TABELA 1 - Porcentagens de viabilidade celular dos extratos dos controles negativo e positivo e do resveratrol.

TABELA 2 - Percentual de letalidade obtido nos ensaios de ecotoxicidade crônica de curta duração do resveratrol em larvas do peixe Danio rerio após $168 \mathrm{~h}$ de exposição.

TABELA 3 - Valores das CL50, intervalos de confiança, média, desvio padrão e coeficiente de variação para os ensaios de ecotoxicidade crônica de curta duração do resveratrol em larvas do peixe Danio rerio. 65

TABELA 4 - Percentual de letalidade obtido nos ensaios de sensibilidade das larvas do peixe Danio rerio após $168 \mathrm{~h}$ de exposição ao $\mathrm{NaCl}$ 68

TABELA 5 - Valores das CL50, intervalos de confiança, média, desvio padrão e coeficiente de variação dos ensaios de sensibilidade das larvas do peixe Danio rerio.

TABELA 6 - Percentual de letalidade obtido no ensaio de ecotoxicidade aguda do resveratrol no estágio embriolarval do peixe Danio rerio após $96 \mathrm{~h}$ de exposição

TABELA 7 - Valor da CL50 e intervalo de confiança para o ensaio de ecotoxicidade aguda do resveratrol no peixe Danio rerio no estágio embriolarval. .73

TABELA 8 - Percentual de taxa de eclosão de larvas de Danio rerio em 48, 72 e $96 \mathrm{~h}$

TABELA 9 - Percentual de letalidade obtido no ensaio de ecotoxicidade aguda do resveratrol no estágio embriolarval do peixe Danio rerio após 168 h de exposição 
TABELA 10 - Valor da CL50 e intervalo de confiança para o ensaio de ecotoxicidade aguda do resveratrol no peixe Danio rerio no estágio

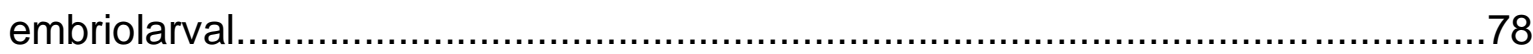




\section{LISTA DE FIGURAS}

FIGURA 1 - Casal de Danio rerio, fêmea (acima) e macho (abaixo). Fonte: Braunbeck e Lammer, 2006.

FIGURA 2 - Ciclo de vida do Danio rerio. O desenvolvimento do Danio rerio ocorre de forma rápida; a clivagem, gastrulação e organogênese ocorrem em 24 horas. Em 48 a 72 h após a fertilização, as larvas eclodem apresentando células de pigmentação. Após passar por fase juvenil, torna-se adulto 90 dias após a fertilização. Fonte: Rezende, 2013. 28

FIGURA 3 - Biossíntese do Resveratrol. .30

FIGURA 4 - Espécies de plantas que sintetizam resveratrol. Fonte: Aggarwal et al., 2004 31

FIGURA 5 - Fórmulas estruturais do resveratrol. .34

FIGURA 6 - Aquários de cultivo de Danio rerio, Laboratório de Genética Toxicológica - Universidade de Brasília. Fonte: O Autor, 2017

FIGURA 7 - (A) Aquários de reprodução de Danio rerio; (B) Aquário de reprodução com uma fêmea e dois machos de Danio rerio. Fonte: O Autor, 2017 42

FIGURA 8 - (A) Ovo de Danio rerio fecundado; (B) Ovo de Danio rerio coagulado. Fonte: Ikari et al., 2013

FIGURA 9 - (A e B) Ovos de Danio rerio recém fertilizados; (C) Larva de Danio rerio recém eclodida. Fonte: $O$ Autor, 2017. .43 
FIGURA 10 - HPLC modelo ÄKTApurifer-GE. Fonte: O Autor, 2017

FIGURA 11 - Leitura das DO em espectrofotômetro leitor tipo ELISA. Fonte: O Autor, 2017. .47

FIGURA 12 - Ensaio de ecotoxicidade crônica de curta duração com larvas de Danio rerio.

FIGURA 13 - Larva de Danio rerio sem batimento cardíaco. Fonte: OECD, 2013

FIGURA 14 - Microplacas de 24 poços. (A) Microplaca com resveratrol (soluçãoteste); (B) Microplaca com Controle Negativo; (C) Microplaca com Controle Solvente. $\quad \mathrm{R}=$ Resveratrol; $\mathrm{Cn}=$ Controle Negativo; $\mathrm{Cs}=$ Controle Solvente 51

FIGURA 15 - Ensaio de ecotoxicidade aguda no estágio embriolarval de Danio rerio (96 h de duração).

FIGURA 16 - Exposição dos embriões de Danio rerio recém fertilizados a diferentes concentrações de resveratrol e controles. 53

FIGURA 17 - (A) Tubo eppendorf contendo $0,5 \mathrm{~mL}$ de solução tampão fosfato e 15 larvas; (B) Sonicador; (C) Centrífuga; (D) Tubo eppendorf com o sobrenadante separado .55

FIGURA 18 - Espectrofotômetro. .56

FIGURA 19 - Cromatograma da solução padrão de resveratrol na concentração de $0,5 \mathrm{mg} \mathrm{mL}^{-1}$

FIGURA 20 - Cromatograma do resveratrol na concentração de $50 \mathrm{mg} \mathrm{L}^{-1}$ sem exposição a luz fluorescente 
FIGURA 21 - Cromatograma do resveratrol na concentração de $50 \mathrm{mg} \mathrm{L}^{-1}$ com exposição a luz fluorescente por $24 \mathrm{~h}$.

FIGURA 22 - Cromatograma do resveratrol na concentração de $100 \mathrm{mg} \mathrm{L}^{-1}$ sem exposição a luz fluorescente.

FIGURA 23 - Cromatograma do resveratrol na concentração de $100 \mathrm{mg} \mathrm{L}^{-1} \mathrm{com}$ exposição a luz fluorescente por $24 \mathrm{~h}$.

FIGURA 24 - Curvas de viabilidade celular obtidas no ensaio in vitro de citotoxicidade do resveratrol pelo método de incorporação do vermelho neutro

FIGURA 25 - Taxa de letalidade das larvas do peixe Danio rerio em função das concentrações do resveratrol após $168 \mathrm{~h}$ de exposição. "0*" refere-se ao controle solvente.

FIGURA 26 - Deformidades nas larvas de Danio rerio após exposição ao resveratrol no período de $144 \mathrm{~h}$ : ( $\mathrm{A}$ e B) Controle; (D e E) Larvas na concentração de $50 \mathrm{mg} \mathrm{L}^{-1}$ com edema do pericárdio e do saco vitelínico (setas pretas); (C) Larva na concentração de $50 \mathrm{mg} \mathrm{L}^{-1}$ com edema do pericárdio, do saco vitelínico e coluna vertebral torta (setas pretas). 66

FIGURA 27 - Taxa de letalidade das larvas do peixe Danio rerio em função das concentrações do $\mathrm{NaCl}$ após $168 \mathrm{~h}$ de exposição 68

FIGURA 28 - Visão geral dos efeitos do resveratrol sobre embriões e larvas de Danio rerio durante $96 \mathrm{~h}$ de exposição. "0*" refere-se ao controle solvente. .71

FIGURA 29 - Curva de letalidade do peixe Danio rerio no estágio embriolarval em função das concentrações do resveratrol após $96 \mathrm{~h}$ de exposição. "0*" refere-se ao controle solvente. 
FIGURA 30 - Embrião exposto ao resveratrol na concentração de $100 \mathrm{mg} \mathrm{L}^{-1}$, com a presença do resveratrol no córion, no período de $96 \mathrm{~h}$

FIGURA 31 - Taxa de eclosão de larvas de Danio rerio durante a exposição ao resveratrol (mg L-1) em 48, 72 e 96 h. " $0^{*}$ " refere-se ao controle solvente. .75

FIGURA 32 - (A) Embrião de Danio rerio morto no período de 96 h; (B) Larva de Danio rerio morta no período de $96 \mathrm{~h}$ após a eclosão. .76

FIGURA 33 - (A) Controle larva de Danio rerio no período de 96 h; (B) Larva de Danio rerio na concentração de $46,9 \mathrm{mg} \mathrm{L}^{-1} \mathrm{com}$ edema do pericárdio e do saco vitelínico (setas pretas), no período de $96 \mathrm{~h}$ .77

FIGURA 34 - Curva de letalidade do peixe Danio rerio no estágio embriolarval em função das concentrações do resveratrol após $168 \mathrm{~h}$ de exposição. "0*” refere-se ao controle solvente. .78

FIGURA 35 - Controle embrião de Danio rerio no período de $24 \mathrm{~h}$ com desenvolvimento normal. .79

FIGURA 36 - (A) Controle no período de $48 \mathrm{~h}$ com pigmentação dos olhos e do corpo; (C) Embrião no período de $48 \mathrm{~h}$, na concentração de $6,25 \mathrm{mg} \mathrm{L}^{-1}$, com pigmentação dos olhos e do corpo; (B e D) Embriões no período de 48 h, na concentração de $100 \mathrm{mg} \mathrm{L}^{-1}$, sem pigmentação dos olhos e do corpo (setas pretas). .80

FIGURA 37 - Controle larva de Danio rerio no período de $72 \mathrm{~h}$ com desenvolvimento normal. .80

FIGURA 38 - Deformidades nas larvas de Danio rerio após exposição ao resveratrol (50 $\mathrm{mg} \mathrm{L}^{-1}$ ) no período de $144 \mathrm{~h}$ : (A) Controle; (B) Larva com edema do pericárdio e do saco vitelínico (setas pretas). 
FIGURA 39 - (A) Embrião morto na concentração de $100 \mathrm{mg} \mathrm{L}^{-1}$ no período de 96 h; (B) Embrião morto na concentração de $100 \mathrm{mg} \mathrm{L}^{-1}$ no período de 120

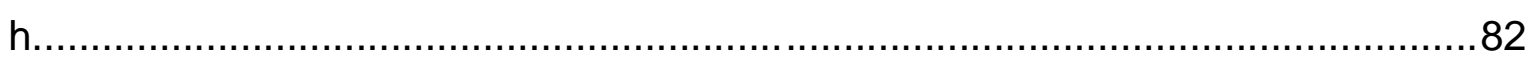

FIGURA 40 - Resultado da quantificação de proteínas no ensaio de biomarcadores enzimáticos no estágio embriolarval do peixe Danio rerio, após 96 $\mathrm{h}$ de exposição ao resveratrol. .83

FIGURA 41 - Resultado da atividade da enzima lactato desidrogenase (LDH) do peixe Danio rerio no estágio embriolarval, após $96 \mathrm{~h}$ de exposição ao resveratrol. * Diferença estatisticamente significativa em relação ao controle (ANOVA p > $0,05)$ .84

FIGURA 42 - Resultado da análise da atividade da enzima colinesterase (ChE) do peixe Danio rerio no estágio embriolarval, após $96 \mathrm{~h}$ de exposição ao resveratrol. * Diferença estatisticamente significativa em relação ao controle (ANOVA $p>0,05$ ). .86 


\section{INTRODUÇÃO}

Os ecossistemas aquáticos recebem uma imensa variedade e quantidade de poluentes devido às atividades antrópicas. Esses poluentes são lançados no ar, no solo ou então diretamente nos corpos de água, ocasionando muitas vezes impactos irreversíveis (Rubinger, 2009).

Ao atingirem o ambiente aquático a interação entre os poluentes e a comunidade biológica local pode ocorrer (Zagatto e Bertoletti, 2006). Os efeitos deletérios que são ocasionados pela ação dos poluentes nos organismos podem causar alterações na reprodução, nas taxas de mortalidade, na diversidade de espécies, na relação predador-presa, assim como nos processos de respiração e fotossíntese (Costa et al., 2008).

Os objetivos da ecotoxicologia são avaliar a toxicidade de poluentes "in situ" e "ex situ" e avaliar o risco que agentes químicos apresentam para os ecossistemas (Brentano, 2006). Os testes de ecotoxicidade são capazes de avaliar impactos ambientais, pois o conhecimento da toxicidade dos contaminantes possibilita estabelecer os limites permissíveis de diversas substâncias químicas para a proteção da vida aquática.

Os estudos ecotoxicológicos estão sendo exigidos por diversos instrumentos legais voltados à proteção da biota em corpos hídricos brasileiros, como na Resolução no. 430/11, do Conselho Nacional do Meio Ambiente (CONAMA), o qual se refere às condições e padrões de lançamentos de efluentes (Bertoletti, 2009; BRASIL, 2011).

O peixe zebrafish, Danio rerio, é um importante modelo animal utilizado nas áreas de biologia de desenvolvimento, genética e biomedicina (Grunwald e Eisen, 2002), sendo utilizado em ensaios ecotoxicológicos através de normas brasileiras (ABNT, 2007; ABTN, 2011) e intermacionais. Como o zebrafish apresenta $70 \%$ de semelhança genética com humanos, bem como semelhanças fisiológicas e anatômicas, este modelo pode ser utilizado para prever efeitos de toxicidade em humanos (Zhang et al., 2003; Hill et al., 2005; Bar-llan et al., 2009).

Além de taxa reprodutiva elevada e rápido desenvolvimento embrionário (fora do corpo materno), a espécie possui grande sensibilidade quando exposta a produtos químicos, por ser capaz de absorver rapidamente os 
compostos que são diretamente adicionados na água e acumulá-los em vários tecidos (Albinati et al., 2009; Sant'ana, 2009). O organismo é de fácil obtenção, manejo e baixo custo (Bugiak, 2009; Rubinger, 2009; Zagatto e Bertoletti, 2006).

A busca pelo homem por uma vida saudável tem impulsionado pesquisas por novas substâncias capazes de atender tal desejo. Entre essas substâncias encontramos os polifenóis (Bachur et al., 2009). O composto fenólico resveratrol (3, 4', 5- trihidroxiestilbeno) é considerado uma fitoalexina que pertence à família estilbeno (Jeandet et al., 2002).

As fitoalexinas são compostos antimicrobianos produzidos por diversas espécies de plantas em condições de estresse, que podem ser causadas por fatores bióticos, como ferimentos nas plantas decorrentes da ação de fungos, ou por fatores abióticos, como exposição à radiação ultravioleta emitida pelo sol e agentes químicos, conferindo as plantas uma proteção contra diferentes doenças (Van Etten et al., 1994; Taiz e Zeiger, 2004).

O resveratrol é formado por dois anéis aromáticos unidos por uma ponte de metileno, sendo identificado em 72 espécies de plantas (Acquaviva et al., 2002), como por exemplo a amora, o amendoim, o eucalipto e a uva (Jang et al, 1997). As espécies de videiras Vitis vinífera e Vitis labrusca, apresentam a maior capacidade de síntese do resveratrol, sendo a uva e seus produtos industrializados fontes importantes do composto (Pan et al., 2009; Penna e Hecktheuer, 2004; Roméro-Pérez et al., 2001; Vuong et al., 2014).

$\mathrm{Na}$ uva o composto é produzido na película do fruto em diversas concentrações e estima-se que a casca da uva fresca contenha 50-100 $\mu \mathrm{g}$ de resveratrol por grama (Fernández-Mar et al., 2012).

Nos vinhos, a concentração de resveratrol depende de vários fatores, como a origem geográfica, tipo de vinho, práticas enológicas, condições climáticas e grau de infecção da planta por fungos (Douillet-Breuil et al., 1999).

O resveratrol é encontrado nas formas isômeras: trans- e cis- resveratrol (3, 4', 5- trihidroxi-trans-estilbeno e 3, 4', 5- trihidroxi-cis-estillbeno), e em formas análogas, como os isômeros trans- e cis- piceido (trans-resveratrol 3-O- $\beta$ glucosideo e cis-resveratrol 3-O- $\beta$-glucosideo) (Trela e Waterhouse, 1996).

Estudos mostram que o resveratrol apresenta uma grande variedade de atividades biológicas, como atividade antioxidante; antiinflamatória; antimicrobiana; anticancerígena; neuroprotetora; cardioprotetora; redução da 
obesidade; inibição da agregação de plaquetas e atividade estrogênica (Chaves et al., 2009; Olas et al., 2002; Ratna e Simonelli, 2002; Paulo, 2011).

A ação antioxidante do composto tem relação com sua conformação estrutural, pois os grupamentos hidroxila servem de doadores de elétrons, neutralizando e sequestrando os radicais livres, prevenindo a peroxidação lipídica (Gülçin, 2010; Leonard et al., 2003; Mokni et al., 2007).

Apesar de estar estabelecido que o resveratrol exerce efeitos benéficos em humanos e outros seres vivos, o seu mecanismo de ação não é bem entendido. Segundo Mukherjee et al. (2010), em baixas doses o resveratrol tem função anti-apoptótica e função cardioprotetora, já em altas dosagens apresenta ações pro-apoptóticas, impedindo o desenvolvimento tumoral, mas por outro lado, também pode provocar aberrações cromossômicas estruturais e aumentar a incidência do infarto do miocárdio.

Sabe-se que o resveratrol é absorvido pelo intestino e eliminado rapidamente (Leonard et al., 2003), sendo que a sua excreção e de seus metabólitos ocorre com o auxílio da bile e da urina (Vitrac et al., 2003), entretanto, não há dados na literatura sobre a concentração do composto no ambiente. Apesar dos inúmeros estudos sobre os benefícios do resveratrol à saúde, há poucos dados na literatura sobre sua toxicidade em organismos aquáticos, tornando o presente estudo fundamental para a contribuição de novas informações sobre a ecotoxicidade do resveratrol no ambiente aquático. 


\section{OBJETIVO}

O objetivo deste trabalho é determinar a toxicidade do resveratrol em embriões e larvas de Danio rerio por meio de ensaios ecotoxicológicos.

Para atingir o objetivo foram realizados os seguintes procedimentos e ensaios:

$\checkmark$ Análise do resveratrol por cromatografia líquida de alta pressão (HPLC);

$\checkmark$ Ensaio in vitro de citotoxicidade do resveratrol;

$\checkmark$ Ensaio de ecotoxicidade crônica de curta duração com larvas do peixe Danio rerio adaptado da norma ABNT-NBR 15499 (ABNT, 2007);

$\checkmark$ Ensaio de sensibilidade com larvas do peixe Danio rerio para obtenção da carta controle baseado na norma ABNT-NBR 15499 (ABNT, 2007);

$\checkmark$ Ensaio de ecotoxicidade aguda no estágio embriolarval do peixe Danio rerio (96 $\mathrm{h}$ de duração) baseado no protocolo da OECD no 236 - Guideline on Fish Embryo Acute Toxicity Test (FET) (2013);

$\checkmark$ Ensaio de ecotoxicidade aguda no estágio embriolarval do peixe Danio rerio (168 h de duração) baseado no protocolo da OECD no 236 - Guideline on Fish Embryo Acute Toxicity Test (FET) (2013);

$\checkmark$ Ensaio de biomarcadores enzimáticos de Danio rerio no estágio embriolarval; 


\section{REVISÃO DA LITERATURA}

\subsection{Ecotoxicologia}

O termo Ecotoxicologia foi proposto pela primeira vez em junho de 1969, pelo toxicologista francês René Truhaut, durante uma reunião do Committee of the International Council of Scientific Unions (ICSU), em Estocolmo (Truhaut, 1977).

O conceito foi discutido, e em 1976 definiu-se ecotoxicologia como sendo: a ciência que estuda os efeitos das substâncias naturais ou sintéticas sobre os organismos vivos, populações e comunidades, animais ou vegetais, terrestres ou aquáticos, que constituem a biosfera, incluindo assim a interação das substâncias com o meio nos quais os organismos vivem num contexto integrado (Plaa, 1982; Cairns e Niederlehner, 1995).

De acordo com SCOPE (1978) a ecotoxicologia é a ciência que estuda os efeitos tóxicos de agentes químicos e físicos nos organismos vivos, principalmente sobre populações e comunidades dentro de ecossistemas definidos. Esses estudos incluem as vias de entrada e transporte de agentes em causa, assim como sua interação com o ambiente.

Segundo Bertoletti (1990), a ecotoxicologia é o estudo do comportamento e as transformações de agentes químicos e fatores abióticos no ambiente, assim como seus efeitos sobre a biota.

A ecotoxicologia resulta em uma visão mais ampla do que a simples avaliação dos efeitos das substâncias sobre os seres vivos. A toxicidade ou ecotoxicidade pode não ser o resultado da ação de uma substância isolada, mas da interação de vários agentes presentes em um determinado ambiente. Desta maneira, a avaliação ecotoxicológica de um determinado ambiente passa pelo conhecimento das fontes de emissão dos poluentes, bem como de suas transformações, difusões e destinos no local (Zagatto e Bertoletti, 2006).

O estudo da ecotoxicologia parte do pressuposto que a sobrevivência humana depende do bem estar de outras espécies, e que os agentes químicos podem causar efeitos prejudiciais em organismos vivos e em processos ecológicos (Yu et al., 2005). 
Consideram-se objetivos da ecotoxicologia: avaliar a toxicidade de poluentes "in situ" e "ex situ", compreender os mecanismos de ação de substâncias tóxicas e avaliar o risco que agentes químicos apresentam para os ecossistemas (Brentano, 2006).

Para Rand et al. (1995) o objetivo da ecotoxicologia é proteger populações e comunidades, entretanto não é possível a utilização de todas as espécies existentes pois o número de organismos é maior e consequentemente, o grau de incerteza na extrapolação dos dados também. A extrapolação dos dados de toxicidade são mais difíceis devido às variações dos fatores ambientais, como por exemplo, a dureza das águas, temperatura, pH, etc.

$\mathrm{Na}$ década de 70 , a pressão da opinião pública sobre as indústrias potencialmente poluidoras permitiu o avanço na área da ecotoxicologia, pois as agências de proteção ambiental, principalmente nos Estados Unidos e na Europa começaram a desenvolver os primeiros protocolos padronizados de teste de toxicidade, utilizando espécies nativas daqueles países (Magalhães e Ferrão Filho, 2008).

No Brasil, testes de ecotoxicidade foram desenvolvidos nas décadas de 70 e 80, entretanto, foi na década de 90 que essa área de estudo se consolidou com a elaboração de procedimentos e normas técnicas (Abessa, 2002). A primeira tentativa em termos de metodologia ocorreu em 1975, em um programa de padronização de testes de toxicidade aguda com peixes, desenvolvido pelo Comitê Técnico de Qualidade das Águas da International Organization for Standarctization (ISO), com a participação da Companhia de Tecnologia de Saneamento Ambiental do Estado de São Paulo (CETESB), a convite da Associação Brasileira de Normas Técnicas (ABNT) (Veiga e Vital, 2002; Zagatto e Bertoletti, 2006).

A partir de 1975, foram desenvolvidos e adaptados vários métodos de ensaios de toxicidade, utilizando alguns grupos e espécies de organismos, dentro os quais se destacam as algas, microcrustáceos e peixes, de águas continentais, estuarinas e marinhas, e testes com sedimentos (Zagatto e Bertoletti, 2006).

Alguns órgãos como Environment Canada e Environmental Protection Agency dos Estados Unidos (U.S. EPA), e de padronização, como American Society for Testing and Materials (ASTM), Organisation for Economic Cooperation and Development (OECD), Association of Analytical Communities (AOAC) e 
International Organization for Standardization (ISO) tem como objetivo o desenvolvimento de protocolos de testes de toxicidade que permitam definir limiares de toxicidade permissíveis com níveis de incerteza aceitáveis e que sirvam de guia para as entidades reguladoras para a tomada de decisões. Onde estes níveis servem de base para a fiscalização em programas de monitoramento da qualidade dos ecossistemas (Sousa, 2002; Costa et al., 2008).

Atualmente, os ensaios de toxicidade e estudos de monitoramento ambiental são empregados com a finalidade de avaliar e conhecer os efeitos da introdução direta e/ou indireta de compostos químicos no meio ambiente (Martini, 2013).

\subsection{Ecotoxicologia Aquática}

A água é um elemento vital para a sobrevivência, entretanto os ecossistemas aquáticos têm sido alterados de maneira significativa em função de múltiplos impactos ambientais advindos de atividades antrópicas, tais como lançamentos de efluentes domésticos e industriais não tratados; derrames acidentais de lixos químicos; mineração; construção de barragens e represas; retilinização e desvio do curso natural de rios; desmatamento e uso inadequado do solo em regiões ripárias e planícies de inundação; superexploração de recursos pesqueiros; introdução de espécies exóticas, entre outros (Goulart e Callisto, 2003).

Ao atingirem o ambiente aquático, os poluentes estão sujeitos a interações, como a concentração ou diluição, sendo que os compostos podem ser alterados em função de diversas reações químicas que participam. A interação entre os poluentes e a comunidade biológica local também pode ocorrer (Zagatto e Bertoletti, 2006).

A toxicidade de uma substância química depende das propriedades, concentração e do tempo de exposição à que o organismo está sendo exposto. Os efeitos tóxicos causados pela exposição à diversos contaminantes pode se manifestar em diferentes níveis de organização biológica, desde estruturas celulares até populações e comunidades. Deste modo, a vulnerabilidade do ambiente aquático depende das propriedades físicas e químicas do composto, de 
sua concentração e das características físicas e químicas do ecossistema (Rand et al., 1995).

Os organismos aquáticos podem ser expostos aos agentes químicos presentes na água, nos sedimentos e nos alimentos. Portanto, a bioacumulação, que é o resultado do processo de acúmulo dos poluentes nos tecidos dos organismos vivos, caso não sejam metabolizados ou excretados por eles, é o impacto mais frequente da poluição, sendo que este acúmulo é transmitido para o nível superior da cadeia trófica (Gomes e Sato, 2011).

Os efeitos deletérios que são ocasionados pela ação dos poluentes nos organismos se propagam pelos demais componentes do ecossistema. Tais efeitos podem causar alterações na reprodução, nas taxas de mortalidade, na diversidade de espécies, na relação predador-presa, assim como nos processos de respiração e fotossíntese (Costa et al., 2008).

A avaliação da toxicidade de agentes químicos no meio aquático ocorre por meio de ensaios ecotoxicológicos, onde organismos representativos da coluna d' água ou dos sedimentos, de ambientes de água doce, estaurina e marinha, são expostos a substâncias potencialmente tóxicas, por um determinado período de tempo, visando observar a resposta dos organismos ao contaminante testado (Azevedo e Chasin, 2003; Zagatto e Bertoletti, 2006).

Os testes de toxicidade avaliam o efeito de substâncias tóxicas sobre a biota, já as análises químicas identificam e quantificam as concentrações dessas substâncias. Deste modo, nos últimos anos, os testes ecotoxicológicos são utilizados para estimar o descarte permissivo de efluentes no ambiente aquático, assim como para avaliar a qualidade da água e a eficiência dos sistemas de tratamento aplicados aos efluentes, sendo tais testes indispensáveis no controle da poluição ambiental (Costa et al., 2008).

\subsection{Ensaios Ecotoxicológicos}

Os ensaios de ecotoxicidade são capazes de avaliar impactos ambientais, pois o conhecimento da toxicidade dos contaminantes possibilita estabelecer os limites permissíveis de diversas substâncias químicas para a proteção da vida aquática (Zagatto e Bertoletti, 2006). 
Com o objetivo de proteger os ecossistemas aquáticos, pois os mesmos constituem os principais receptáculos de contaminantes, sejam eles lançados diretamente nos corpos d'água, emitidos no ar ou depositados nos solos, os ensaios de ecotoxicologia aquática são muito utilizados (GherardiGoldstein et al., 1990; Kendall et al., 2001).

O uso dos testes ecotoxicológicos integra os conceitos da ecologia, em relação à diversidade e representatividade dos organismos e seu significado ecológico nos ecossistemas, e da toxicologia, em relação aos efeitos adversos dos poluentes sobre comunidades biológicas (Plaa, 1982).

Para Abessa (2002), a utilização dos ensaios ecotoxicológicos apresenta diversas finalidades como por exemplo:

- O conhecimento da qualidade de águas, sedimentos, solo e ar;

- As estimativas do efeito de descargas de contaminantes sobre as populações naturais;

- A definição de áreas críticas;

- Análise de risco ecológico;

- Como integrantes em programas de monitoramento ambiental;

- A detecção dos primeiros sinais de impacto devido a compostos químicos;

- O fornecimento do significado biológico para dados de contaminação;

Os ensaios ecotoxicológicos são classificados de acordo com a duração (agudo ou crônico), método de adicionar a solução-teste (sistema estático, semi-estático e de fluxo contínuo) e propósito (teste de composto isolado; monitoramento da qualidade de efluente; toxicidade relativa; sensibilidade relativa, taxa de crescimento, entre outros) (Rubinger, 2009).

\subsubsection{Ensaios de Ecotoxicidade Aguda}

Os testes de toxicidade aguda avaliam os efeitos sofridos pelos organismos aquáticos em um curto período de exposição ao agente tóxico ou à 
amostra ambiental (Rand e Petrocelli, 1985; Fracácio, 2001). Normalmente o efeito observado é a letalidade ou outra manifestação que a anteceda, como o estado de imobilidade em alguns microcrustáceos (Aragão e Araújo, 2006).

Para Pankratz (2001) o teste de toxicidade aguda é um método de teste usado para determinar a concentração de uma substância de produzir efeito venenoso a um organismo por um curto tempo de exposição que resulta em danos biológicos severos ou a morte.

No Brasil os ensaios de toxicidade aguda são empregados no monitoramento de efluentes industriais com o intuito de minimizar o impacto ambiental, avaliar as eficiências das estações de tratamento, bem como requisito para obtenção e manutenção de licenças junto aos órgãos ambientais de alguns Estados (Magalhães e Ferrão Filho, 2008).

Devido à facilidade de execução, curta duração e baixo custo, os ensaios de toxicidade aguda foram os primeiros a serem desenvolvidos e, portanto, constituem a base de dados ecotoxicológicos (Rubinger, 2009).

\subsubsection{Ensaios de Ecotoxicidade Crônica}

Na década de 60 , a necessidade de avaliar o potencial de risco de substâncias tóxicas à biota aquática em longo prazo, proporcionou $\mathrm{O}$ desenvolvimento do teste de toxicidade crônica, que compreende um método de teste usado para determinar a concentração da substância que produz um efeito adverso em um organismo-teste após um extenso período de tempo (Pankratz, 2001).

No início, os testes de toxicidade crônica baseavam-se na duração do ciclo de vida completo do organismo, o que implicava em ensaios muito onerosos, e que levou ao desenvolvimento de novos tipos de ensaios como os que abrangem parte do ciclo de vida ou os estágios iniciais de vida dos organismosteste, tais como aqueles que contemplam períodos críticos da vida do organismo (embriões, larvas, jovens) e consequentemente gastam menos tempo de exposição, tornando-os mais acessíveis (Aragão e Araújo, 2006).

Os testes de toxicidade crônica são portanto, caracterizados por uma maior duração, podendo abranger todo o ciclo de vida do organismo ou parte dele, envolvendo, geralmente os estágios de vida mais sensíveis (Zagatto e 
Bertoletti, 2006). Pode-se observar a letalidade, como também os organismos podem sobreviver, porém frequentemente apresentam suas funções biológicas afetadas, como crescimento, reprodução, desenvolvimento de ovos e etc (McKim, 1977; Magalhães e ferrão Filho, 2008).

Ensaios crônicos são muito importantes, já que nos ambientes aquáticos é mais frequente a ocorrência de efeitos crônicos do que agudos, e isso se deve a alguns fatores, como por exemplo, a diluição dos contaminantes e as relações antagonistas entre as substâncias, assim os organismos ficam expostos a baixas concentrações de determinados poluentes por longos períodos, ocasionando efeitos crônicos em níveis subletais e letais ao longo do tempo. Estes ensaios também são utilizados sempre que os ensaios agudos não forem suficientes para caracterizar um efeito tóxico, portanto, nem sempre a toxicidade aguda reflete o potencial deletério de um efluente, sendo necessária a realização de teste de toxicidade crônica para complementar o estudo (Magalhães e Ferrão Filho, 2008).

\subsection{Organismo-teste}

Para a escolha do organismo-teste é necessário que o mesmo apresente sensibilidade a diversos agentes químicos, e que sua sensibilidade seja constante. É primordial obter os conhecimentos sobre a biologia da espécie a ser utilizada, como a reprodução, hábitos alimentares, fisiologia e comportamento. Os organismos de pequeno porte e ciclo de vida não muito longo são ideais aos ensaios ecotoxicológicos (Domingues e Bertoletti, 2006; Rand e Petroceli, 1985).

Os critérios decisivos da escolha do organismo-teste, é sobre tudo, as boas experiências de seu manuseio e a sua importância na cadeia alimentar, bem como a sua ampla disseminação e fácil disponibilidade (Zagatto e Bertoletti, 2006).

Os organismos utilizados em ensaios de toxicidade podem ser coletados em ambientes naturais, obtidos através de produtores especializados ou cultivados em laboratório (Domingues e Bertoletti, 2006).

É recomendado que sejam utilizados nos ensaios de ecotoxicidade organismos de três diferentes níveis tróficos, no entanto, por razões práticas e 
econômicas, em grande parte os ensaios de ecotoxicidade são realizados com uma única espécie de organismo-teste (Ribo, 1997).

\subsubsection{Danio rerio (Zebrafish)}

Os peixes são animais vertebrados e representam consumidores de ordem diversas: primários, secundários ou terciários. São utilizados como bioindicadores por se desenvolverem bem em cultivo de laboratório e por serem de fácil observação. Os ensaios que utilizam peixes têm por objetivo compreender como um agente tóxico afeta organismos de maior grau de estruturação como os vertebrados (Zagatto e Bertoletti, 2006; Rubinger, 2009).

Peixes são sensíveis a mudanças no ambiente. A espécie Danio rerio possui grande sensibilidade quando exposta a produtos químicos, por ser capaz de absorver rapidamente os compostos que são diretamente adicionados na água e acumulá-los em vários tecidos (Albinati et al., 2009; Sant'ana, 2009).

O peixe zebrafish, Danio rerio (FIG. 1), é um importante modelo animal utilizado nas áreas de biologia de desenvolvimento, genética e biomedicina (Grunwald e Eisen, 2002). Devido a esta base de conhecimento, tornou-se um modelo de estudo popular. Como o zebrafish apresenta $70 \%$ de semelhança genética com humanos, bem como semelhanças fisiológicas e anatômicas, incluindo células endoteliais, presença de barreira hematoencefálica e respostas imunogênicas, este modelo pode ser utilizado para prever efeitos de toxicidade em humanos (Zhang et al., 2003; Hill et al., 2005; Bar-llan et al., 2009). Além disso, zebrafish e mamíferos mostram respostas fisiológicas semelhantes à substâncias tóxicas, como a indução de enzimas metabolizadoras e estresse oxidativo (Rubinstein, 2003). 


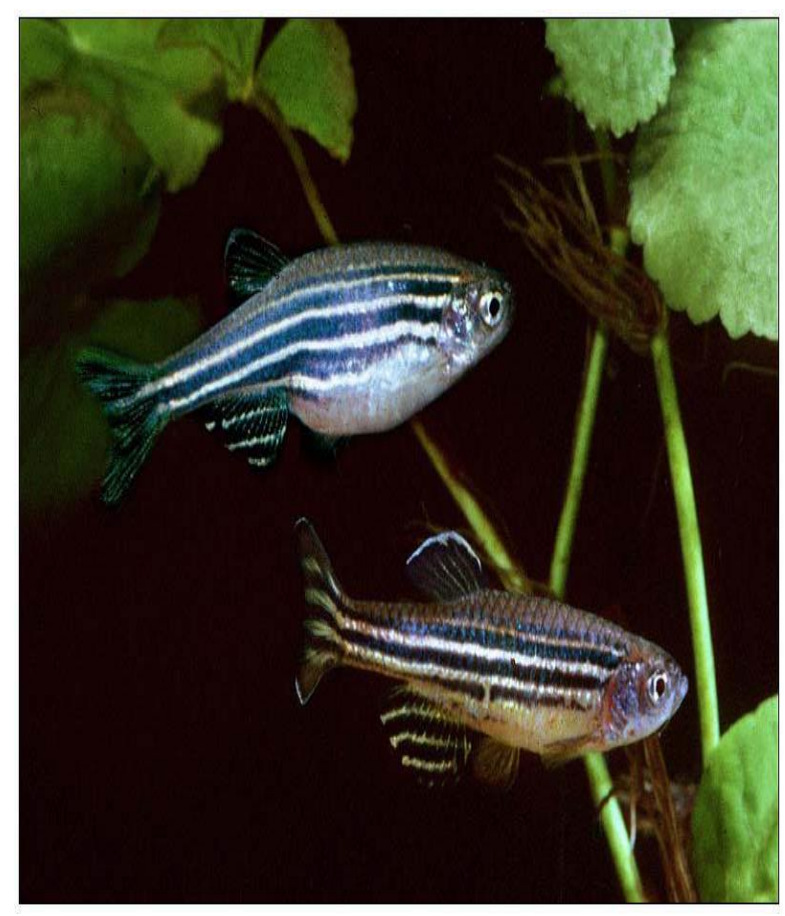

FIGURA 1 - Casal de Danio rerio, fêmea (acima) e macho (abaixo). Fonte: Braunbeck e Lammer, 2006.

O modelo zebrafish apresenta muitas vantagens sobre outros modelos de animais. Pertencente à família Cyprinidae e de comprimento médio de 4 a 5 centímetros (ABNT, 2011), não é necessário um grande espaço para o manejo deste peixe, e já que vivem em cardumes na natureza, em condições laboratoriais podem ser mantidos em grande número em um mesmo aquário (Schneider et al., 2009). Além de taxa reprodutiva elevada e rápido desenvolvimento embrionário (fora do corpo materno), este modelo é fácil de se manter sob condições experimentais e barato em comparação com outros modelos animais tradicionais, tais como os ratos.

A espécie é originária da Índia e do Paquistão, estando presente atualmente em diversos países (ABNT, 2011). O zebrafish vive naturalmente em águas rasas com pouca correnteza, tipicamente em regiões alagáveis associadas às plantações de arroz. A alimentação é tipicamente onívora, e sua dieta natural consiste principalmente de zooplâncton, fitoplâncton e insetos. O zebrafish apresenta comportamento social e mantém relação de dominância e submissão entre os indivíduos (Spence et al., 2008).

Em comparação com as demais espécies de peixe, alcançam a maturidade sexual em três meses de vida e podem produzir 200 a 300 ovos por 
desova. Como a fertilização é externa, e os ovos são transparentes e grandes (0.5 - $0.7 \mathrm{~mm}$ ), pode-se acompanhar o desenvolvimento do embrião utilizando um estereomicroscópio simples. Os precursores de todos os órgãos já estão presentes $36 \mathrm{~h}$ após a fertilização. As larvas eclodem entre 48 a $72 \mathrm{~h}$ e no quinto dia após fertilização (dpf), a maioria dos tecidos já estão desenvolvidos (Kimmel et al., 1995). A FIG. 2 representa o ciclo de vida do peixe Danio rerio.

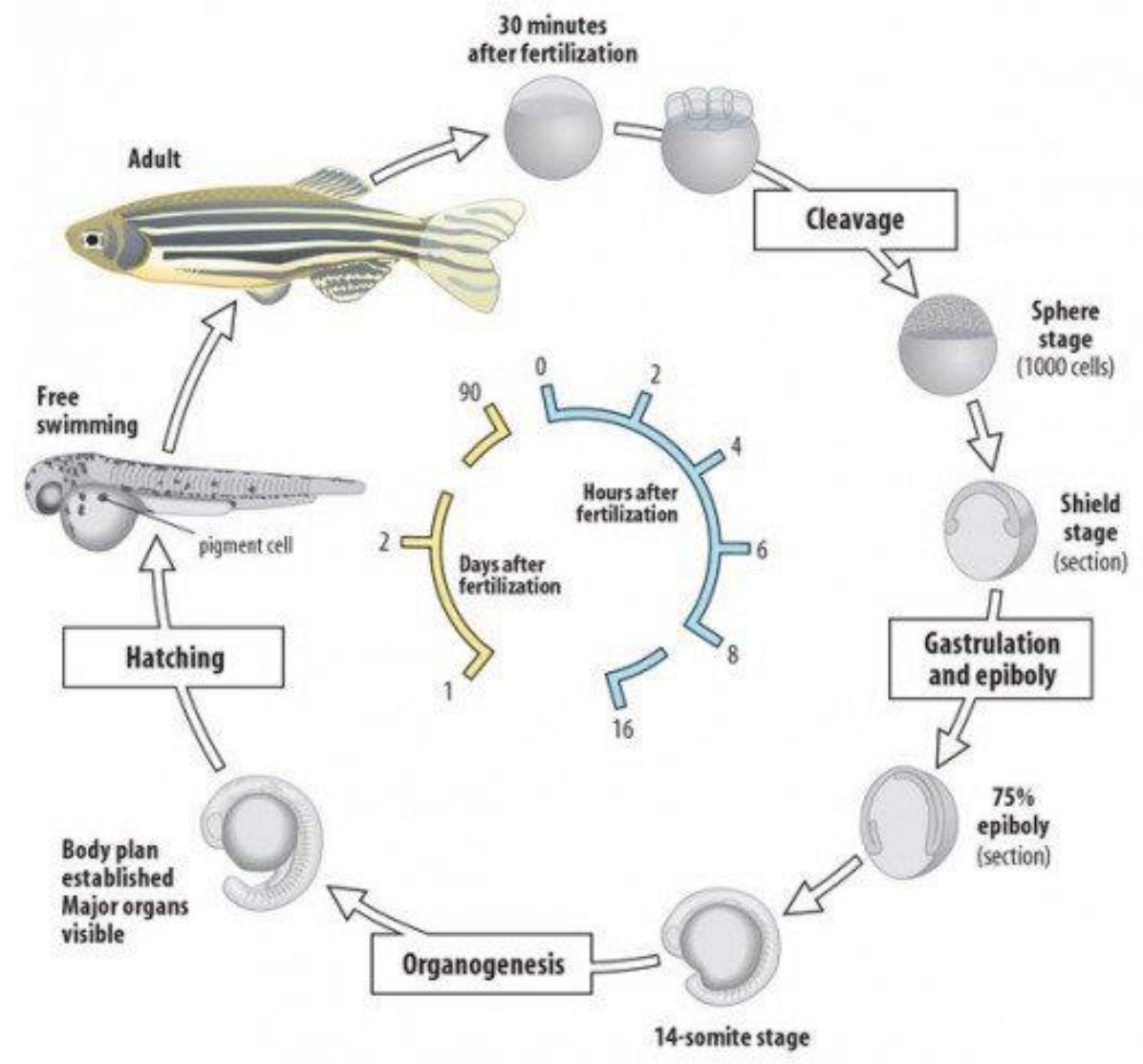

FIGURA 2 - Ciclo de vida do Danio rerio. O desenvolvimento do Danio rerio ocorre de forma rápida; a clivagem, gastrulação e organogênese ocorrem em $24 \mathrm{~h}$. Em 48 a $72 \mathrm{~h}$ após a fertilização, as larvas eclodem apresentando células de pigmentação. Após passar por fase juvenil, torna-se adulto 90 dias após a fertilização. Fonte: Rezende, 2013.

\subsection{Legislação Ambiental}

A legislação brasileira tem apresentado avanço nas questões ambientais nos últimos anos. A revisão da Resolução no. 20/86, do Conselho Nacional do Meio Ambiente (CONAMA), introduziu os ensaios de toxicidade. Desta forma, os estudos ecotoxicológicos são exigidos por diversos instrumentos 
legais voltados à proteção da biota em corpos hídricos brasileiros (Bertoletti, 2009).

No capítulo II da Resolução №. 430/11 CONAMA, o qual se refere às condições e padrões de lançamento de efluentes, é estabelecido no artigo 18, que o efluente não deverá causar efeitos tóxicos aos organismos aquáticos no corpo receptor, sendo que no $\S 1^{\circ}$ do artigo mencionado, é estabelecido que os critérios de ecotoxicidade devem se basear em resultados de ensaios ecotoxicológicos aceitos pelo órgão ambiental, utilizando organismos aquáticos (BRASIL, 2011).

A Resolução №. 03/2000, da Secretaria do Meio Ambiente (SMA), estabelece os critérios para a realização do controle ecotoxicológico de efluentes líquidos no Estado de São Paulo (Pusceddu, 2009).

Para os estados, cujos órgãos ambientais estaduais não possuem uma legislação específica para toxicidade, devem seguir as orientações da Resolução no. 430/11 CONAMA (BRASIL, 2011).

\subsection{Resveratrol}

A busca pelo homem por uma vida saudável tem impulsionado pesquisas por novas substâncias capazes de atender tal desejo. Entre essas substâncias encontramos os polifenóis (Bachur et al., 2009). O composto fenólico resveratrol (3, 4', 5- trihidroxiestilbeno) é considerado uma fitoalexina que pertence à família estilbeno (Jeandet et al., 2002).

As fitoalexinas são compostos antimicrobianos produzidos por diversas espécies de plantas em condições de estresse, que podem ser causadas por fatores bióticos, como ferimentos nas plantas decorrentes da ação de fungos, ou por fatores abióticos, como exposição à radiação ultravioleta emitida pelo sol e agentes químicos, conferindo as plantas uma proteção contra diferentes doenças (Van Etten et al., 1994; Taiz e Zeiger, 2004).

Os sinais químicos, induzidos por estresse na planta, desencadeiam a biossíntese do resveratrol (FIG. 3). A enzima estilbeno sintase catalisa a reação entre substratos presentes nas plantas, sendo uma molécula de $p$-coumaroyl-CoA e três moléculas de malonyl-CoA, originando o resveratrol no local afetado (Jeandet et al., 2002; Schöppner e Kindi, 1984). 


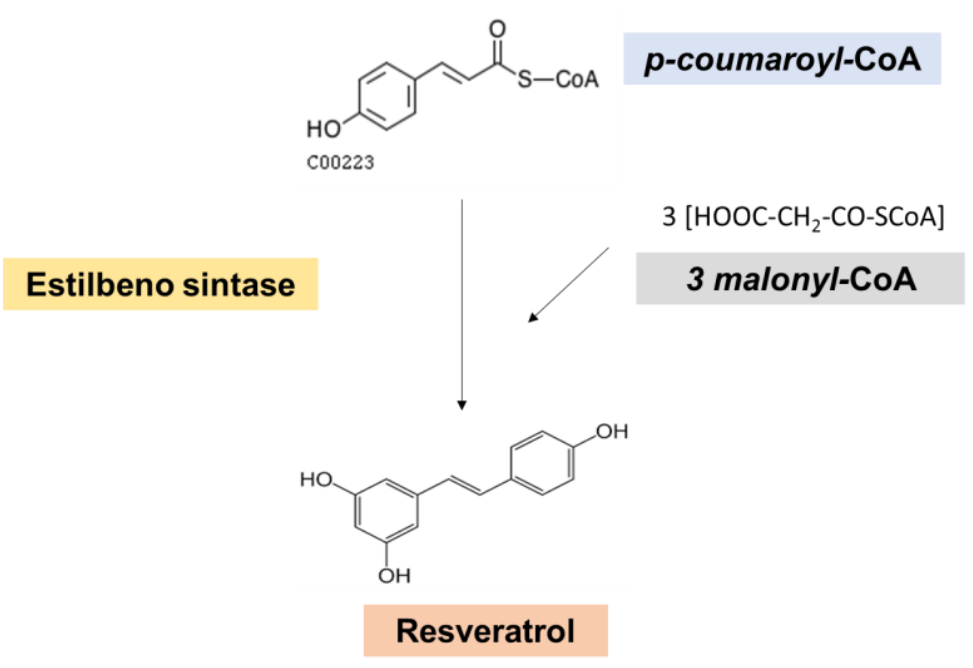

FIGURA 3 - Biossíntese do Resveratrol.

A enzima estilbeno sintase, em condições fisiológicas normais, é encontrada na parede celular em baixas concentrações e nos cloroplastos em uma menor proporção. A quantidade desta enzima na película do fruto aumenta ao longo do seu desenvolvimento (Pan et al., 2009).

\subsection{Fontes do Resveratrol}

O resveratrol foi identificado em 72 espécies de plantas, distribuídas em 31 gêneros e 12 famílias (FIG. 4) (Acquaviva et al., 2002). Dentre estas plantas, destacam-se por suas ações terapêuticas, o amendoim (Arachis hypogacea, Fabaceae), o eucalipto (Eucalyptus wandoo, Myrtaceae), a amora (Morus rubra, Moráceae), o kojo-kon (Polygonum cuspidatum, Polygonaceae) e a uva (Vitis vinifera e Vitis labrusca, Vitaceae) (Jang et al., 1997; Afonso et al., 2015; Chukwumah et al., 2009; Du et al., 2007; Lang et al., 2015; Francioso et al., 2014). 

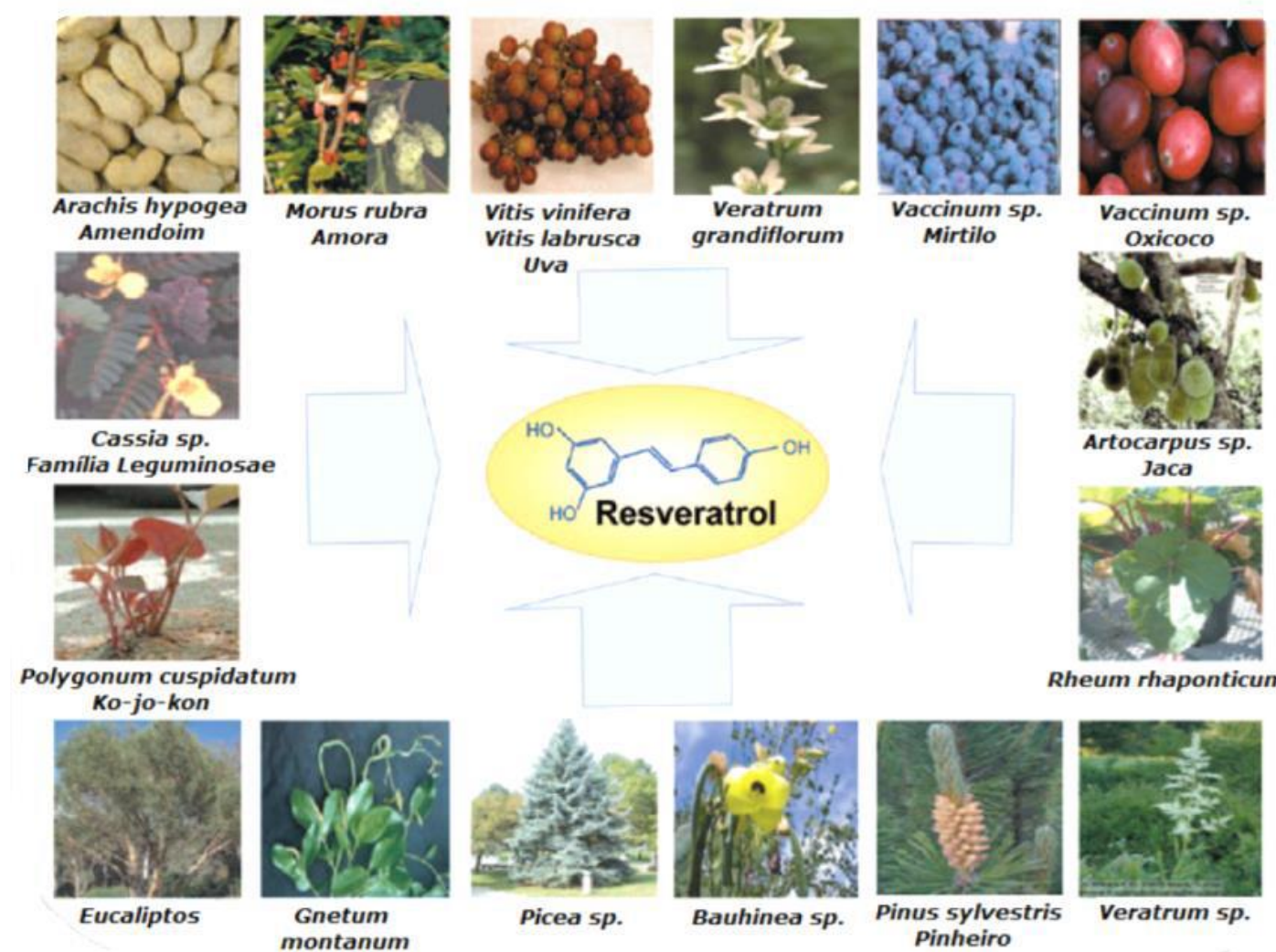

Vaccinum sp.

Mirtilo

Oxicoco

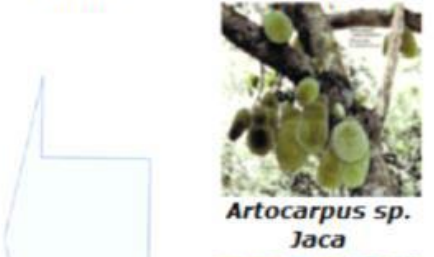

Jaca

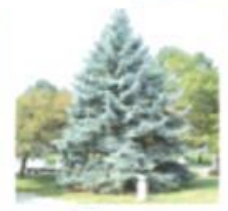

Picea sp.

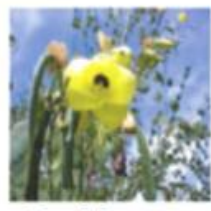

Bauhinea sp. montanum

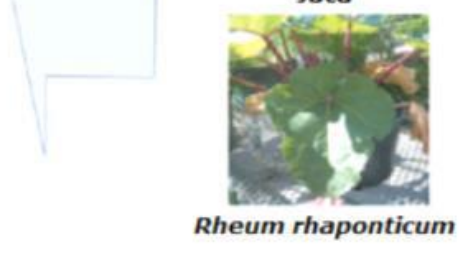

FIGURA 4 - Algumas espécies de plantas que sintetizam resveratrol. Fonte: Aggarwal et al., 2004.

Na uva o composto é produzido na película do fruto em concentrações que dependem da intensidade e durabilidade do estresse causado na videira durante sua fase frutífera, e do estágio de desenvolvimento do fruto. Ferimentos na uva causados pela ação de fungos, principalmente pela espécie Botrytis cinéria, é um estresse biótico que desencadeia a produção do resveratrol (Pan et al., 2009).

As espécies de videiras Vitis vinífera e Vitis labrusca, apresentam a maior capacidade de síntese do resveratrol, sendo a uva e seus produtos industrializados fontes importantes do composto (Pan et al., 2009; Penna e Hecktheuer, 2004; Roméro-Pérez et al., 2001; Vuong et al., 2014).

Análises realizadas em diferentes amostras de uva evidenciaram que 0 resveratrol apresentou maior concentração na película do fruto, aproximadamente $27,5 \mu \mathrm{g} / \mathrm{g}$. Já no bagaço da uva, constituído por caules, cascas e sementes após a extração do sumo, apresentou menor concentração resveratrol $(6,0 \mu \mathrm{g} / \mathrm{g})$ (Careri et al., 2003). Para Fernández-Mar et al. (2012) estima-se que a casca da uva fresca contenha 50-100 $\mu \mathrm{g}$ de resveratrol por grama. 
Nos vinhos, a concentração de resveratrol depende de vários fatores, como a origem geográfica, tipo de vinho, práticas enológicas, condições climáticas e grau de infecção da planta por fungos (Douillet-Breuil et al., 1999). Na vinificação, o processo de maceração com cascas e sementes é o fator responsável pelos altos níveis de resveratrol em vinhos tintos (Bertagnolli et al., 2007).

De acordo com o Souto et al. (2001), 36 tipos diferentes de vinhos brasileiros foram analisados. As concentrações de resveratrol encontradas em vinhos tintos foram de 0,82 a $5,75 \mathrm{mg} / \mathrm{L}$. Devido à ausência do contato da casca da uva ao mosto, nos vinhos brancos, a concentração de resveratrol é inferior a $1,8 \mathrm{mg} / \mathrm{L}$. Nos vinhos roses, a concentração de resveratrol é de $2,15 \mathrm{mg} / \mathrm{L}$, um valor intermediário (Frémont, 2000). Já as concentrações de resveratrol em vinhos da América do Norte, Europa e Japão, variam de 0,1 a $14,5 \mathrm{mg} / \mathrm{L}$ (Mukherjee et al., 2010).

Os sucos de uva produzidos no Brasil apresentam aproximadamente 0,19 a $0,90 \mathrm{mg} / \mathrm{L}$ de resveratrol, sendo uma boa opção para os abstêmios (Sautter et al., 2005). Outros produtos industrializados derivados da uva (geleias e gelatinas) apresentam o resveratrol em concentrações inferiores a $0,15 \mathrm{mg} / \mathrm{L}$ (Goldberg et al., 1994).

\subsection{Histórico do Resveratrol}

A uva é uma das frutas mais antigas e mais difundidas no mundo. As práticas do cultivo da videira e da produção de vinho remetem-se a época préromana (Fabião, 1998).

Segundo Pickleman (1990), o primeiro registro sobre o uso do vinho para fins medicinais provém do Antigo Egito, sendo procedente de anos anteriores a 2000 a.C. Na Suméria, unguentos eram misturados ao vinho com a finalidade de combater as doenças de pele.

Homero, na Grécia Antiga, descreveu na llíada e na Odisséia (850 a.C) o valor do uso do vinho no tratamento de feridas causadas em guerras (Béliveau e Gingras, 2007; Pickeleman, 1990).

Do século $\mathrm{V}$ ao $\mathrm{XV}$, as supostas propriedades curativas, rejuvenescedora, estimulante do apetite e promovedora da higienização dos 
dentes, tornaram o vinho aromatizados com ervas parte integrante da prática médica na Idade Média (Béliveau e Gingras, 2007; Pickeleman, 1990).

Apesar dos relatos que há 7.000 anos no Mediterrâneo o vinho já era consumido, somente em 1992 foi comprovada a ação benéfica do vinho, quando foi publicado o Paradoxo Francês (Moraes e Locatelli, 2010).

Os franceses apresentam uma dieta alimentar com elevados níveis de gordura animal e altos índices de tabagismo e sedentarismo. O que despertou a atenção científica, é que apesar da população francesa não ter hábitos de vida considerados saudáveis, as mortes causadas por doenças cardiovasculares são poucas comparadas com outros países industrializados, fato atribuído ao consumo de vinho, ingerido regularmente durante as refeições (Facco et al., 2007; Gillespie e Lenz, 2012).

Segundo a Organização Mundial da Saúde (OMS), nos anos de 1961 a 2000, o consumo mundial de vinho permaneceu constante em decorrência do equilíbrio entre a leve redução do consumo por países tradicionalmente apreciadores da bebida e o discreto aumento em outras culturas, tendo-se estimado um consumo mundial médio de 1,3 litros de vinho por adulto/ ano (Who, 2004). A OMS evidencia os efeitos benéficos à saúde exercidos pelo etanol, presente nas bebidas alcoólicas, quando consumido moderadamente (Who, 2014).

Dentre os polifenóis contidos no vinho, o resveratrol é considerado o composto fenólico de maior eficácia biológica (Frémont, 2000; Soleas et al., 1997).

\subsection{Estrutura Química do Resveratrol}

O resveratrol é formado por dois anéis aromáticos unidos por uma ponte de metileno (-CH2-). Esta geometria molecular é a base estrutural de diferentes compostos, sendo diferenciados em relação ao número e a posição das hidroxilas; substituição das hidroxilas por diversos radicais como os açúcares, metil, grupo metoxila; formação de dímeros, trímeros ou então extensos polímeros e o isomerismo (trans e cis) (Soleas et al., 1997).

Consta na literatura uma vasta descrição destes compostos, sendo enfatizadas as formas isômeras trans- e cis- resveratrol $(3,4$ ', 5- trihidroxi-trans- 
estilbeno e 3, 4', 5- trihidroxi-cis-estilbeno); trans- e cis- piceido (trans-resveratrol 3-O- $\beta$-glucosideo e cis-resveratrol 3-O- $\beta$-glucosideo) e viniferins (trans-viniferins) (FIG. 5) (Trela e Waterhouse, 1996).
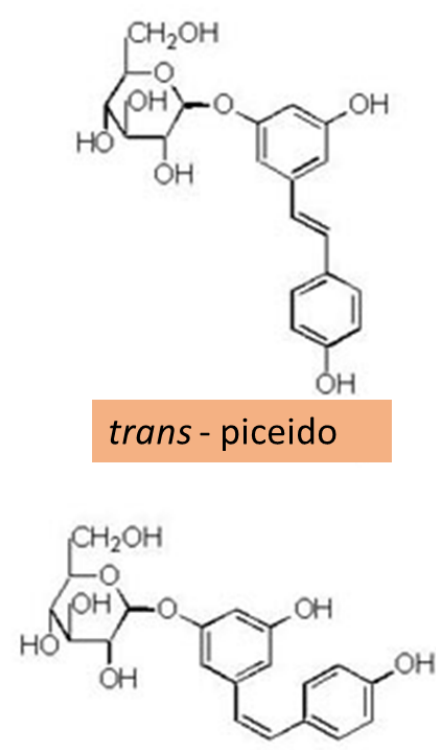

cis-piceido

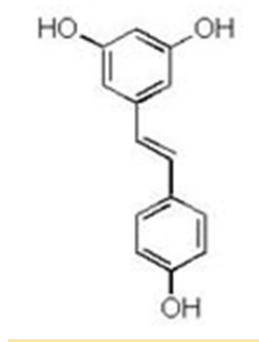

trans-resveratrol

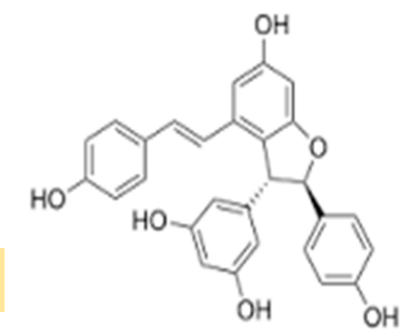

trans - viniferins

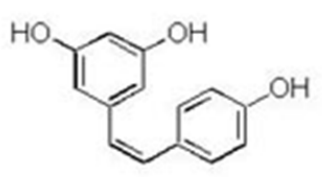

cis-resveratrol

FIGURA 5 - Fórmulas estruturais do resveratrol.

O isômero trans é biologicamente mais ativo que o isômero cis, provavelmente devido à conformação não planar. Em relação à estabilidade química, o trans-resveratrol é mais estável que o cis-resveratrol. $\mathrm{O}$ isômero trans pode se converter no isômero cis quando exposto à radiação ultravioleta, e o processo inverso ocorre em soluções de pH ácido (Amri et al., 2012).

A degradação dos dois isômeros ocorre por exposições à radiação UV e a soluções de $\mathrm{pH}$ elevado. Já a estabilidade é alcançada quando são mantidos sob o abrigo da luz, sendo o trans-resveratrol mantido em soluções de $\mathrm{pH}$ ácido e o cis-resveratrol mantido em soluções de pH neutro (Trela e Waterhouse, 1996).

A glicosilação da molécula de resveratrol dá origem ao piceido. A glicosilação é a inclusão de uma molécula de glicose na estrutura do resveratrol, tornando-o mais resistente a degradação enzimática e aos processos de oxidação (Pezet et al., 2004).

Pelo processo de dimerização oxidativa da molécula de resveratrol, os compostos viniferins são formados (Jeandet et al., 2002). 


\subsection{Biodisponibilidade do Resveratrol}

Devido ao resveratrol e seus derivados estarem presentes em uma variedade de alimentos e bebidas, considerável atenção tem sido dada a absorção, metabolismo e distribuição do composto nos tecidos dos organismos vivos (Leonard et al., 2003; Moreno, 2016).

Um estudo sobre a biodisponibilidade do resveratrol em humanos foi realizado por Walle et al. (2004), em indivíduos saudáveis, do sexo masculino, com a administração de doses orais $(25 \mathrm{mg}$ ) e intravenosas (i.v. - 0,2 mg) de resveratrol marcado $\left({ }^{14} \mathrm{C}\right)$. O estudo demonstrou que o composto apresenta alta taxa de absorção (70\% aproximadamente), sendo metabolizado de modo rápido e amplamente, resultando em concentrações plasmáticas reduzidas.

Estudos mais novos demonstraram que a absorção do resveratrol administrado por via oral em humanos é de 75\%. A absorção ocorre por difusão trans-epitelial (transporte passivo), e o metabolismo ocorre no fígado e no intestino, o que resulta a baixa biodisponibilidade do resveratrol em menos de $1 \%$ (Walle, 2011).

Devido a sua baixa solubilidade em água, o resveratrol encontra-se ligado a proteínas no plasma. Entre as proteínas do plasma, a albumina, proteína carreadora plasmática para o resveratrol, é a mais importante, devido a sua afinidade por moléculas hidrofóbicas. As lipoproteínas também são responsáveis pelo transporte do composto (Mischiatti, 2012).

Estudos mostraram metabólitos de resveratrol presentes na urina e no plasma. Sulfatos e glucoronídeos são os metabólitos com maior frequência, e a quantidade e a natureza dos mesmos podem diferir de uma pessoa a outra. Os cinco metabolitos identificados na urina foram: monosulfato de resveratrol, cisresveratrol monoglucoronideo, trans-resveratrol monoglucoronideo, diidroresveratrol e diidroresveratrol monoglucoronideo (Boocock et al., 2007; Cottart et al., 2010; Walle et al., 2004). O composto também é transformado nos derivados mono (3-sulfato-resveratrol) e disulfato (3,4'-disulfato-resveratrol e 3,5disulfato) após $4 \mathrm{~h}$ nas células hepáticas (Lancon et al., 2007).

Uma revisão recente do metabolismo do resveratrol declarou que nos seres humanos, com doses superiores a $250 \mathrm{mg}$, as formas monossulfato tornamse o metabólito dominante no plasma e na urina (Cottart et al., 2014). 
Pardal et al. (2014) analisaram a absorção e a metabolização do resveratrol em larvas de zebrafish (Danio rerio), e observaram que as principais vias metabólicas para o resveratrol no peixe são semelhantes às dos mamíferos (glicuronidação e sulfatação), sendo o monosulfato de resveratrol, o metabólito mais abundante. Os metabólitos encontrados em larvas de zebrafish foram detectados após $1 \mathrm{~h}$ dos organismos terem sidos expostos ao composto, confirmando assim que o resveratrol é rapidamente absorvido e metabolizado.

Segundo Hoshino et al. (2010), a molécula original de resveratrol é degradada $20 \%$ após o tempo de incubação in vitro, já os derivados sulfatados são mais estáveis.

O período de meia-vida do composto é de aproximadamente 6,5 -14,9 $\mathrm{h}$ após administração oral e de 7,5-18,8 h após administração intravenosa (Walle et al., 2004). Em relação aos metabólitos, o tempo de meia-vida é similar, entretanto seus níveis no plasma, quando comparados com o resveratrol, foram de três a oito vezes maiores nas $4 \mathrm{~h}$ anteriores à eliminação pela urina (Boocock et al., 2007).

A excreção do resveratrol e de seus metabólitos ocorre com auxílio da bile e da urina (Vitrac et al., 2003; Wang et al., 2008), e apesar dos esforções dedicados na tentativa de obter conhecimentos in vivo sobre absorção, metabolismo e distribuição do resveratrol nos diversos tecidos, os estudos encontram dificuldades na deteç̧ão e quantificação do composto devido à sua rápida absorção pelo intestino, limitada estabilidade dos metabólitos, ampla distribuição pelos órgãos após a ingestão e rápida eliminação. É necessário portanto, estudos mais aprofundados para que as conclusões sobre o impacto na saúde proporcionado pelas dietas com elevado teor de resveratrol sejam obtidas (Leonard et al., 2003; Bitterman e Chung, 2015).

\subsection{Atividades Biológicas do Resveratrol}

Vários estudos têm destacado e comprovado os benefícios do resveratrol à saúde. A ação antioxidante do composto tem relação com sua conformação estrutural, pois os grupamentos hidroxila servem de doadores de elétrons, neutralizando e sequestrando os radicais livres, prevenindo a peroxidação lipídica (Gülçin, 2010; Leonard et al., 2003; Mokni et al., 2007). 
Os radicais livres são produzidos de forma contínua pelo organismo durante os eventos fisiológicos. Essas moléculas podem provocar danos às proteínas, lipídeos e ao material genético. O organismo possui compostos antioxidantes que mantém os radicais livres em concentrações subtóxicas, porém, alguns fatores exógenos, como a radiação UV, podem potencializar a produção dos radicais livres, superando a capacidade antioxidante do organismo, ocasionando um estresse oxidativo (Jenkins, 2002; Pytel et al., 2005). Portanto, a capacidade antioxidante do resveratrol é um importante mecanismo de prevenção ou inibição de processos oxidativos que acometem diversas linhagens celulares (Leonard et al., 2003; Sgambato et al., 2001).

Sabe-se que a oxidação da lipoproteína de baixa densidade (LDL) aumenta o risco de doenças coronarianas e infarto do miocárdio. O resveratrol, além de capturar os radicais livres, previne a oxidação do LDL, atuando como um agente cardioprotetor (Mischiatti, 2012). O composto diminui a agregação plaquetária e protege o endotélio vascular contra malefícios ocasionados por dietas inadequadas (Chaves et al., 2009; Olas et al., 2002).

Resveratrol apresenta função estrogênica devido a sua semelhança com o dietilestilbestrol. O resveratrol apresenta atividade agonística ao estrogênio nas concentrações de 10-1000 $\mu \mathrm{mol} / \mathrm{kg}$ (Ratna e Simonelli, 2002).

Devido à alta lipossolubilidade, este composto consegue cruzar a barreira hemato-encefálica, atingindo assim o sistema nervoso central (SNC), justificando suas ações neuroprotetoras, inibindo ou diminuindo a incidência de doenças neurodegenerativas, como as síndromes de Alzheimer e Parkinson, e protegendo também o cérebro contra danos causados por processos de isquemia cerebral (Sinha et al., 2002; Vasanthi et al., 2012; Wang et al., 2004). O estudo feito por Sakata et al. (2010), revelou que o resveratrol induz a heme oxigênase I em culturas de células neurais de ratos fornecendo neuroproteção contra radicais livres ou danos excitotóxicos.

Com a ação de inibir as enzimas ciclo-oxigenases (COX-1 e COX-2) que estão relacionadas com a produção de moléculas pró-inflamatórias, o resveratrol atua como controlador dos processos inflamatórios (Mischiatti, 2012).

Constam na literatura estudos sobre a atuação do resveratrol na inibição das lesões induzidas pelo Herpes (tipos 1 e 2), na inibição do crescimento da bactéria Helycobacter pylori, no combate ao HIV-1 e na redução da obesidade 
(Mahady et al., 2003; Heredia et al., 2000; Naderali, 2009; Olas et al., 2002; Docherty et al., 2004).

O uso do composto por tempo prolongado reduz a glicose do sangue em condições de hiperglicemia, porém não afeta os níveis de glicose em animais com o nível glicêmico normal (Szkudelska e Szkudelski, 2010).

Experimentos in vitro e in vivo demonstram a capacidade do resveratrol em suprimir o crescimento de várias linhagens de células cancerosas de diversos órgãos como mama, crânio, pulmão, ovário, fígado, estômago, próstata, cólon, leucemias e linfomas (Freitas et al., 2010; Mukherjee et al., 2010; Sautter, 2003).

A comprovação do seu poder antitumoral deve-se a alguns mecanismos, como a sincronização das células em determinada fase do ciclo celular; atividade antioxidante; ativação da apoptose e regulação das três fases do processo da carcinogênese, que compreendem o início, a promoção e a progressão do tumor (Sgambato et al., 2001; Chang et al., 2015; Wieder et al., 2001; Pervaiz, 2004).

Os efeitos anti-proliferativo e pró-apoptótico exercidos pelo resveratrol são caracterizados pela diminuição das proteínas do ciclo celular in vitro (Aggarwal et al., 2004) e aumento das proteínas da apoptose nos modelos de tumor in vivo (Yu et al., 2003). Além de atuar nos mecanismos quimiopreventivos descritos acima, o resveratrol também possui potencial quimioterapêutico (Nemen e Senna, 2011).

Segundo Paulo (2011) o resveratrol administrado em doses pequenas, associado a quimioterápicos, reduz os efeitos tóxicos dos quimioterápicos sobre as células normais melhorando a eficácia do tratamento.

O resveratrol junto com seus metabólitos formados, acumulados nas células epiteliais ao longo do trato gastrointestinal, fornece benefícios à saúde, sendo mais bem absorvido pelo corpo humano quando associado a matrizes biológicas, como o vinho e outros derivados da uva, do que quando ingerido de forma isolada (Ortuño et al., 2010; Walle et al., 2004).

\subsection{Toxicidade do Resveratrol}

Apesar de estar estabelecido que o resveratrol exerce efeitos benéficos em humanos e outros seres vivos, o seu mecanismo de ação não é bem 
entendido. Em reperfusão hepática isquêmica em ratos, o pré-tratamento com baixas doses de resveratrol preservou a defesa antioxidante do fígado. Entretanto, quando uma alta dose do composto foi administrada, observou-se ação pro-oxidante, agravando assim o dano hepático (Cottart et al., 2008).

Segundo Mukherjee et al. (2010), em baixas doses o resveratrol tem função anti-apoptótica e função cardioprotetora, já em altas dosagens apresenta ações pro-apoptóticas, impedindo o desenvolvimento tumoral, mas por outro lado, também pode provocar aberrações cromossômicas estruturais e aumentar a incidência do infarto do miocárdio. As funções do composto tendem a indicar que seus efeitos gerados apresentam dose-dependência.

Segundo Moreno (2009) o resveratrol exerceu efeito radioprotetor em células de tecido conectivo de camundongo quando foram irradiadas com radiação gama, nas concentrações entre $2,85 \mathrm{mg} \mathrm{L}^{-1}$ e $5,7 \mathrm{mg} \mathrm{L}^{-1}$. Já o resveratrol na concentração de $6,84 \mathrm{mg} \mathrm{L}^{-1}$ promoveu dandos as células $\mathrm{NCl}$-H292 (células de pulmão humano), em cultura após 24 h da irradiação (Moreno, 2016).

Magalhães (2012) concluiu que o resveratrol teve efeito radioprotetor em cultura de células de rabdomiossarcoma humano (RD), na concentração de $3,4 \mathrm{mg} \mathrm{L}^{-1}$ e apresentou efeito citotóxico na concentração de $13,7 \mathrm{mg} \mathrm{L}^{-1}$.

Crowell et al. (2004), realizaram um estudo em ratos com o objetivo de verificar a toxicidade do resveratrol. Os organismos receberam as seguintes doses de trans-resveratrol durante 4 semanas: 300,1000 e $3000 \mathrm{mg} / \mathrm{kg} / \mathrm{dia}$. Na maior dose administrada efeitos adversos foram observados. Dentre os efeitos destacou-se perda de peso, redução do consumo de alimentos, níveis elevados de disfunção renal e hepática, além de alterações em parâmetros hematológicos. Dos 40 ratos que receberam tal dose, 2 morreram.

Em outro estudo, com voluntários saudáveis, uma única dose de resveratrol foi administrada em 4 concentrações diferentes: 0,5; 1; 2,5 e $5 \mathrm{~g}$. Nenhum efeito adverso foi observado nos voluntários (Boocock et al., 2007).

Segundo Gillespie e Lenz (2012), estudos sugerem que as doses orais de até $1 \mathrm{~g}$ por dia de resveratrol, em humanos, são bem toleradas. Desconforto gastrointestinal e diarréia foram observados com administrações orais do composto em doses superiores a 2,5 g por dia. 


\section{MATERIAIS E MÉTODOS}

\subsection{Substância-teste}

O resveratrol $(3,4,5$ - trihidroxi-trans-estilbeno) utilizado nos ensaios do presente estudo foi adquirido da empresa Sunrise Chemical Ltd. - China, importado e comercializado pela empresa Pharma Nostra, Campinas- SP. O resveratrol foi extraído da raíz da planta Polygonum cuspidatum Sieb, e as empresas mencionadas acima atestam o composto como sendo a forma isômera trans padronizada com um teor de pureza de $99,44 \%$. O composto apresenta a fórmula molecular $\mathrm{C}_{14} \mathrm{H}_{12} \mathrm{O}_{3}$ e massa molar de $228 \mathrm{~g} \mathrm{~mol}^{-1}$. Possui solubilidade em etanol (50 $\mathrm{mg} \mathrm{mL}^{-1}$ ) e em dimetilsulfóxido (DMSO) (16 $\mathrm{mg} \mathrm{mL}^{-1}$ ), porém baixa solubilidade em água (3 mg $100 \mathrm{~mL}^{-1}$ ). Seu ponto de fusão é de 253-255드 (Amri et al., 2012).

\subsection{Organismo-teste}

Os peixes adultos da espécie Danio rerio (matrizes) são mantidos no Laboratório Especial de Toxinologia Aplicada (LETA), do Instituto Butantan, e no Laboratório de Genética Toxicológica (G-TOX), da Universidade de Brasília. Os aquários são preenchidos com água deionizada reconstituída, condutividade de $500 \mu \mathrm{S}, \mathrm{pH} 7,0$ a 7,5 , temperatura de $28 \pm 1^{\circ} \mathrm{C}$, e fotoperíodo de $14 \mathrm{~h}$ luz/10 $\mathrm{h}$ escuro (FIG. 6). 


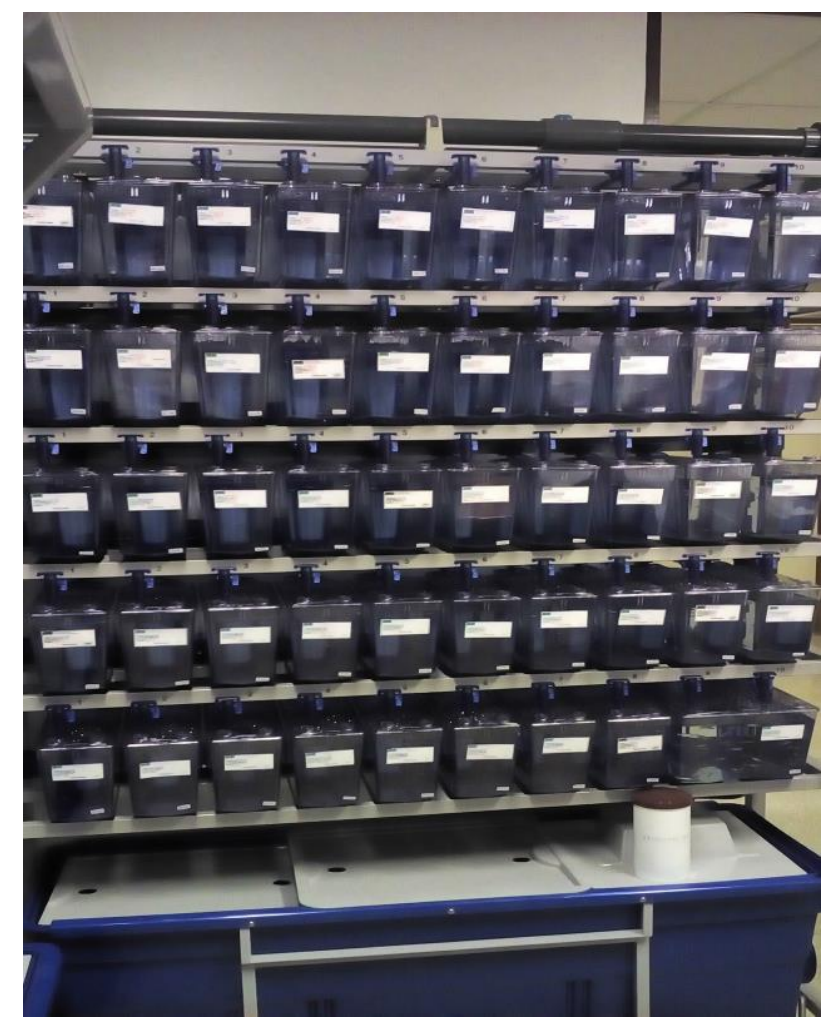

FIGURA 6 - Aquários de cultivo de Danio rerio, Laboratório de Genética Toxicológica - Univerisade de Brasília. Fonte: O Autor, 2017.

Machos e fêmeas adultos são mantidos separados e alimentados três vezes ao dia com ração para peixe e artêmias. Os reprodutores entre 4-24 meses de idade (ABNT, 2011), são colocados em pequenos aquários, próprios para a reprodução, na proporção de dois machos para uma fêmea (FIG. 7). Os aquários são mantidos sem a incidência de luz por algumas horas (período noturno). Ao amanhecer, ou seja, no início da luz ocorre a desova, e os ovos se depositam no fundo dos aquários. Este sistema possibilita somente a passagem dos ovos para o fundo dos recipientes e os protege contra o ataque dos reprodutores (ABNT, 2011). 


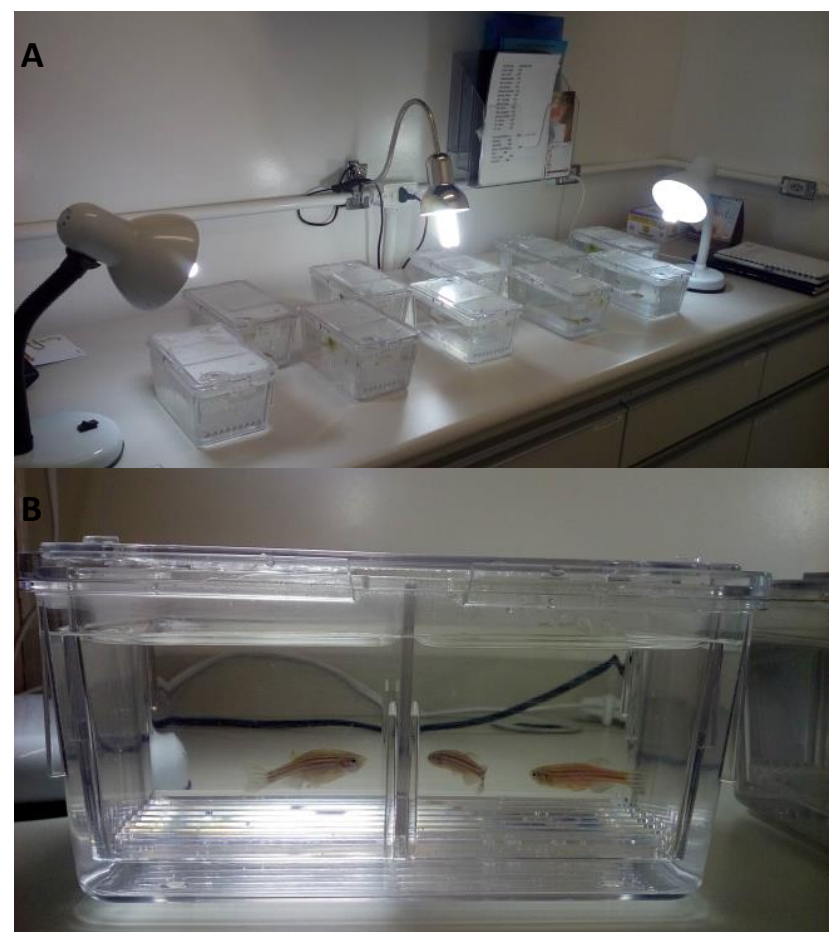

FIGURA 7 - (A) Aquários de reprodução de Danio rerio; (B) Aquário de reprodução com uma fêmea e dois machos de Danio rerio. Fonte: O Autor, 2017.

Após a desova, os ovos provenientes do Laboratório de Toxinologia Aplicada - Instituto Butantan, foram coletados dos aquários com pipeta de pasteur e transferidos para tubos falcon, e transportados para o Laboratório de Ecotoxicologia do Centro de Química e Meio Ambiente (CQMA), do Instituto de Pesquisas Energéticas e Nucleares (IPEN/CNEN-SP). Com o auxílio de uma lupa binocular, os ovos foram separados em fecundados (ovos translúcidos) e não fecundados (coagulados ou fungados) (FIG. 8).
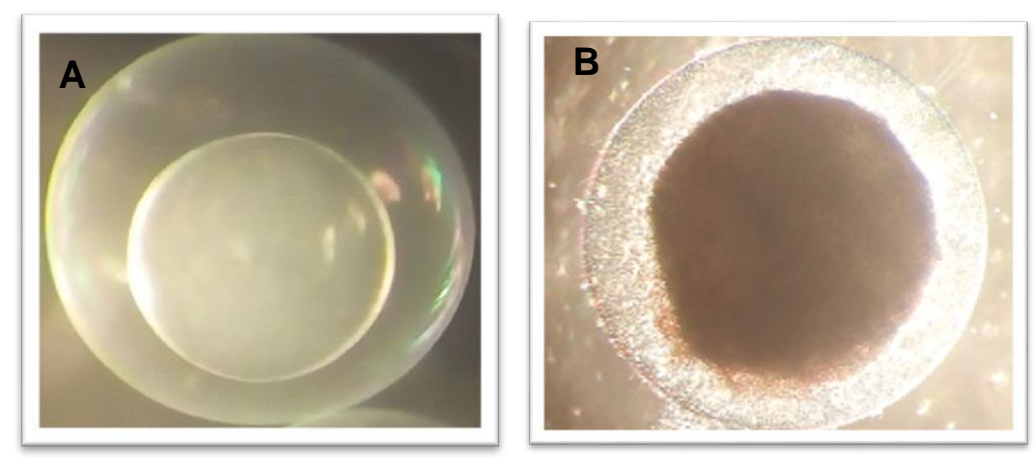

FIGURA 8 - (A) Ovo de Danio rerio fecundado; (B) Ovo de Danio rerio coagulado. Fonte: Ikari et al., 2013. 
Os ovos fecundados, provenientes do Laboratório de Toxinologia Aplicada - Instituto Butantan (FIG. 9 A e B), foram usados no ensaio de ecotoxicidade aguda no estágio embriolarval do peixe Danio rerio (168 h de duração), já para obter as larvas, os ovos foram mantidos em incubadora a temperatura de $28 \pm 1^{\circ} \mathrm{C}$, com fotoperíodo de $12 \mathrm{~h}$ de luz. Após $48 \mathrm{~h}$ da desova, as larvas eclodidas (FIG. 9 C) foram usadas nos ensaios de ecotoxicidade crônica de curta duração e ensaios de sensibilidade.

Os ovos fecundados, provenientes do Laboratório de Genética Toxicológica - Universidade de Brasília, foram usados no ensaio de ecotoxicidade aguda no estágio embriolarval do peixe Danio rerio ( $96 \mathrm{~h}$ de duração) e no ensaio de biomarcadores enzimáticos de Danio rerio no estágio embriolarval.
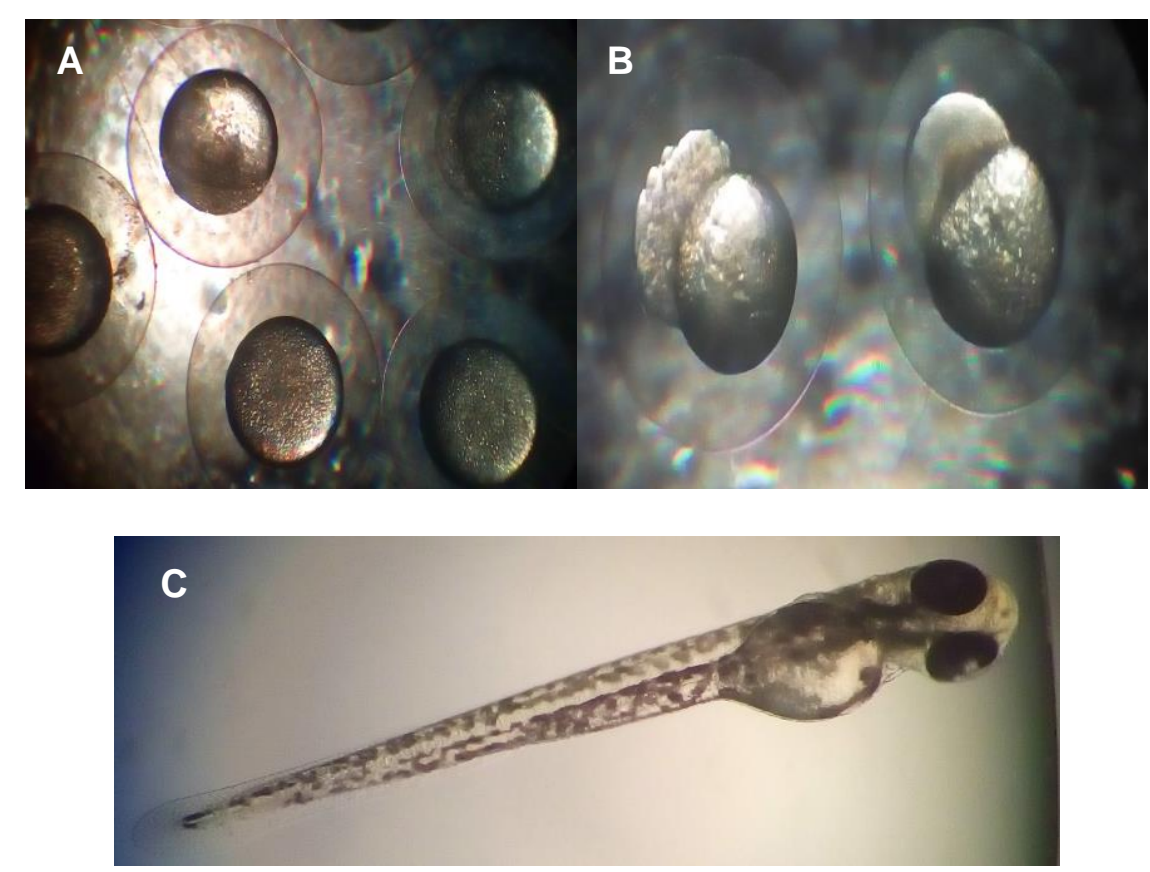

FIGURA 9 - (A e B) Ovos de Danio rerio recém fertilizados; (C) Larva de Danio rerio recém eclodida. Fonte: O Autor, 2017.

O uso de Danio rerio no presente estudo foi autorizado pela Comissão de Ética no Uso de Animais (CEUA/IPEN), sob coordenação do Centro de Biotecnologia (CB), do Instituto de Pesquisas Energéticas e Nucleares (IPEN/CNEN-SP), sob o parecer № 139/14/CEUA-IPEN/SP, e pela Comissão de Ética no Uso de Animais do Instituto Butantan. 


\subsection{Análise do resveratrol por cromatografia líquida de alta pressão (HPLC)}

Segundo Udenigwe et al. (2008) em presença de luz visível o isômero trans é convertido em cis-resveratrol. As soluções de trans-resveratrol apresentam estabilidade em ausência de luz (Trela e Waterhouse, 1996). Para verificar a estabilidade do resveratrol após $24 \mathrm{~h}$ de exposição a luz fluorescente foi realizado a análise do composto por meio de HPLC. O ensaio foi realizado no Centro de Biotecnologia (CB), do Instituto de Pesquisas Energéticas e Nucleares (IPEN/CNEN-SP).

Preparou-se uma solução padrão de resveratrol em $0,8 \%$ de DMSO e água deionizada na concentração de $0,5 \mathrm{mg} \mathrm{mL}^{-1}$, a qual foi mantida sob abrigo da luz. As soluções-teste na concentração de 50 e $100 \mathrm{mg} \mathrm{L}^{-1}$ foram preparadas como no ensaio 4.4.2, e mantidas sob abrigo da luz, e $250 \mathrm{ml}$ de cada soluçãoteste foi mantida em incubadora, com exposição a luz fluorescente por $24 \mathrm{~h}$, nas mesmas condições do ensaio 4.4.2.

A análise do resveratrol presente na solução padrão e nas soluçõesteste (50 e $100 \mathrm{mg} \mathrm{L}^{-1}$ ) sem exposição e com exposição a luz fluorescente foi realizada por meio de HPLC, modelo ÄKTApurifer-GE com o software UNICORN Manager 5.11 (FIG. 10). Utilizamos gradiente, coluna de fase reversa C18 $(5 \mu \mathrm{x}$ $250 \mathrm{~mm} \times 4,6 \mathrm{~mm}$ ) proveniente da Thermo Scientific, acoplada a uma pré-coluna de mesma composição.

A fase móvel foi composta por solução de ácido fosfórico $\mathrm{pH} 3$ (solvente A) e acetonitrila pura (solvente B) sob fluxo de $1 \mathrm{~mL}$ min. Após ambientação da coluna, que equivale em $25 \%$ de acetonitrila, foi realizado um gradiente em step, que consistiu em: $0-10 \mathrm{~min}=25 \%$ solvente $\mathrm{B} ; 10-14 \mathrm{~min}=$ $50 \%$ solvente $B ; 14-18 \mathrm{~min}=75 \%$ solvente $B ; 18-25 \mathrm{~min}=100 \%$ solvente $\mathrm{B}$. O volume da amostra injetada foi de $500 \mu \mathrm{l}$ e a detecção realizada a $306 \mathrm{~nm}$ com detector UV. 


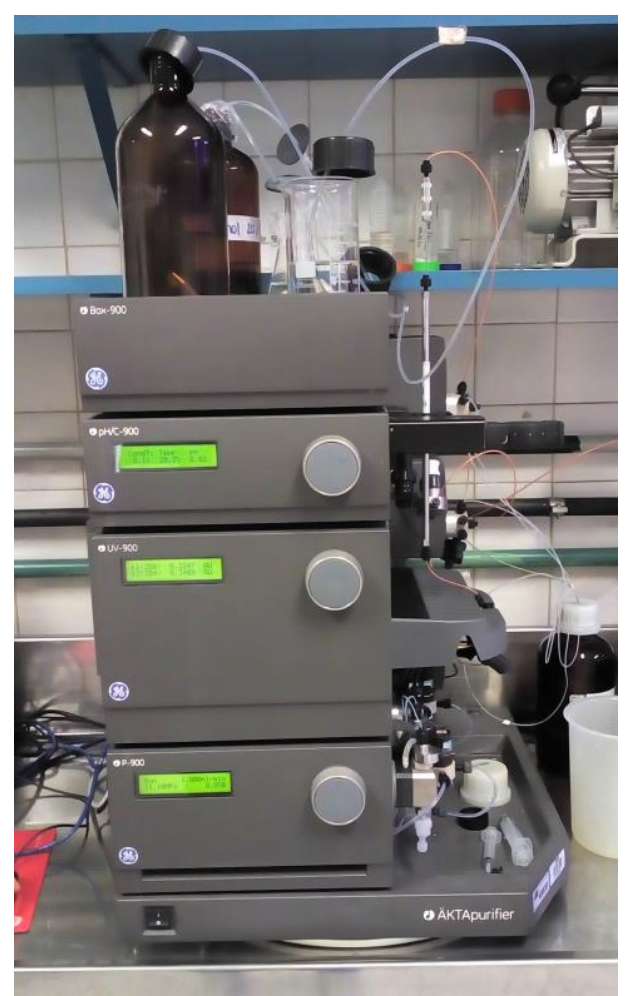

FIGURA 10 - HPLC modelo ÄKTApurifer-GE. Fonte: O Autor, 2017.

\subsection{Avaliação da toxicidade do resveratrol}

\subsubsection{Ensaio in vitro de citotoxicidade do resveratrol}

Para verificar o nível de toxicidade do resveratrol, foi realizado o ensaio de citotoxicidade in vitro com base na norma ISO 10993-5 e nas metodologias descritas na literatura (Rogero et al., 2003; Moreno, 2009). O ensaio foi realizado no Laboratório de Ecotoxicologia do Centro de Química e Meio Ambiente (CQMA), do Instituto de Pesquisas Energéticas e Nucleares (IPEN/CNEN-SP).

Para determinar o índice de citotoxicidade $\left(\mathrm{IC}_{50}\right.$ - concentração do extrato que induz $50 \%$ de lise ou morte celular) do resveratrol, o ensaio foi realizado pelo método de incorporação do corante vermelho neutro. O corante é solúvel em água, atravessa a membrana plasmática celular e se concentra nos lisossomos de células vivas.

Este estudo foi realizado com a linhagem celular NCTC-L929 (CCIAL 020), células de tecido conectivo de camundongo, distribuída em microplaca de 96 poços com densidade populacional de $7 \times 10^{5}$, preparadas e cedidas pelo Núcleo de Culturas Celulares do Instituto Adolfo Lutz, SP - Brasil. 
Foi preparada uma solução-estoque de resveratrol, solubilizado em DMSO, na concentração de $1.000 \mathrm{mg} \mathrm{L}^{-1}$, que foi diluída em meio de cultura celular MEM (Meio mínimo de Eagle) contendo 5\% de soro fetal bovino (SFB), na proporção de 1/20. Esta solução foi passada em membrana tipo Millipore com poros de 0,22 $\mu \mathrm{m}$ de diâmetro. A partir dessa solução estéril, foram realizadas cinco diluições seriadas em MEM com $5 \%$ de SFB, obtendo-se as concentrações: $50 ; 25 ; 12,5 ; 6,25$ e $3,12 \mathrm{mg} \mathrm{L}^{-1}$.

Foram preparados extratos dos controles: i) negativo - 0,1 g/mL MEM de HDPE (polietileno de alta densidade) e ii) positivo - látex de borracha natural na proporção de 0,1 g/10 mL MEM. Essas soluções ficaram em estufa por $24 \mathrm{~h}$ em $37^{\circ} \mathrm{C}$. Os extratos dos controles foram diluídos em série nas concentrações de $100 \%, 50 \%, 25 \%, 12,5 \%$ e $6,25 \%$.

Após o descarte do meio de cultura contido na microplaca, foi adicionado um volume de $0,2 \mathrm{~mL}$ de cada solução do resveratrol e dos controles nos poços correspondentes da microplaca. Como controle de células, foi adicionado 0,2 $\mathrm{mL}$ de MEM com 5\% de SFB.

Realizada a distribuição das soluções, a microplaca foi mantida por 24 h em estufa a $37^{\circ} \mathrm{C}$ e atmosfera úmida com $5 \%$ de $\mathrm{CO}_{2}$. Os procedimentos de preparo das soluções e de distribuição das mesmas na microplaca constituem a fase asséptica do ensaio. Os procedimentos foram realizados em laboratório esterilizado por luz UV e a manipulação da microplaca e do material estéril foi efetuado na câmara de fluxo laminar.

Transcorridas $24 \mathrm{~h}$ de incubação, as soluções contidas na microplaca foram substituídas por $0,2 \mathrm{~mL}$ de solução de vermelho neutro em meio MEM (50 $\mu \mathrm{g} \mathrm{m}^{-1}$ ) e a microplaca foi incubada por $3 \mathrm{~h}$, com a finalidade de incorporação do corante pelas células vivas. Após este período, a microplaca foi lavada duas vezes com a solução salina tamponada com fosfato (PBS) e em seguida com 0,2 $\mathrm{mL}$ de solução de lavagem (cloreto de cálcio 1\% em formaldeído 0,5\%).

Para extração do corante vital incorporado pelas células vivas e integras foi adicionado em cada poço $0,2 \mathrm{~mL}$ de solução de extração: ácido acético glacial $0,2 \%$ em etanol (1:1). A solução de extração é responsável pela lise da membrana celular, liberando o vermelho neutro contido no interior das células, portanto, a quantidade de corante liberada torna-se diretamente 
proporcional ao número de células sobreviventes após o processo de contato direto com os solutos.

A microplaca foi agitada por 10 min e submetida à leitura de densidade óptica (DO) em espectrofotômetro leitor tipo ELISA, em $540 \mathrm{~nm}$, com filtro de referência de 600 nm (FIG. 11).

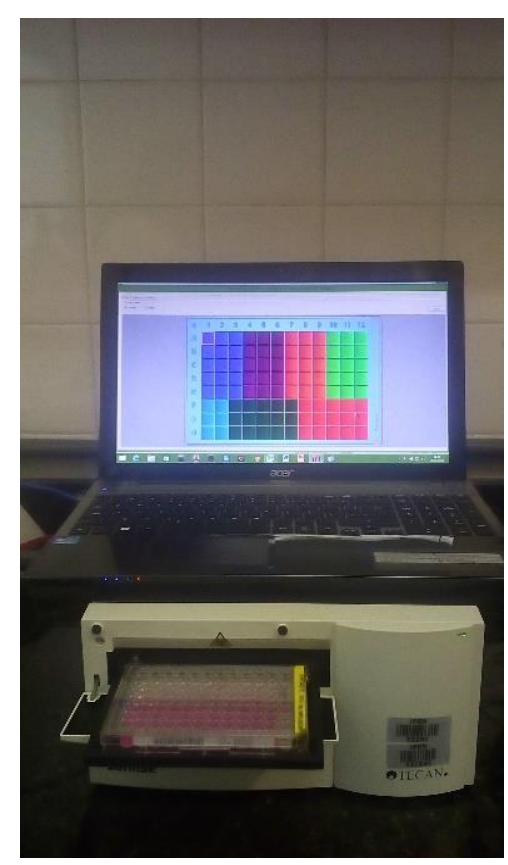

FIGURA 11 - Leitura das DO em espectrofotômetro leitor tipo ELISA. Fonte: O Autor, 2017.

\subsubsection{Ensaio de ecotoxicidade crônica de curta duração com larvas do peixe Danio rerio}

O ensaio de ecotoxicidade crônica de curta duração com larvas do peixe Danio rerio foi realizado com adaptações da norma ABNT-NBR 15499 (2007), para determinação da concentração letal do resveratrol (CL50 concentração da amostra que causa efeito letal em $50 \%$ dos organismos no tempo de exposição). Os experimentos foram realizados no Laboratório de Ecotoxicologia do Centro de Química e Meio Ambiente (CQMA), do Instituto de Pesquisas Energéticas e Nucleares (IPEN/CNEN-SP).

O princípio do ensaio foi expor larvas de Danio rerio recém eclodidas (com menos de $24 \mathrm{~h}$ ) a diferentes concentrações de resveratrol, por um período de $168 \mathrm{~h}$ e avaliar a letalidade. Um ensaio preliminar foi realizado para determinar a faixa de concentração a ser usada. Neste ensaio preliminar, as concentrações 
de resveratrol foram: 0,$5 ; 1,1 ; 2,3 ; 4,8 ; 10,3 ; 22 ; 46,9 ; 100 \mathrm{mg} \mathrm{L}^{-1}$, além do controle com água deionizada reconstituída e controle solvente (DMSO).

A partir deste teste, os ensaios definitivos foram realizados em triplicata. Os organismos ficaram expostos as seguintes concentrações do resveratrol: 3,$12 ; 6,25 ; 12,5 ; 25 ; 50$ e $100 \mathrm{mg} \mathrm{L}^{-1}$, além do controle com água deionizada reconstituída e controle solvente (DMSO), sendo quatro réplicas para cada concentração, com 10 larvas por réplica, totalizando 40 por concentração (FIG. 12). Mantidos sem alimentação, em incubadora na faixa de temperatura de $25 \pm 2^{\circ} \mathrm{C}$ e fotoperíodo de $12 \mathrm{~h}$ luz/12 $\mathrm{h}$ escuro.

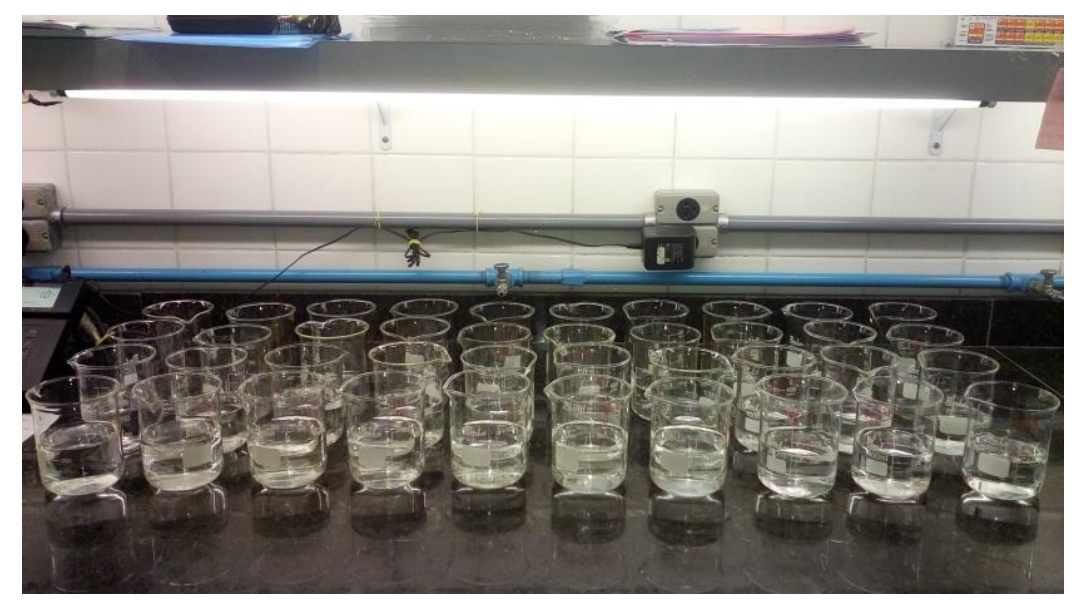

FIGURA 12 - Ensaio de ecotoxicidade crônica de curta duração com larvas de Danio rerio. Fonte: O Autor, 2017.

As soluções-teste, com volume de $250 \mathrm{~mL}$ cada, foram preparadas no momento da realização do ensaio, a partir da solução-estoque: $100 \mathrm{mg}$ de resveratrol em $16 \mathrm{~mL}$ de DMSO e $984 \mathrm{~mL}$ de água deionizada. Em relação ao controle solvente foram utilizadas soluções de DMSO nas concentrações de: 2, 4 e $8 \mathrm{mg} \mathrm{L}^{-1}$. As soluções-teste foram renovadas diariamente (ensaio semi-estático), portanto, foram produzidas diariamente, assim como a solução-estoque, e os parâmetros como oxigênio, $\mathrm{pH}$ e condutividade de cada solução-teste inicial e final foram registrados.

As larvas foram observadas a cada $24 \mathrm{~h}$ durante o ensaio, e a letalidade foi avaliada pela ausência do batimento cardíaco por 2 min em lupa binocular, com ampliação mínima de 80x (FIG. 13). Ao final de cada ensaio, a concentração letal do resveratrol (CL50) foi determinada com base nos resultados de letalidade dos organismos. O ensaio é considerado válido se a letalidade dos organismos no controle for menor ou igual a $20 \%$. 


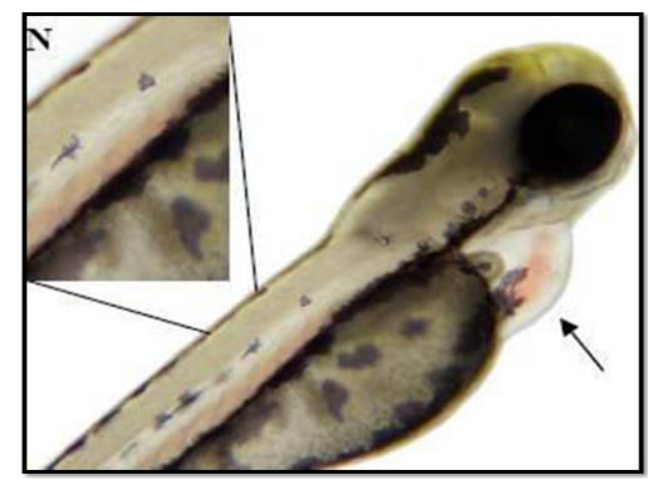

FIGURA 13 - Larva de Danio rerio sem batimento cardíaco. Fonte: OECD, 2013.

\subsubsection{Ensaio de sensibilidade com larvas do peixe Danio rerio e obtenção da carta- controle}

Como solicita a norma ABNT-NBR 15499 (2007), para garantir que a sensibilidade dos organismos esteja adequada, e assim conceder maior confiabilidade aos ensaios crônicos de curta duração com o resveratrol, faz-se necessário a realização de ensaios de sensibilidade mensalmente com uma substância de referência. A substância de referência é um agente químico, denominado de controle positivo, que atua em testes de toxicidade detectando efeitos fora da variação normal, mediante a utilização de uma série de múltiplas concentrações. Representam assim, um meio de detectar mudanças do organismo-teste e de avaliar a precisão destes testes (Castro, 2008).

Os experimentos foram realizados no Laboratório de Ecotoxicologia do Centro de Química e Meio Ambiente (CQMA), do Instituto de Pesquisas Energéticas e Nucleares (IPEN/CNEN-SP).

Neste trabalho, como substância de referência foi utilizado o cloreto de sódio $(\mathrm{NaCl})$ e um ensaio preliminar foi realizado para determinar a faixa de concentração a ser usada. As concentrações de $\mathrm{NaCl}$ foram: 2; 5; 10 e $15 \mathrm{~g} \mathrm{~L}^{-1}$. A partir do ensaio preliminar os ensaios definitivos foram realizados.

As larvas de Danio rerio recém eclodidas (com menos de $24 \mathrm{~h}$ ) foram expostas as seguintes concentrações de $\mathrm{NaCl}$ : 2; 3; 4,5; 6,8 e 10,1 $\mathrm{g} \mathrm{L}^{-1}$, além do controle com água deionizada reconstituída, sendo quatro réplicas para cada concentração, com 10 larvas por réplica, totalizando 40 por concentração. Os 
ensaios de sensibilidade foram conduzidos sob as mesmas condições dos ensaios crônicos de curta duração com larvas de Danio rerio (4.4.2).

As soluções-teste, com volume de $250 \mathrm{~mL}$ cada, foram preparadas no momento da realização do ensaio, a partir da solução-estoque: $20 \mathrm{mg}$ de $\mathrm{NaCl}$ em $1000 \mathrm{~mL}$ de água deionizada. Ao final de cada ensaio, para a construção da carta-controle, a concentração letal do $\mathrm{NaCl}$ (CL50 - concentração da amostra que causa efeito letal em $50 \%$ dos organismos no tempo de exposição) foi determinada com base nos resultados de letalidade dos organismos.

A carta-controle consiste em um gráfico com 20 resultados de testes de sensibilidade anteriores com a mesma substância testada. É calculado o valor médio (x), o desvio padrão $(\sigma)$ e o coeficiente de variação $(C V)$ das CL50 obtidas. Se não houver 20 resultados, deve-se calcular a média provisória de cinco. $O$ resultado pode apresentar variação do desvio padrão de até $\pm 2 \sigma$. Caso extrapole esses valores, é indício de que pode haver alta sensibilidade dos organismos, ou de algum procedimento inadequado durante a realização do ensaio.

\subsubsection{Ensaio de ecotoxicidade aguda no estágio embriolarval do peixe Danio rerio (96 $\mathrm{h}$ de duração)}

O ensaio de ecotoxicidade para avaliação de efeito agudo no desenvolvimento embriolarval do peixe Danio rerio foi realizado baseado no protocolo da OECD no 236 (Guideline on Fish Embryo Acute Toxicity Test -FET) (2013). O ensaio foi realizado no Laboratório de Genética Toxicológica (G-Tox), da Universidade de Brasília (UNB) sob coordenação do Prof. Dr. Cesar Koppe Grisolia e do Dr. Rhaul de Oliveira.

O princípio do ensaio foi expor embriões de Danio rerio recém fertilizados a diferentes concentrações de resveratrol, por um período de $96 \mathrm{~h}$ e avaliar a letalidade. Os organismos ficaram expostos as seguintes concentrações do resveratrol: 0,$5 ; 1,1 ; 2,3 ; 4,8 ; 10,3 ; 22 ; 46,9 ; 100 \mathrm{mg} \mathrm{L}^{-1}$, além do controle negativo (água deionizada reconstituída) e controle solvente (DMSO), sendo três réplicas para cada concentração.

Microplacas de 24 poços foram usadas, e em cada poço foi exposto um embrião com $2 \mathrm{~mL}$ de solução-teste, sendo que 20 poços continham as soluçõesteste e 4 poços continham o controle negativo. Em relação ao controle solvente, 
20 poços continham o controle solvente e 4 poços o controle negativo. Já no controle negativo, os 24 poços continham apenas o controle negativo (FIG. 14). As microplacas foram mantidas em incubadora, na faixa de temperatura de $26 \pm$ $1^{\circ} \mathrm{C}$ e fotoperíodo de $12 \mathrm{~h} \mathrm{luz} / 12 \mathrm{~h}$ escuro (FIG. 15).

\begin{tabular}{|c|c|c|c|}
\hline$R$ & $R$ & $R$ & $R$ \\
\hline$R$ & $R$ & $R$ & $R$ \\
\hline$R$ & $R$ & $R$ & $R$ \\
\hline$R$ & $R$ & $R$ & $R$ \\
\hline$R$ & $R$ & $R$ & $R$ \\
\hline$C n$ & $C n$ & $C n$ & $C n$ \\
\hline
\end{tabular}

A

\begin{tabular}{|l|l|l|l|}
\hline$C n$ & $C n$ & $C n$ & $C n$ \\
\hline$C n$ & $C n$ & $C n$ & $C n$ \\
\hline$C n$ & $C n$ & $C n$ & $C n$ \\
\hline$C n$ & $C n$ & $C n$ & $C n$ \\
\hline$C n$ & $C n$ & $C n$ & $C n$ \\
\hline$C n$ & $C n$ & $C n$ & $C n$ \\
\hline
\end{tabular}

B

\begin{tabular}{|l|l|l|l|}
\hline Cs & Cs & Cs & Cs \\
\hline$C s$ & $C s$ & $C s$ & $C s$ \\
\hline$C s$ & $C s$ & $C s$ & $C s$ \\
\hline$C s$ & $C s$ & $C s$ & $C s$ \\
\hline$C s$ & $C s$ & $C s$ & $C s$ \\
\hline$C n$ & $C n$ & $C n$ & $C n$ \\
\hline
\end{tabular}

C

FIGURA 14 - Microplacas de 24 poços. (A) Microplaca com resveratrol (soluçãoteste); (B) Microplaca com Controle Negativo; (C) Microplaca com Controle Solvente. $\mathrm{R}=$ Resveratrol; $\mathrm{Cn}=$ Controle Negativo; $\mathrm{Cs}=$ Controle Solvente.

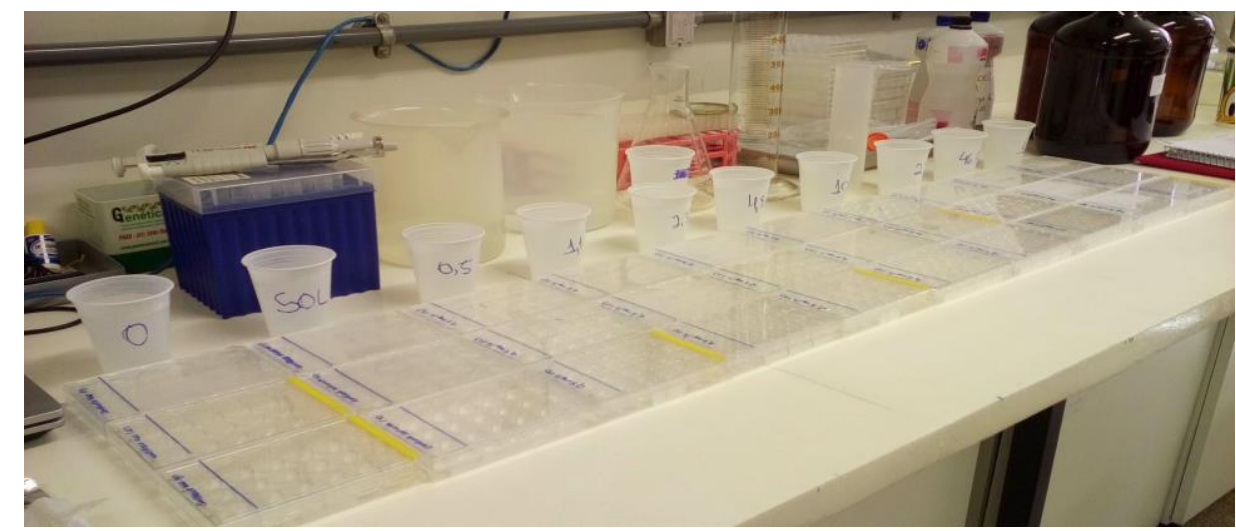

FIGURA 15- Ensaio de ecotoxicidade aguda no estágio embriolarval de Danio rerio (96 h de duração). Fonte: O Autor, 2017.

As soluções-teste foram preparadas no momento da realização do ensaio, a partir da solução-estoque: $100 \mathrm{mg}$ de resveratrol em $100 \mu \mathrm{L}$ de DMSO e 999,9 $\mathrm{mL}$ de água deionizada. As soluções foram renovadas após $48 \mathrm{~h}$ do início do ensaio (ensaio semi-estático). No controle solvente foi adicionado $15 \mu \mathrm{L}$ de DMSO em 999,98 mL, a maior concentração de solvente usada no teste. 
A cada $24 \mathrm{~h}$ os organismos foram observados com o auxílio de um microscópio invertido. Na fase embrionária foram observados os seguintes parâmetros: coagulação de ovos fertilizados, batimentos cardíacos, pigmentação dos olhos e do corpo, formação de somitos, desprendimento da cauda, eclosão e letalidade. Após a eclosão, os parâmetros avaliados nas larvas foram: batimentos cardíacos, edemas, coluna vertebral torta e letalidade.

Ao final do ensaio, a concentração letal do resveratrol (CL50 concentração da amostra que causa efeito letal em $50 \%$ dos organismos no tempo de exposição) foi determinada com base nos resultados de letalidade dos organismos. O resultado do ensaio é válido se a sobrevivência dos organismos no controle for maior ou igual a $90 \%$.

\subsubsection{Ensaio de ecotoxicidade aguda no estágio embriolarval do peixe Danio rerio (168 $\mathrm{h}$ de duração)}

O ensaio de ecotoxicidade para avaliação de efeito agudo no desenvolvimento embriolarval do peixe Danio rerio foi realizado baseado no protocolo da OECD no 236 (Guideline on Fish Embryo Acute Toxicity Test -FET) (2013). Os experimentos foram realizados no Laboratório de Ecotoxicologia do Centro de Química e Meio Ambiente (CQMA), do Instituto de Pesquisas Energéticas e Nucleares (IPEN/CNEN-SP).

O princípio do ensaio foi expor embriões de Danio rerio recém fertilizados a diferentes concentrações de resveratrol, por um período de $168 \mathrm{~h}$ e avaliar a letalidade. Os organismos ficaram expostos as seguintes concentrações do resveratrol: 3,$12 ; 6,25 ; 12,5 ; 25 ; 50$ e $100 \mathrm{mg} \mathrm{L}^{-1}$, assim como no controle negativo (água deionizada reconstituída) e controle solvente (DMSO), sendo três réplicas para cada concentração.

As soluções-teste foram preparadas no momento da realização do ensaio, a partir da solução-estoque: $100 \mathrm{mg}$ de resveratrol em $16 \mathrm{~mL}$ de DMSO e $984 \mathrm{~mL}$ de água deionizada. As soluções-teste foram renovadas diariamente (ensaio semi-estático), portanto, foram produzidas diariamente, assim como a solução-estoque. No controle solvente foi adicionado $8 \mathrm{~mL}$ de DMSO em $992 \mathrm{~mL}$ de água deionizada reconstituída, a maior concentração de solvente usada no teste. A distribuição dos embriões nas microplacas, assim como a faixa de 
temperatura e fotoperíodo que as microplacas foram mantidas foi semelhante ao ensaio 4.4.4.

A cada $24 \mathrm{~h}$ os organismos foram observados com o auxílio de um microscópio invertido. Na fase embrionária foram observados os seguintes parâmetros: coagulação de ovos fertilizados, batimentos cardíacos, pigmentação dos olhos e do corpo, formação de somitos, desprendimento da cauda e letalidade. Após a eclosão, os parâmetros avaliados nas larvas foram: batimentos cardíacos, edemas, coluna vertebral torta e letalidade.

Ao final do ensaio, a concentração letal do resveratrol (CL50 concentração da amostra que causa efeito letal em $50 \%$ dos organismos no tempo de exposição) foi determinada com base nos resultados de letalidade dos organismos. $O$ resultado do ensaio é válido se a sobrevivência dos organismos no controle for maior ou igual a $90 \%$.

\subsubsection{Ensaio de biomarcadores enzimáticos de Danio rerio no estágio embriolarval}

O ensaio de biomarcadores enzimáticos foi realizado no Laboratório de Genética Toxicológica (G-Tox), da Universidade de Brasília (UNB) sob coordenação do Prof. Dr. Cesar Koppe Grisolia e do Dr. Rhaul de Oliveira.

Embriões de Danio rerio recém fertilizados foram expostos a diferentes concentrações de resveratrol, por um período de $96 \mathrm{~h}$. Os organismos ficaram expostos as seguintes concentrações do composto: 0,$5 ; 1,1 ; 2,3$ e 4,8 $\mathrm{mg} \mathrm{L}^{-1}$, além do controle negativo (água deionizada reconstituída) e controle solvente (DMSO) (FIG. 16), na faixa de temperatura de $26 \pm 1^{\circ} \mathrm{C}$ e fotoperíodo de $12 \mathrm{~h}$ luz/12 h escuro.

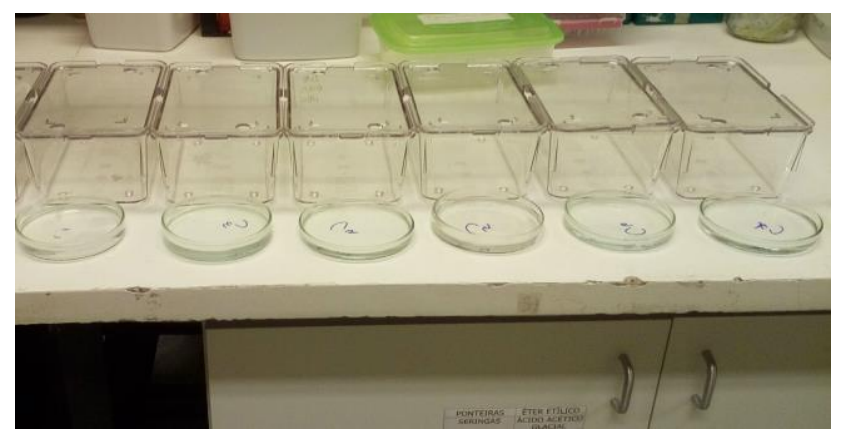

FIGURA 16 - Exposição dos embriões de Danio rerio recém fertilizados a diferentes concentrações de resveratrol e controles. Fonte: O Autor, 2017. 
Foram utilizados 250 embriões por concentração, as soluções-teste, com volume de $500 \mathrm{~mL}$ cada, foram preparadas no momento da realização do ensaio, a partir da solução-estoque: $100 \mathrm{mg}$ de resveratrol em $100 \mu \mathrm{L}$ de DMSO e 999,9 $\mathrm{mL}$ de água deionizada. Todas as soluções-teste apresentaram a mesma concentração de solvente DMSO. As soluções foram renovadas após $48 \mathrm{~h}$ do início do ensaio (ensaio semi-estático). O controle solvente foi preparado com 2,4 $\mu \mathrm{L}$ de DMSO em $500 \mathrm{~mL}$ de água deionizada reconstituída, a maior concentração de solvente usada no teste.

Após $96 \mathrm{~h}$ de exposição ao resveratrol, larvas foram transferidas para tubos eppendorf. Ao total 60 tubos, contendo $0,5 \mathrm{~mL}$ de solução tampão fosfato $(\mathrm{pH} 7,4)$ e 15 larvas cada, foram mantidos no congelador $(-20 \stackrel{\circ}{\circ})$. No dia do ensaio para análise da atividade das enzimas lactato desidrogenase (LDH) e colinesterase $(\mathrm{ChE})$, as amostras foram descongeladas, homogeneizadas em sonicador e centrifugadas durante $20 \mathrm{~min}$, a $10.000 \mathrm{rpm}$ a $4 \stackrel{\circ}{\circ} \mathrm{C}$, para separar o sobrenadante a ser utilizado nos ensaios (FIG. 17). 

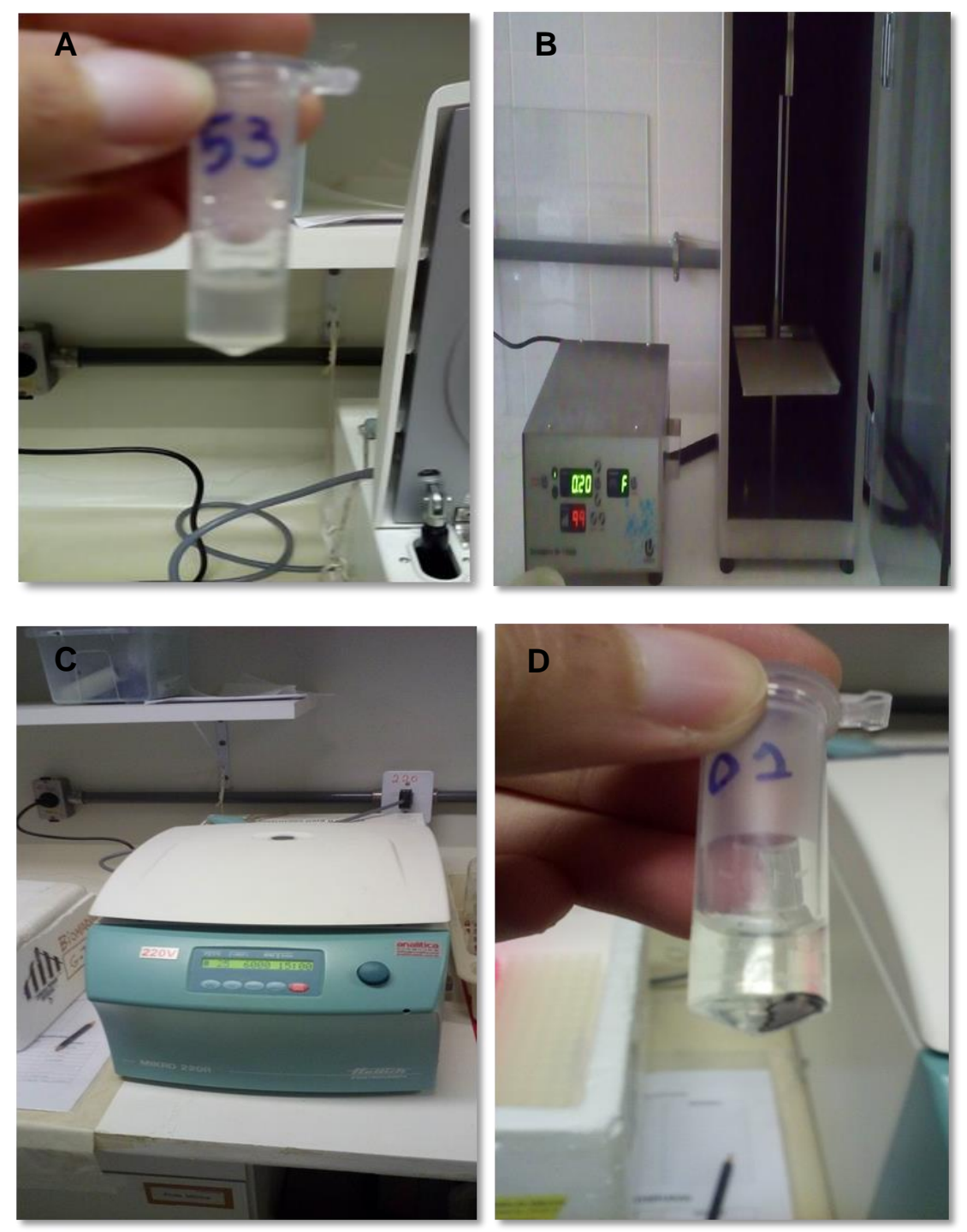

FIGURA 17 - (A) Tubo eppendorf contendo $0,5 \mathrm{~mL}$ de solução tampão fosfato e 15 larvas; (B) Sonicador; (C) Centrífuga; (D) Tubo eppendorf com 0 sobrenadante separado. Fonte: O Autor, 2017.

Foram determinadas as concentrações de proteínas $\left(\mathrm{mg} \mathrm{mL}^{-1}\right)$ nos sobrenadantes de cada amostra, em quadruplicata, pelo método de Bradford (1976), usando Y-globulina bovina como padrão e leitura em 595 nm.

Os sobrenadantes das amostras foram colocados em microplacas de 96 poços, e as atividades enzimáticas foram medidas espectrofotometricamente (FIG. 18) em quadruplicata, sendo os resultados expressos em nmol. $\mathrm{min}^{-1} \cdot \mathrm{mg}^{-1} \mathrm{de}$ proteína total. 


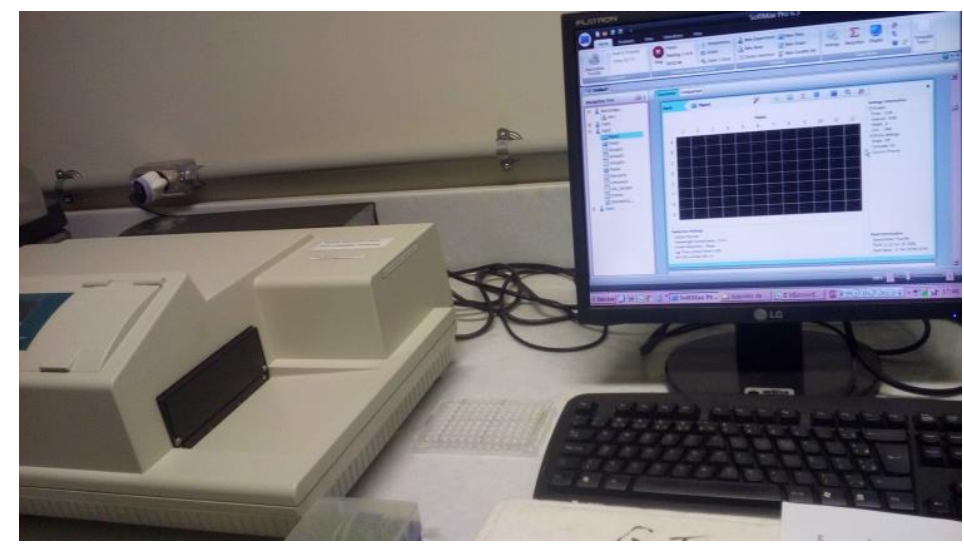

FIGURA 18 - Espectrofotômetro. Fonte: O Autor, 2017.

\subsubsection{Lactato desidrogenase (LDH)}

O procedimento de análise da atividade da lactato desidrogenase foi de acordo com a metodologia descrita por Vassault (1983) com modificações de Diamantino et al. (2001), usando como substrato o piruvato.

As atividades foram determinadas usando $20 \mu \mathrm{L}$ da amostra e $250 \mu \mathrm{L}$ de $\operatorname{NADH}(0,24 \mathrm{mM})$ e $40 \mu \mathrm{L}$ de piruvato $(10 \mathrm{mM})$ em solução de Tris- $\mathrm{NaCl}(0,1 \mathrm{M}$, $\mathrm{pH} 7.2)$, medidas em $340 \mathrm{~nm}$, a cada $40 \mathrm{~s}$, durante $5 \mathrm{~min}$.

\subsubsection{Colinesterase (ChE)}

A atividade da colinesterase foi determinada usando acetiltiocolina como substrato, de acordo com método descrito por Ellman et al. (1961) e adaptado por Guilhermino et al. (1996). As atividades foram analisadas usando 10 $\mu \mathrm{L}$ da amostra e $250 \mu \mathrm{L}$ da solução de reação, contendo acetiltiocolina (75 mM) e ácido 5,5- ditiobis-2-nitrobenzoico (DTNB) (10 mM) em solução tampão $(0,1 \mathrm{M}, \mathrm{pH}$ 7.2), medidas em $416 \mathrm{~nm}$, a cada $40 \mathrm{~s}$, durante $5 \mathrm{~min}$. 


\section{RESULTADOS E DISCUSSÃO}

\subsection{Análise do resveratrol por cromatografia líquida de alta pressão (HPLC)}

O cromatograma da solução padrão de resveratrol na concentração de $0,5 \mathrm{mg} \mathrm{mL}^{-1}$ está representado na FIG. 19. O tempo de retenção foi de aproximadamente $15 \mathrm{~min}$, e conforme as características dadas pelo fornecedor do resveratrol utilizado no presente estudo (4.1), o composto está puro e há apenas o isômero trans-resveratrol.

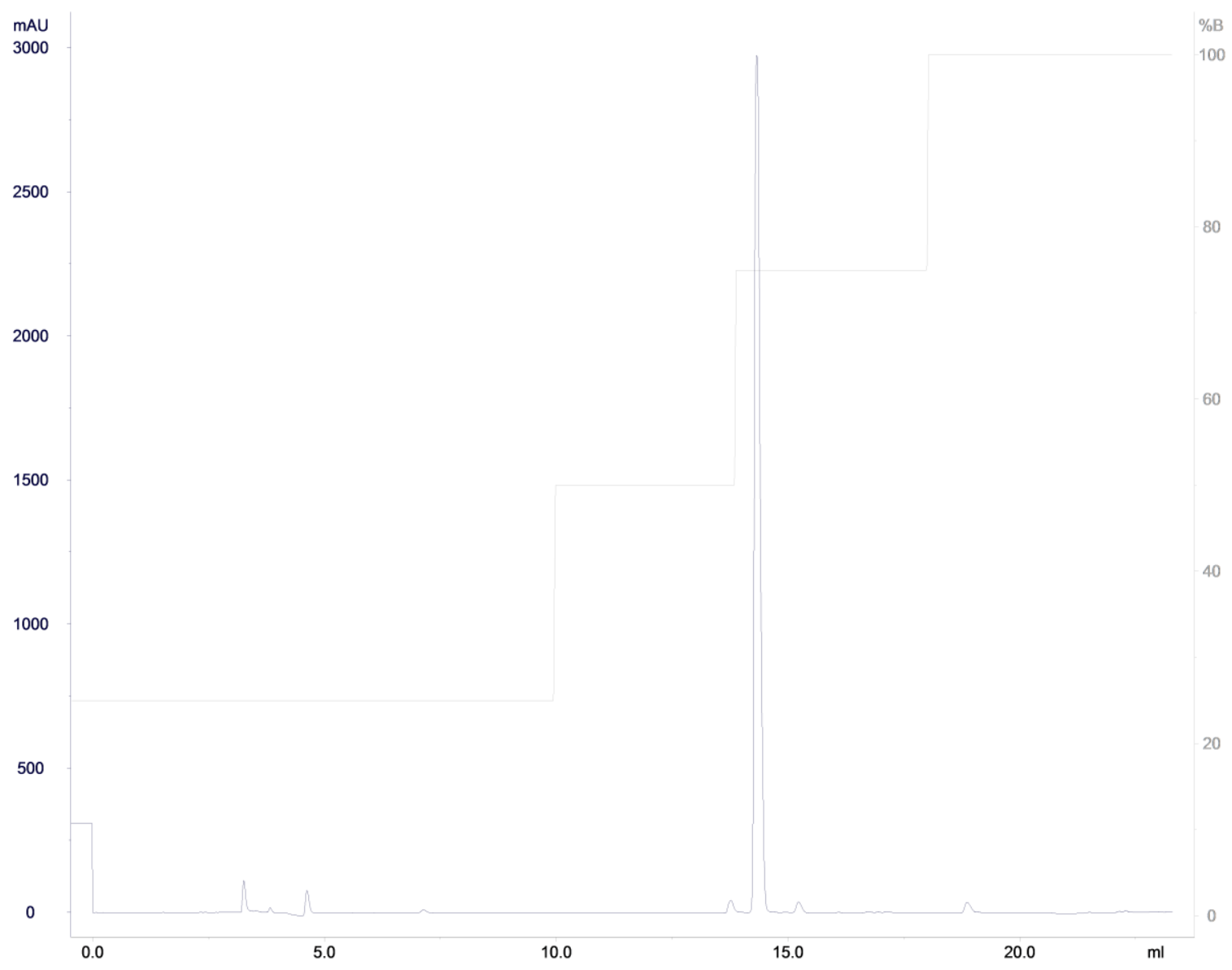

FIGURA 19 - Cromatograma da solução padrão de resveratrol na concentração de $0,5 \mathrm{mg} \mathrm{mL}^{-1}$.

Os cromatogramas das soluções-teste de resveratrol, na concentração de 50 e $100 \mathrm{mg} \mathrm{L}^{-1}$, sem exposição e com exposição a luz fluorescente por $24 \mathrm{~h}$ estão representados nas FIG. 20, 21, 22 e 23. O tempo de retenção sem exposição e com exposição a luz fluorescente foi a mesma, aproximadamente 15 
min. Após $24 \mathrm{~h}$ de exposição a luz fluorescente podemos observar que o resveratrol se manteve estável. Por esse método não observamos a degradação do resveratrol e nem a conversão da forma trans para cis-resveratrol após $24 \mathrm{~h}$ de exposição a luz fluorescente.

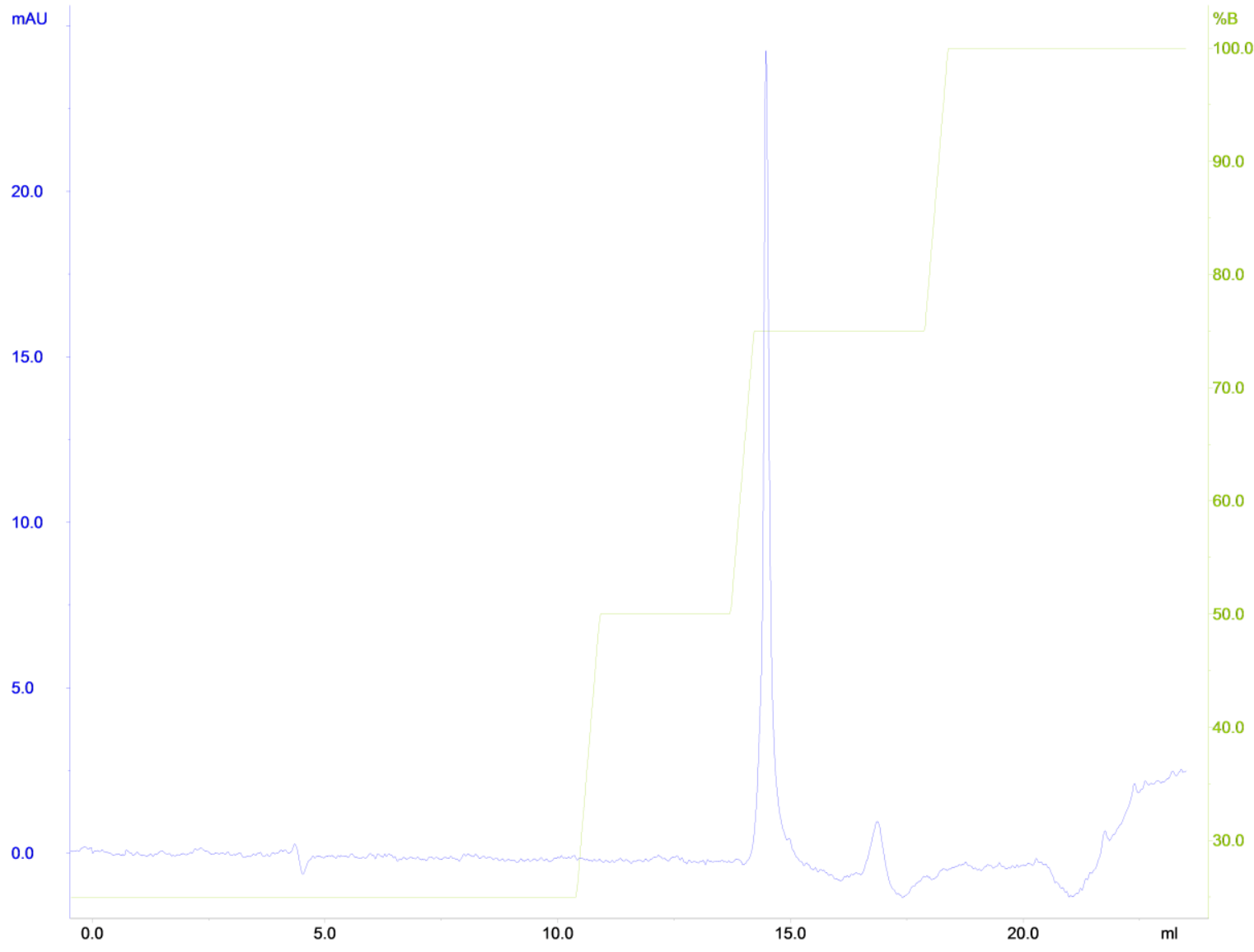

FIGURA 20 - Cromatograma do resveratrol na concentração de $50 \mathrm{mg} \mathrm{L}^{-1}$ sem exposição a luz fluorescente. 
FIGURA 21 - Cromatograma do resveratrol na concentração de $50 \mathrm{mg} \mathrm{L}^{-1} \mathrm{com}$ exposição a luz fluorescente por $24 \mathrm{~h}$. 


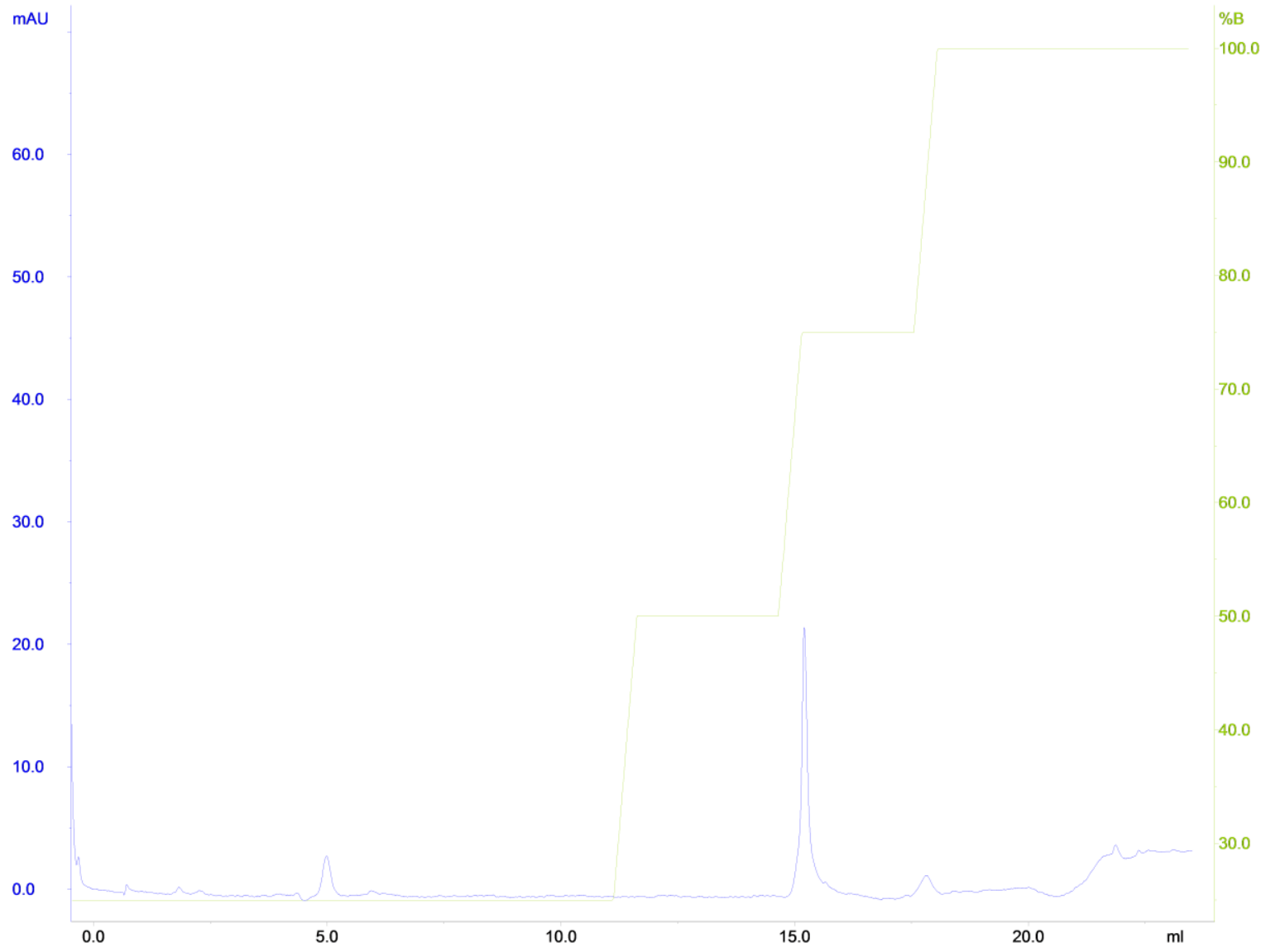

FIGURA 22 - Cromatograma do resveratrol na concentração de $100 \mathrm{mg} \mathrm{L}^{-1}$ sem exposição a luz fluorescente. 


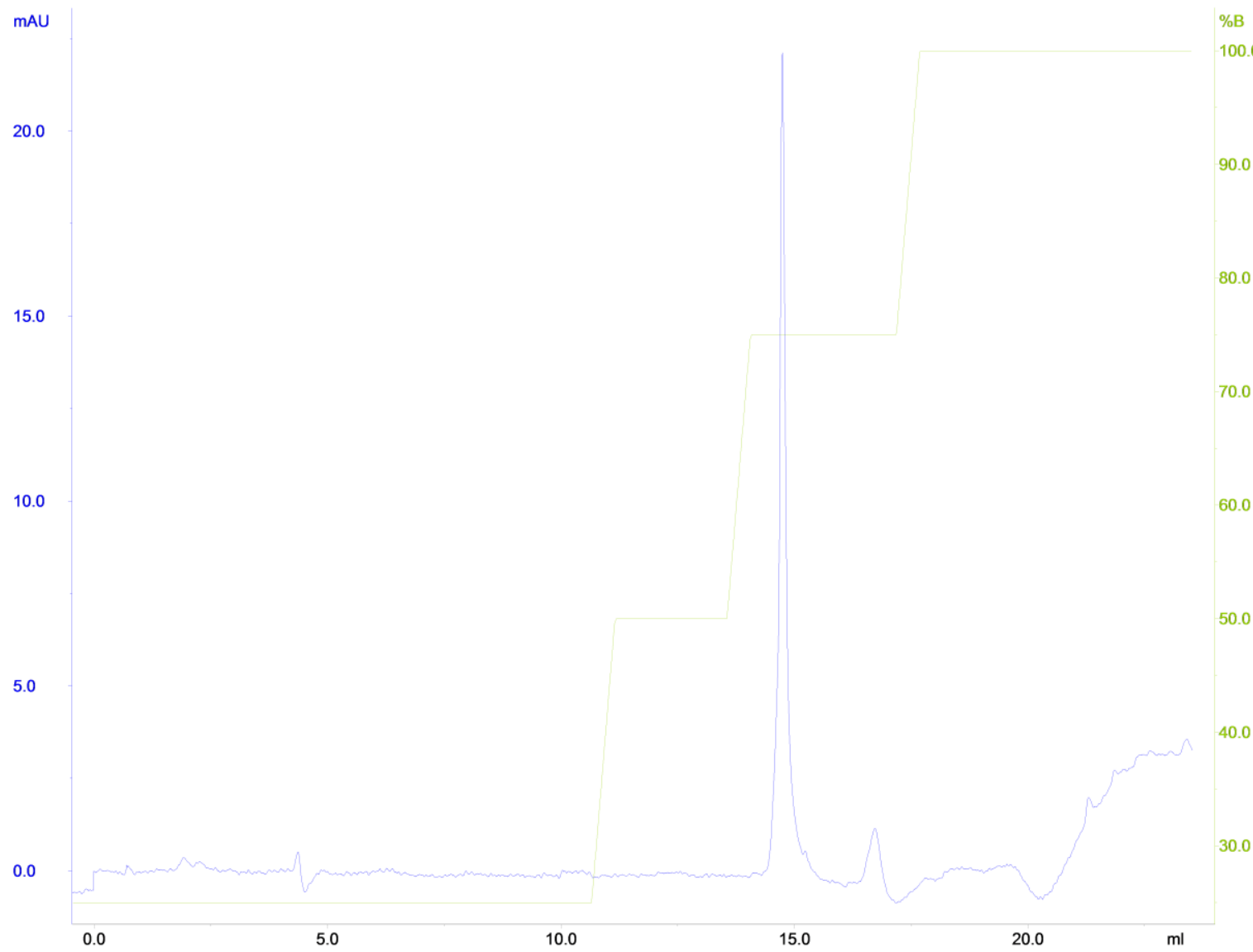

FIGURA 23 - Cromatograma do resveratrol na concentração de $100 \mathrm{mg} \mathrm{L}^{-1} \mathrm{com}$ exposição a luz fluorescente por $24 \mathrm{~h}$.

\subsection{Ensaio in vitro de citotoxicidade do resveratrol}

Neste ensaio in vitro de citotoxicidade do resveratrol, a partir da DO obtida de cada poço da microplaca, foram calculados os valores médio das DO e seus respectivos desvios padrão, cujos valores representam os efeitos celulares promovidos durante o período de contato direto do resveratrol e dos extratos dos controles negativo e positivo com a cultura celular.

O cálculo da porcentagem de viabilidade celular foi realizado em relação ao controle de células do ensaio, que representam $100 \%$ de viabilidade, utilizando a equação:

$\%$ Viabilidade Celular $=\left(D_{S L} \times 100\right) / D O_{c c}$ 
Onde, DOSL representa o valor médio das DO de cada concentração de resveratrol e dos extratos dos controles negativo e positivo e DOcc, o valor médio das DO do controle de células.

$\mathrm{Na}$ TAB. 1 estão apresentados os valores da \% viabilidade celular obtidas no ensaio de citotoxicidade do resveratrol.

TABELA 1 - Porcentagens de viabilidade celular dos extratos dos controles negativo e positivo e do resveratrol.

\begin{tabular}{cccc}
$\begin{array}{c}\text { Concentração } \\
\text { Extrato (\%) }\end{array}$ & \multicolumn{3}{c}{ Viabilidade celular (\%) } \\
\cline { 2 - 4 } & $\begin{array}{c}\text { Controle } \\
\text { Negativo }\end{array}$ & $\begin{array}{c}\text { Controle } \\
\text { Positivo }\end{array}$ & Resveratrol \\
\hline 100 & $86 \pm 14$ & $30 \pm 10$ & $32 \pm 13$ \\
50 & $91 \pm 20$ & $85 \pm 11$ & $81 \pm 10$ \\
25 & $95 \pm 18$ & $95 \pm 13$ & $80 \pm 11$ \\
12,5 & $96 \pm 13$ & $90 \pm 16$ & $80 \pm 6$ \\
6,25 & $91 \pm 15$ & $109 \pm 2$ & $80 \pm 3$
\end{tabular}

Para a estimativa do índice de citotoxicidade $\left(\mathrm{IC}_{50}\right)$ os dados da TAB. 1 foram projetados em gráfico com a viabilidade celular (\%) em função das concentrações dos extratos dos controles negativo e positivo, e do resveratrol (\%). A FIG. 24 apresenta as curvas de viabilidade celular obtidas no ensaio de citotoxicidade do resveratrol pelo método de incorporação do vermelho neutro. 


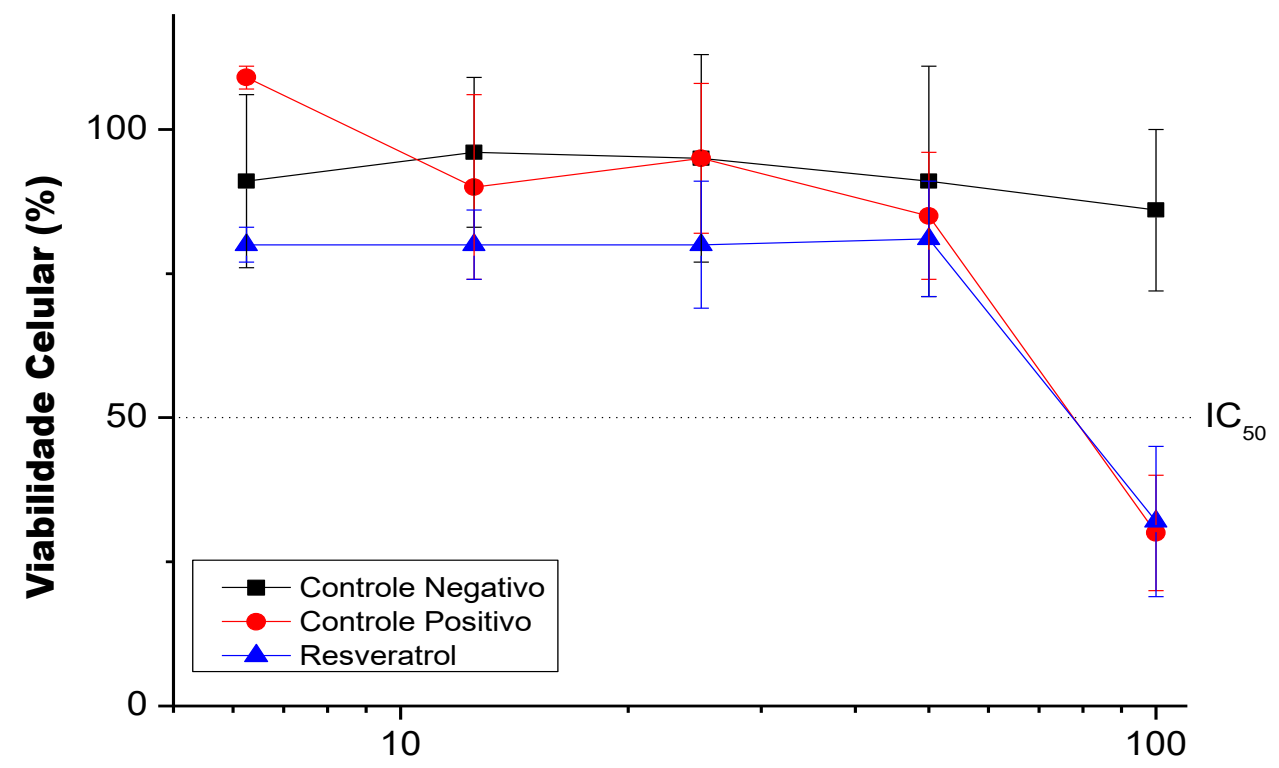

Concentração extrato (\%)

FIGURA 24 - Curvas de viabilidade celular obtidas no ensaio in vitro de citotoxicidade do resveratrol pelo método de incorporação do vermelho neutro.

Os controles são utilizados para a verificação da eficácia do ensaio. A amostra cuja curva de viabilidade celular se projeta acima da linha do $\mathrm{IC}_{50}$ é considerado não citotóxica, como observado no controle negativo. Já a amostra que apresenta uma curva de viabilidade celular abaixo ou que cruze a linha do $\mathrm{IC}_{50}$ é considerada citotóxica, como observado no controle positivo.

O $\mathrm{IC}_{50}$ (índice de citotoxicidade - a concentração da amostra que induz $50 \%$ de lise ou morte celular) é estimado na intersecção entre a curva de viabilidade celular e a linha de $50 \%$ de viabilidade no gráfico. O controle positivo apresentou $\mathrm{IC}_{50}$ de $78 \%$, portanto, 0 extrato do controle positivo nesta concentração provocou morte em $50 \%$ da população celular do ensaio.

A curva de viabilidade celular do resveratrol demonstrou um perfil igual ao do controle positivo, sendo obtido um $\mathrm{IC}_{50}$ cerca de $78 \%$, valor que corresponde à concentração de $39 \mathrm{mg} \mathrm{L}^{-1}$, ou seja, o resveratrol na concentração de $39 \mathrm{mg} \mathrm{L}^{-1}$ causou a morte de $50 \%$ da população celular do ensaio.

Este ensaio proporcionou a estimativa de uma faixa de concentração do resveratrol ao estudo da determinação da ecotoxicidade do composto no estágio embriolarval de peixes da espécie Danio rerio. 
5.3 Ensaio de ecotoxicidade crônica de curta duração com larvas do peixe Danio rerio

O percentual de letalidade para cada ensaio está apresentado na TAB.

2.

TABELA 2 - Percentual de letalidade obtido nos ensaios de ecotoxicidade crônica de curta duração do resveratrol em larvas do peixe Danio rerio após $168 \mathrm{~h}$ de exposição.

\begin{tabular}{cccc}
\hline Concentração & \multicolumn{3}{c}{ Letalidade (\%) } \\
\cline { 2 - 4 } Resveratrol (mg L $\left.{ }^{-1}\right)$ & Ensaio 1 & Ensaio 2 & Ensaio 3 \\
\hline Controle Solvente & 0 & 0 & 0 \\
0 & 2,5 & 0 & 0 \\
3,12 & 0 & 2,5 & 0 \\
6,25 & 2,5 & 5 & 0 \\
12,5 & 2,5 & 0 & 2,5 \\
25 & 2,5 & 0 & 2,5 \\
50 & 35 & 50 & 40 \\
100 & 100 & 100 & 100 \\
\hline
\end{tabular}

A FIG. 25 apresenta o gráfico da taxa de letalidade (\%) das larvas do peixe Danio rerio em relação à concentração de resveratrol $\left(\mathrm{mg} \mathrm{L}^{-1}\right)$. O resultado da mortalidade das larvas nos controles foi inferior a $20 \%$ como requerido para validade do ensaio. 


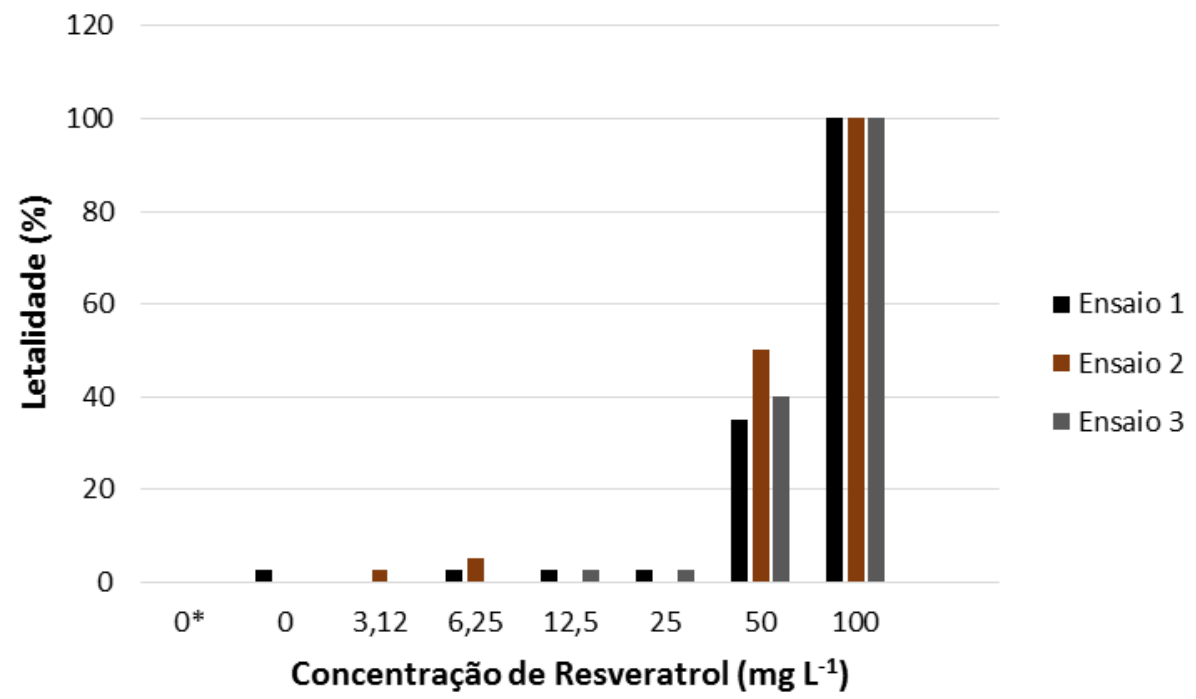

FIGURA 25 - Taxa de letalidade das larvas do peixe Danio rerio em função das concentrações do resveratrol após $168 \mathrm{~h}$ de exposição. " 0 *" refere-se ao controle solvente.

Estes ensaios avaliaram a CL50/168h, concentração que causa efeito letal em $50 \%$ dos organismos após $168 \mathrm{~h}$ de exposição ao resveratrol.

Os valores das CL50 e os intervalos de confiança dos ensaios de ecotoxicidade crônica de curta duração do resveratrol em larvas do peixe Danio rerio foram obtidos pelo programa estatístico Trimmed Spearman-Karber. Na TAB. 3 são apresentados os valores das CL50, os intervalos de confiança, a média, o desvio padrão (DP) e o coeficiente de variação (CV).

TABELA 3 - Valores das CL50, intervalos de confiança, média, desvio padrão e coeficiente de variação para os ensaios de ecotoxicidade crônica de curta duração do resveratrol em larvas do peixe Danio rerio.

\begin{tabular}{ccc}
\hline Ensaio & CL50 (mg L-1) & $\begin{array}{c}\text { Intervalo de confiança } \\
\left(\mathbf{m g ~ L}^{-1}\right)\end{array}$ \\
\hline 1 & 52,67 & $(46,70-59,39)$ \\
2 & 49,68 & $(44,29-55,72)$ \\
3 & 51,76 & $(46,01-58,23)$ \\
Média & 51,37 & \\
Desvio padrão & 1,53 & \\
Coeficiente de variação & & \\
$(\%)$ & 0,03 & \\
\hline
\end{tabular}


O valor médio da CL50/168h do resveratrol obtido nos ensaios de ecotoxicidade crônica de curta duração realizados com larvas do peixe Danio rerio foi de $51,37 \mathrm{mg} \mathrm{L}^{-1}$.

Nas concentrações de 50 e $100 \mathrm{mg} \mathrm{L}^{-1}$ foram observadas deformidades nos organismos e com o passar das horas a letalidade foi verificada. As deformidades constatadas foram: edema do pericárdio, edema do saco vitelínico e coluna vertebral torta (FIG. 26). Tais deformidades foram observadas por diversos autores que estudaram a toxicidade de fámacos e metais pesados: Akande et al. (2010); Asharani et al. (2008); Li et al. (2017); Oliveira et al. (2009); Oliveira et al. (2017); Tesolin et al. (2014); Tokunaga et al. (2016); Watson et al. (2014); Yin et al. (2014) e Zhang et al. (2015). Devido a falta de dados sobre a toxicidade do resveratrol em Danio rerio utilizou-se os estudos acima.

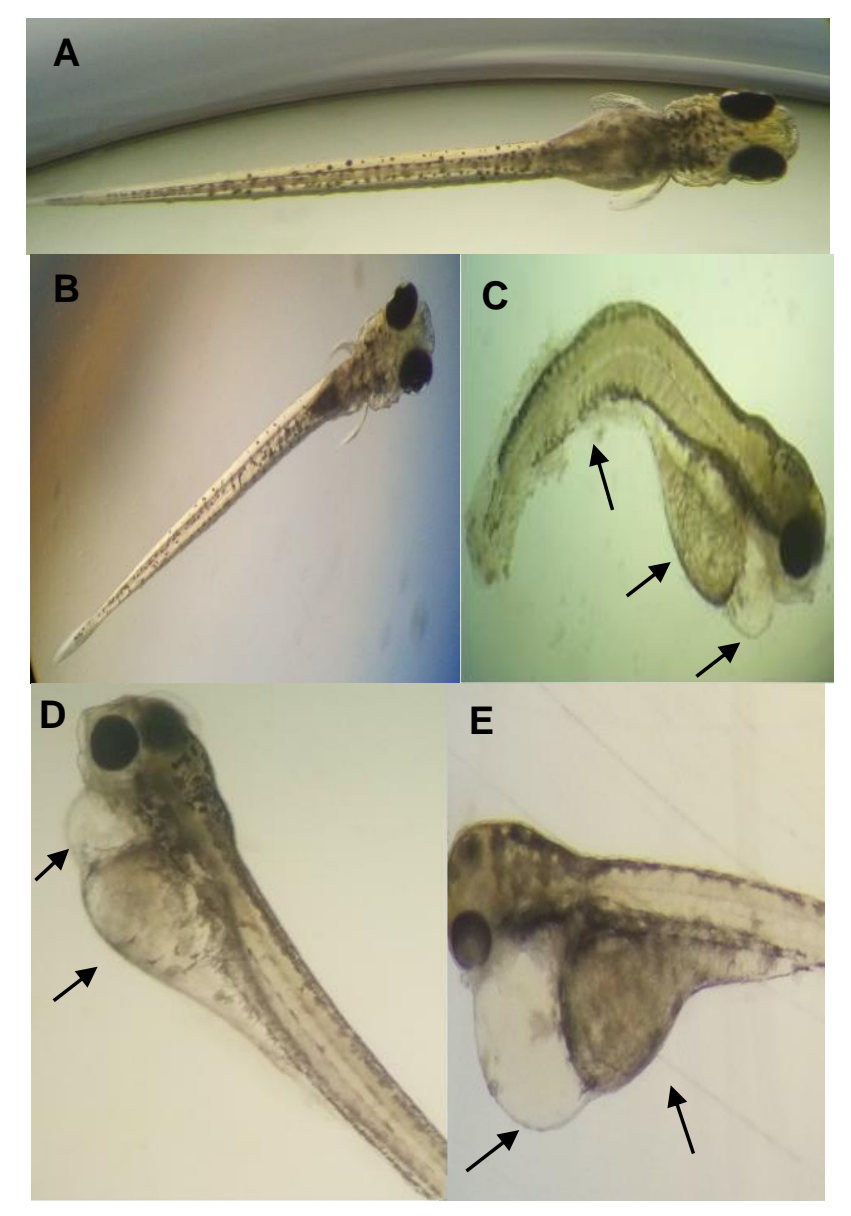

FIGURA 26 - Deformidades nas larvas de Danio rerio após exposição ao resveratrol no período de $144 \mathrm{~h}$ : (A e B) Controle; ( $\mathrm{D}$ e E) Larvas na concentração de $50 \mathrm{mg} \mathrm{L}^{-1} \mathrm{com}$ edema do pericárdio e do saco vitelínico (setas pretas); (C) Larva na concentração de $50 \mathrm{mg} \mathrm{L}^{-1}$ com edema do pericárdio, do saco vitelínico e coluna vertebral torta (setas pretas). Fonte: O Autor, 2017. 
O edema tem sido uma das malformações mais observadas em ensaios de toxicidade com Danio rerio (Tesolin et al., 2014). O edema é um acúmulo anormal de líquido no tecido e pode ocorrer em órgãos específicos ou em qualquer parte do corpo (Huang et al., 2014). O aparecimento do edema pericárdico deve-se à disfunção cardíaca, funcionando como indicador de disfunção osmótica ou metabólica, frequentemente associada a extravasamento dos vasos endoteliais (Dejana et al., 2009; Hallare et al., 2005; Ali et al., 2014) ou deve-se a uma disfunção renal, pois o sistema de regulação depende do envolvimento renal. Os rins atuam no balanço de água, e levam ao sistema nervoso central informações sobre o volume extracelular através das aferências nervosas (Coelho, 2004).

As deformações da coluna vertebral podem ser associadas à depleção ou desregulação de íons como cálcio e fósforo, ou com redução da miosina, ambos necessários para o desenvolvimento normal do organismo (Cheng et al., 2000).

As larvas com deformidades apresentaram menor atividade nadante comparado com as larvas do controle. No estudo de Suvarchala e Philip (2016) com o 3,5,6-Tricloro-2-piridinol (TCP), as larvas de Danio rerio apresentaram as mesmas deformidades observadas no nosso trabalho, assim como o comportamento de natação alterado. Esses mesmos efeitos foram observados por Lutte (2015) que estudou o metabolismo de adenosina em um modelo de síndrome alcoólica fetal em Danio rerio.

$\mathrm{Na}$ concentração de $100 \mathrm{mg} \mathrm{L}^{-1}$, a letalidade máxima foi obtida em apenas $48 \mathrm{~h}$. Em relação aos parâmetros medidos (oxigênio, $\mathrm{pH}$ e condutividade) de cada solução-teste não houve grande alteração de valores. Foi possível observar que os valores finais de oxigênio foram menores que os valores iniciais devido ao seu consumo pelos organismos, porém, os valores estavam dentro do recomendado pela norma. 
5.4 Ensaio de sensibilidade com larvas de Danio rerio e obtenção da carta controle

O percentual de letalidade para cada ensaio está apresentado na TAB. 4.

TABELA 4 - Percentual de letalidade obtido nos ensaios de sensibilidade das larvas do peixe Danio rerio após $168 \mathrm{~h}$ de exposição ao $\mathrm{NaCl}$.

\begin{tabular}{cccc}
\hline Concentração & \multicolumn{3}{c}{ Letalidade (\%) } \\
\cline { 2 - 4 } $\mathbf{N a C l}\left(\mathbf{g ~ L}^{-1}\right)$ & Ensaio 1 & Ensaio 2 & Ensaio 3 \\
\hline 0 & 0 & 5 & 0 \\
2 & 0 & 20 & 0 \\
3 & 0 & 20 & 2,5 \\
4,5 & 22,5 & 32,5 & 25 \\
6,8 & 70 & 100 & 80 \\
10,1 & 100 & 100 & 100 \\
\hline
\end{tabular}

A FIG. 27 apresenta a taxa de letalidade (\%) das larvas do peixe Danio rerio nos ensaios de sensibilidade ao $\mathrm{NaCl}\left(\mathrm{g} \mathrm{L}^{-1}\right)$.

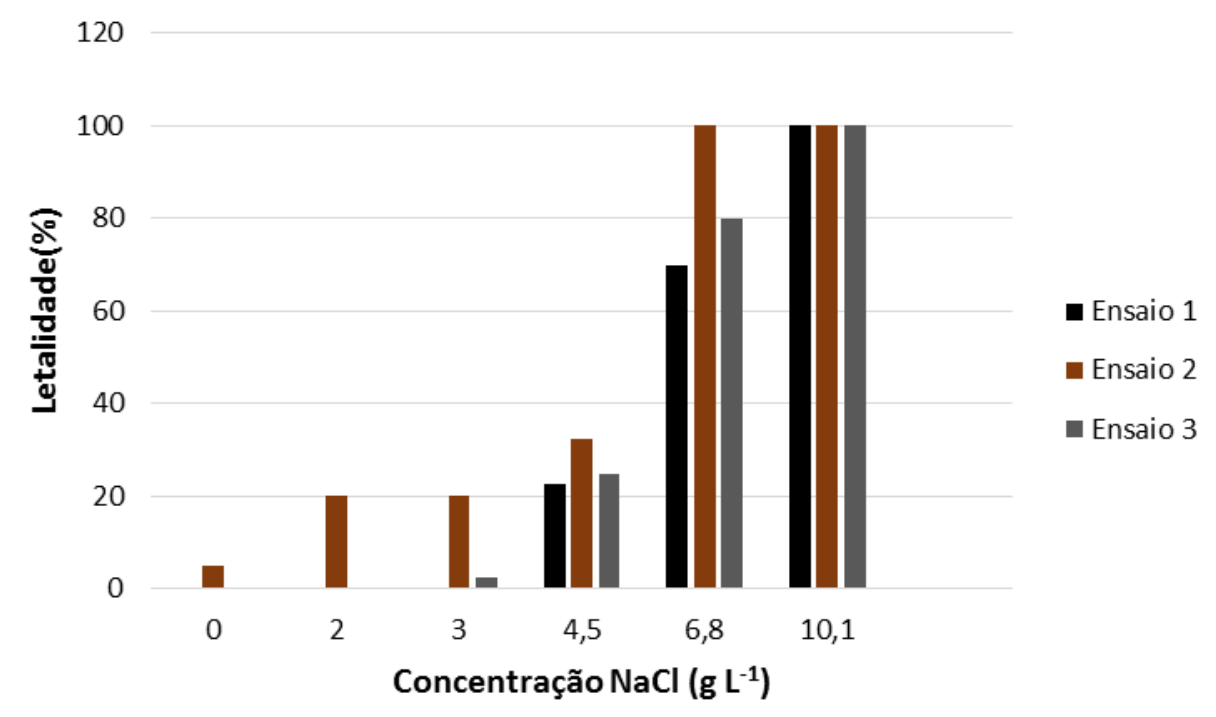

FIGURA 27 - Taxa de letalidade das larvas do peixe Danio rerio em função das concentrações do $\mathrm{NaCl}$ após $168 \mathrm{~h}$ de exposição. 
Estes ensaios avaliaram a CL50/168h, concentração que causa efeito letal em $50 \%$ dos organismos após $168 \mathrm{~h}$ de exposição ao $\mathrm{NaCl}$.

Os valores das CL50 e dos intervalos de confiança dos ensaios de sensibilidade realizados neste trabalho foram obtidos pelo programa estatístico Trimmed Spearman-Karber. Na TAB. 5 são apresentados os valores das CL50, os intervalos de confiança, a média, o desvio padrão (DP) e o coeficiente de variação (CV).

TABELA 5 - Valores das CL50, intervalos de confiança, média, desvio padrão e coeficiente de variação dos ensaios de sensibilidade das larvas do peixe Danio rerio.

\begin{tabular}{ccc}
\hline Ensaio & CL50 (g L-1 $)$ & $\begin{array}{c}\text { Intervalo de confiança } \\
\left(\mathbf{g ~ L} \mathbf{~}^{-1}\right)\end{array}$ \\
\hline 1 & 5,1 & $(4,8-5,5)$ \\
2 & 4,8 & $(4,3-5,4)$ \\
3 & 5,3 & $(4,9-5,8)$ \\
Média & $\mathbf{5 , 0 6}$ & \\
Desvio padrão & 0,25 & \\
Coeficiente de variação & & \\
$(\%)$ & 4,96 & \\
\hline
\end{tabular}

O valor médio da CL50/168h do $\mathrm{NaCl}$ obtido nos ensaios de sensibilidade realizados com larvas do peixe Danio rerio foi de $5,06 \mathrm{~g} \mathrm{~L}^{-1}$. Este resultado está abaixo do valor encontrado na literatura para ensaio de sensibilidade em adultos de Danio rerio, onde a CL50 foi de 7,91 g L-1 (Castro, 2008). De acordo com Bertoletti (2009) a fase larval do organismo é mais sensível do que a fase embrionária e juvenil, o que corrobora com nossos resultados.

Em todas as concentrações foram observadas deformidades nos organismos e com o passar do tempo a letalidade foi observada. As deformidades constatadas foram: edema do pericárdio, edema do saco vitelínico e coluna vertebral torta. Na concentração de $10,1 \mathrm{~g} \mathrm{~L}^{-1}$, a letalidade máxima foi obtida em apenas $48 \mathrm{~h}$, sendo que os organismos desidratam e se desfazem. 
As larvas também apresentaram comportamento diferenciado com o passar do tempo, comparado com as larvas do controle, pois quanto maior a concentração de $\mathrm{NaCl}$, menor a atividade nadante dos organismos.

Em relação aos parâmetros medidos (oxigênio, pH e condutividade) de cada solução-teste não houve grande alteração de valores. Foi possível observar que os valores finais de oxigênio foram menores que os valores iniciais devido ao seu consumo pelos organismos, porém, os valores estavam dentro do recomendado pela norma.

Os valores obtidos nos ensaios de sensibilidade mostraram que os organismos estavam apropriados para os ensaios de ecotoxicidade crônica de curta duração. 
5.5 Ensaio de ecotoxicidade aguda no estágio embriolarval do peixe Danio rerio (96 $\mathrm{h}$ de duração)

A FIG. 28 apresenta a proporção de: ovos coagulados e embriões que morreram durante o ensaio (barras pretas), embriões que permaneceram vivos (barras cinzas claras), larvas vivas (barras cinzas) e larvas mortas (barras marrons) em relação a concentração de resveratrol.

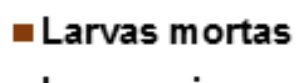

- Larvas vivas

Embriōes vivos

- Ovos coagulados
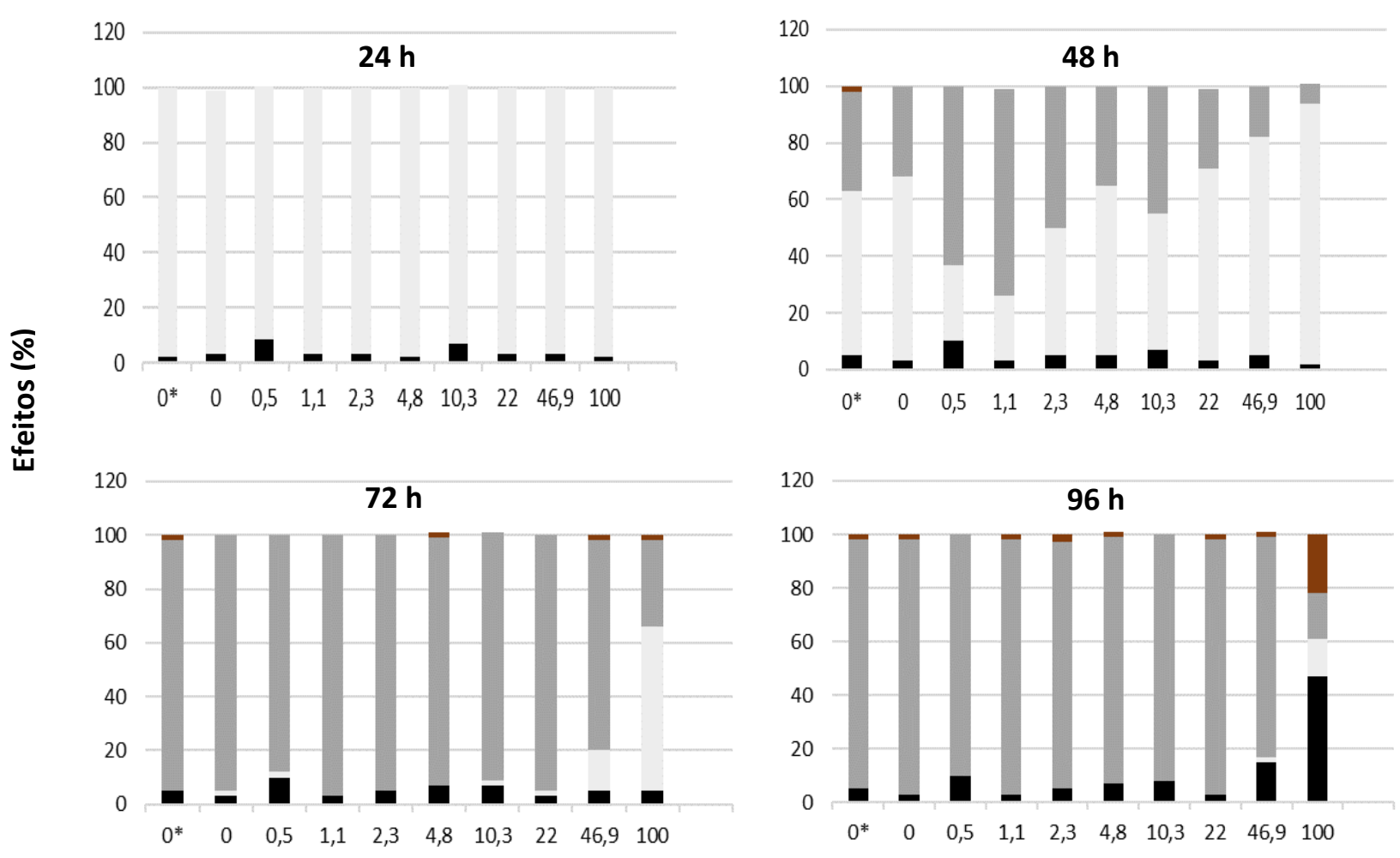

Concentração de Resveratrol (mg L-1)

FIGURA 28 - Visão geral dos efeitos do resveratrol sobre embriões e larvas de Danio rerio durante $96 \mathrm{~h}$ de exposição. "0*" refere-se ao controle solvente.

O percentual de letalidade do ensaio de ecotoxicidade aguda do resveratrol em Danio rerio no estágio embriolarval está apresentado na TAB. 6. 
TABELA 6 - Percentual de letalidade obtido no ensaio de ecotoxicidade aguda do resveratrol no estágio embriolarval do peixe Danio rerio após 96 h de exposição.

\begin{tabular}{cc}
\hline $\begin{array}{c}\text { Concentração } \\
\text { Resveratrol }\left(\text { mg L }^{-1}\right)\end{array}$ & Letalidade (\%) \\
\hline Controle Solvente & 6 \\
0 & 4 \\
0,5 & 10 \\
1,1 & 5 \\
2,3 & 8 \\
4,8 & 8 \\
10,3 & 8 \\
22 & 5 \\
46,9 & 16 \\
100 & 70 \\
\hline
\end{tabular}

A FIG. 29 apresenta a curva de letalidade (\%) do peixe Danio rerio no estágio embriolarval no ensaio de ecotoxicidade aguda do resveratrol $\left(\mathrm{mg} \mathrm{L}^{-1}\right)$. $\mathrm{O}$ resultado da mortalidade dos organismos nos controles foi inferior a $10 \%$ como requerido para validade do ensaio.

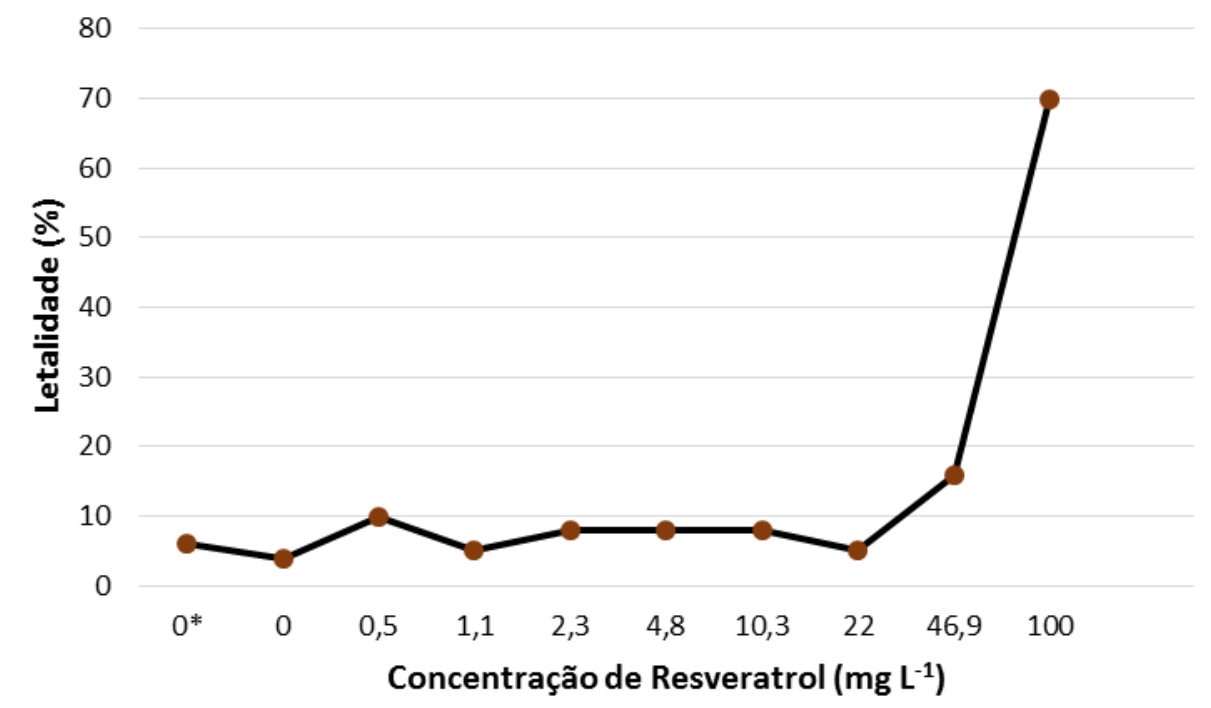

FIGURA 29 - Curva de letalidade do peixe Danio rerio no estágio embriolarval em função das concentrações do resveratrol após $96 \mathrm{~h}$ de exposição. "0*" refere-se ao controle solvente. 
Este ensaio avaliou a CL50/96h, concentração que causa efeito letal em $50 \%$ dos organismos após $96 \mathrm{~h}$ de exposição ao resveratrol.

O valor da CL50 e do intervalo de confiança do ensaio de ecotoxicidade aguda no estágio embriolarval do peixe Danio rerio foi obtido pelo programa estatístico Trimmed Spearman-Karber. Na TAB. 7 é apresentado o valor da CL50 e o intervalo de confiança.

TABELA 7 - Valor da CL50 e intervalo de confiança para o ensaio de ecotoxicidade aguda do resveratrol no peixe Danio rerio no estágio embriolarval.

\begin{tabular}{ccc}
\hline Ensaio & CL50 (mg L-1) & $\begin{array}{c}\text { Intervalo de confiança } \\
\left(\mathbf{m g ~ L}^{-1}\right)\end{array}$ \\
\hline 1 & 75,33 & $(70-84,6)$ \\
\hline
\end{tabular}

A CL50/96h (75,33 $\left.\mathrm{mg} \mathrm{L}^{-1}\right)$ obtida neste ensaio de ecotoxicidade aguda no estágio embriolarval do peixe Danio rerio é maior que a CL50 (51,37 $\left.\mathrm{mg} \mathrm{L}^{-1}\right)$ obtida no ensaio de ecotoxicidade crônica de curta duração com as larvas do peixe Danio rerio (5.3).

A diferença da sensibilidade dos organismos pode ser explicada pelo fato de que os embriões quando foram expostos ao resveratrol, no ensaio de ecotoxicidade aguda no estágio embriolarval, estavam dentro do ovo, o qual forneceu uma proteção, uma barreira contra a entrada do composto (FIG. 30).

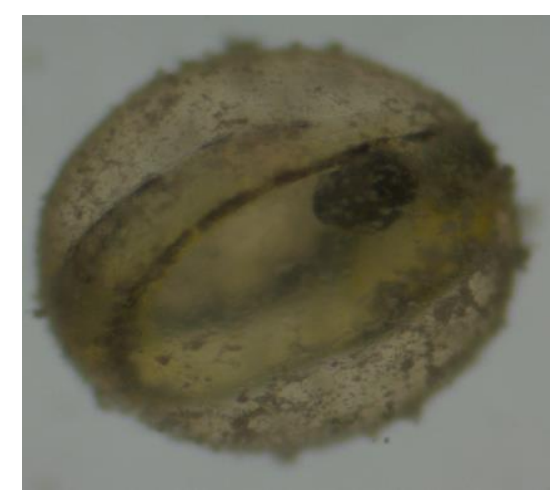

FIGURA 30 - Embrião exposto ao resveratrol na concentração de $100 \mathrm{mg} \mathrm{L}^{-1}$, com a presença do resveratrol no córion, no período de $96 \mathrm{~h}$. Fonte: O Autor, 2017.

Porém, como a alta letalidade dos organismos (70\%) na concentração de $100 \mathrm{mg} \mathrm{L}^{-1}$ foi verificada neste ensaio, e no estudo de Vallverdú-Queralt et al. (2015), o resveratrol foi encontrado em embriões de Danio rerio que foram 
expostos ao extrato de vinho tinto, pode-se inferir que o resveratrol atravessou o córion do ovo e causou efeitos nos embriões. Já as larvas recém eclodidas não apresentam nenhuma estrutura que impeça, ou diminua a exposição ao resveratrol quando foram mantidas em contato ao composto, no ensaio de ecotoxicidade crônica de curta duração.

A eclosão tem sido largamente usada como um parâmetro no estágio embriolarval de peixes. O percentual da taxa de eclosão de Danio rerio observado durante o ensaio de ecotoxicidade aguda está apresentado na TAB. 8.

TABELA 8 - Percentual de taxa de eclosão de larvas de Danio rerio em 48, 72 e $96 \mathrm{~h}$.

\begin{tabular}{cccc}
\hline $\begin{array}{c}\text { Resveratrol } \\
\left(\mathbf{m g ~ L}^{-1}\right)\end{array}$ & $\mathbf{4 8 ~ \mathbf { h }}$ & $\mathbf{7 2} \mathbf{~}$ & $\mathbf{9 6} \mathbf{~}$ \\
\cline { 2 - 4 } & 37 & 100 & 100 \\
\hline Controle Solvente & 32 & 97 & 100 \\
0 & 63 & 98 & 100 \\
0,5 & 73 & 100 & 100 \\
1,1 & 50 & 100 & 100 \\
2,3 & 35 & 100 & 100 \\
4,8 & 45 & 98 & 100 \\
10,3 & 28 & 98 & 100 \\
22 & 18 & 84 & 97 \\
46,9 & 7 & 36 & 76 \\
100 & & &
\end{tabular}

A FIG. 31 apresenta a taxa de eclosão das larvas de Danio rerio durante a exposição ao resveratrol ( $\left.\mathrm{mg} \mathrm{L}^{-1}\right)$ em 48, 72 e $96 \mathrm{~h}$. 


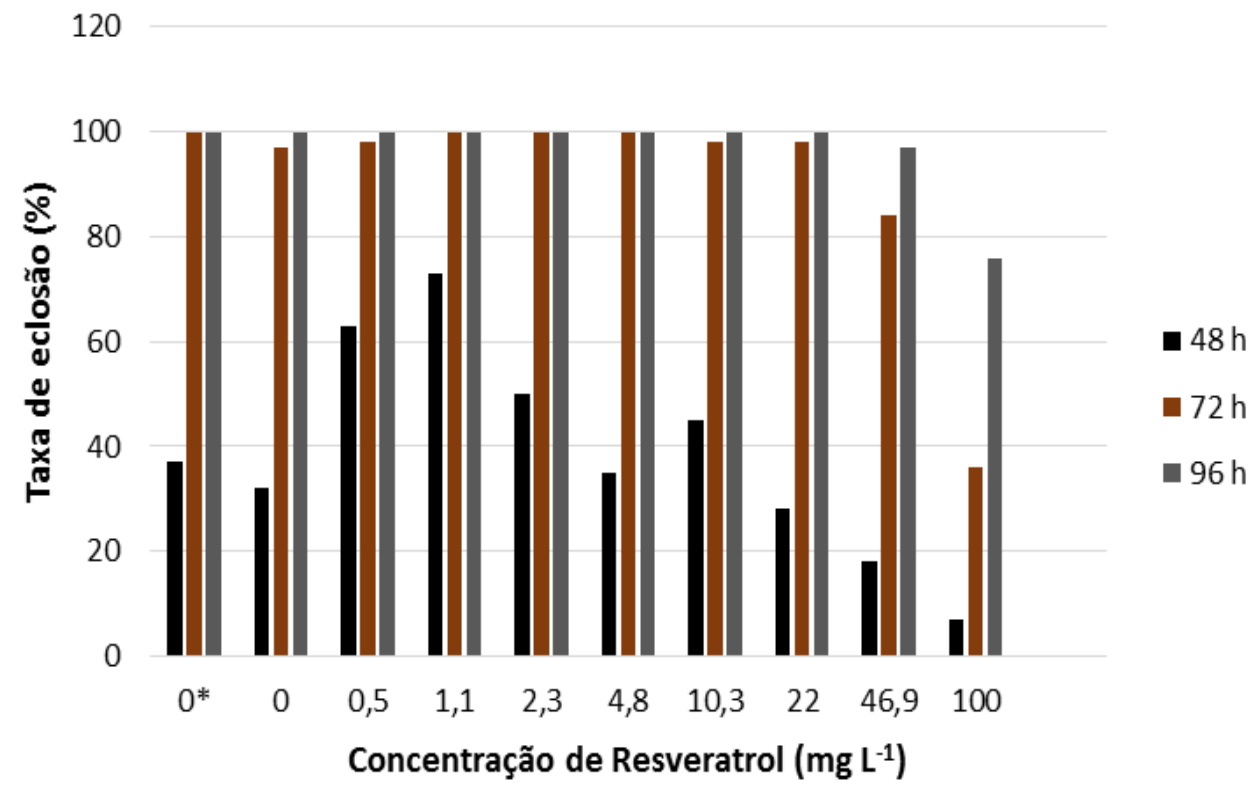

FIGURA 31 - Taxa de eclosão de larvas de Danio rerio durante a exposição ao resveratrol ( $\left.\mathrm{mg} \mathrm{L}^{-1}\right)$ em 48, 72 e $96 \mathrm{~h}$. "0*” refere-se ao controle solvente.

Como demostrado na TAB. 8 e no gráfico da FIG. 31, a exposição ao resveratrol em baixas concentrações $\left(0,5 ; 1,1\right.$ e $\left.2,3 \mathrm{mg} \mathrm{L}^{-1}\right)$ aumentou a taxa de eclosão comparada com o grupo controle, no período de $48 \mathrm{~h}$. Já nas concentrações de 46,9 e $100 \mathrm{mg} \mathrm{L}^{-1}$, a taxa de eclosão foi baixa no período de 48 h. O atraso na eclosão também foi observado, entre 72 e 96 h, nos embriões expostos a $100 \mathrm{mg} \mathrm{L}^{-1}$ de resveratrol.

Sabe-se que sinais físicos e químicos detectados pelo embrião ativam a produção da enzima relacionada a eclosão (corionase), que degrada a camada interna do córion e permite movimentos que proporcionam o evento da eclosão (Fuiman, 2002). Diferentes mecanismos tóxicos podem justificar o atraso na eclosão ou a falha, como a indução da função anormal da enzima corionase e/ou a incapacidade das larvas emergentes para quebrar a casca dos ovos (Hallare et al., 2005; Jezierska et al., 2009).

Segundo Jezierska et al. (2009) os metais pesados podem inibir ou acelerar o processo de eclosão dos peixes. Dave e Xiu (1991) relataram o atraso da eclosão de embriões de Danio rerio expostos ao cobre e ao níquel. Os autores mencionados acima sugerem que o cobre pode inativar a enzima corionase e causar distúrbios osmóticos que também podem afetar os movimentos musculares necessários para quebrar o ovo. $\mathrm{O}$ atraso da eclosão de Danio rerio 
também foi verificado no estudo de Zhou et al. (2009); Bai et al. (2010); Muller et al. (2015) e Oliveira et al. (2009). Entretando, a eclosão prematura foi observada nos estudos de Jesus et al. (2013) e de Oliveira et al. (2013), onde houve aumento da taxa de eclosão de Danio rerio expostos ao antisséptico clorexidina e ao antibiótico amoxicilina.

Apesar de não terem sido observadas consequências da eclosão prematura de Danio rerio durante o período de exposição ao resveratrol $(0,5 ; 1,1$ e 2,3 $\mathrm{mg} \mathrm{L}^{-1}$ ), os efeitos subsequentes no desenvolvimento não devem ser excluídos.

Na FIG. 32 pode-se observar um embrião morto no período de $96 \mathrm{~h}$, e uma larva que eclodiu no período de $96 \mathrm{~h}$, porém logo após a eclosão não sobreviveu. Ambos os organismos foram expostos ao resveratrol na concentração de $100 \mathrm{mg} \mathrm{L}^{-1}$.

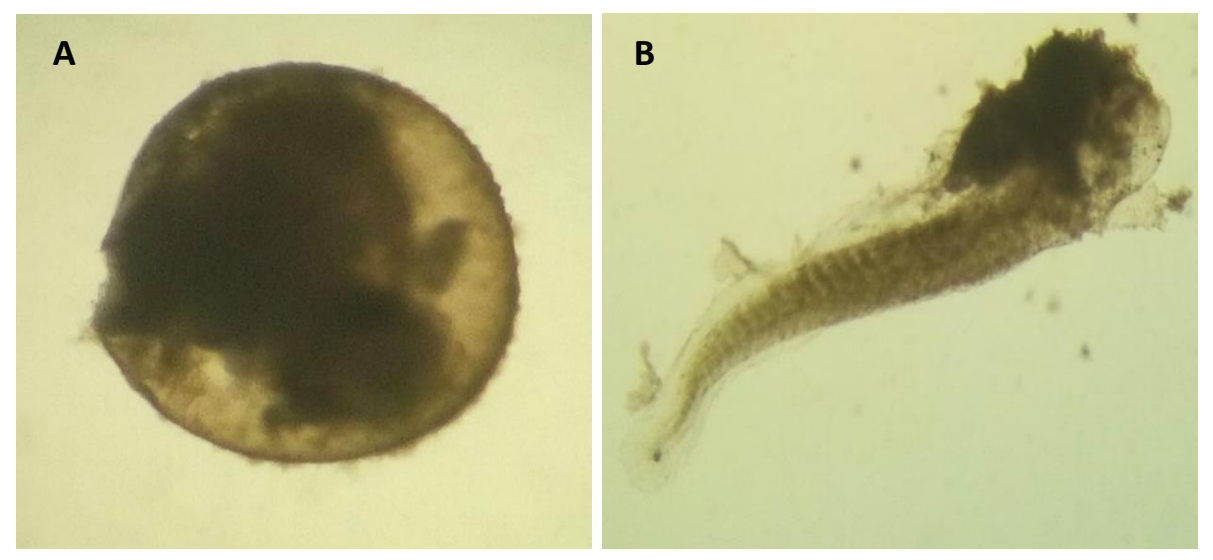

FIGURA 32 - (A) Embrião de Danio rerio morto no período de 96 h; (B) Larva de Danio rerio morta no período de 96 h após a eclosão. Fonte:O Autor, 2017.

Deformidades foram observadas nos organismos expostos a 46,9 e $100 \mathrm{mg} \mathrm{L}^{-1}$ e com o passar das horas a letalidade foi verificada. As deformidades constatadas foram: edema do pericárdio, edema do saco vitelínico e coluna vertebral torta (FIG. 33). 

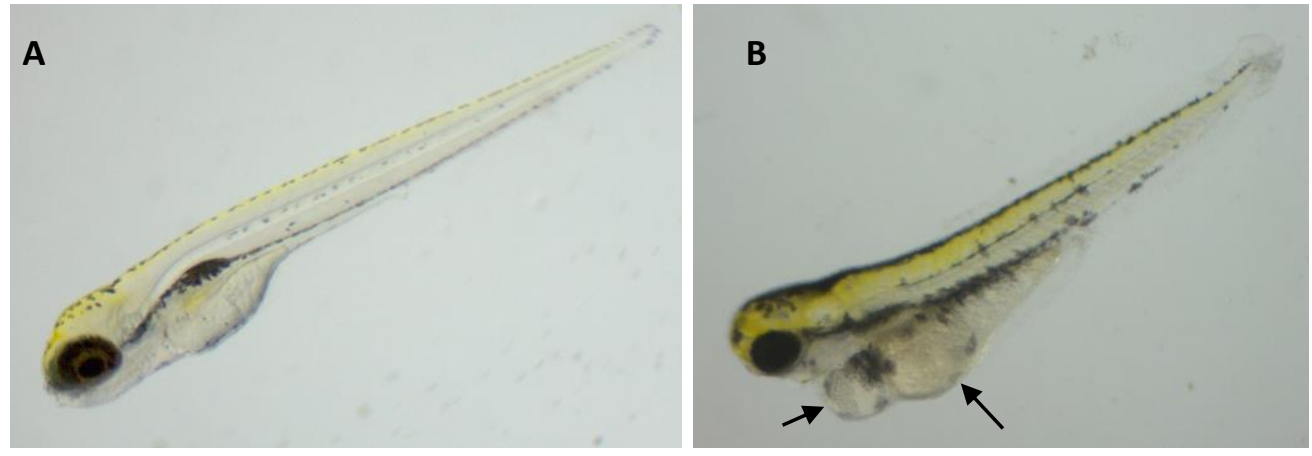

FIGURA 33 - (A) Controle larva de Danio rerio no período de 96 h; (B) Larva de Danio rerio na concentração de $46,9 \mathrm{mg} \mathrm{L}^{-1} \mathrm{com}$ edema do pericárdio e do saco vitelínico (setas pretas), no período de 96 h. Fonte: O Autor, 2017.

\subsection{Ensaio de ecotoxicidade aguda no estágio embriolarval do peixe Danio rerio (168 $\mathrm{h}$ de duração)}

O percentual de letalidade do ensaio de ecotoxicidade aguda do resveratrol em Danio rerio no estágio embriolarval está apresentado na TAB. 9.

TABELA 9 - Percentual de letalidade obtido no ensaio de ecotoxicidade aguda do resveratrol no estágio embriolarval do peixe Danio rerio após 168 h de exposição.

\begin{tabular}{cc}
\hline $\begin{array}{c}\text { Concentração } \\
\text { Resveratrol }\left(\mathbf{m g ~ L ~}^{-1}\right)\end{array}$ & Letalidade (\%) \\
\hline Controle Solvente & 6 \\
0 & 7 \\
3,12 & 20 \\
6,25 & 25 \\
12,5 & 22 \\
25 & 18 \\
50 & 37 \\
100 & 100 \\
\hline
\end{tabular}

A FIG. 34 apresenta a curva de letalidade (\%) do peixe Danio rerio no estágio embriolarval no ensaio de ecotoxicidade aguda do resveratrol $\left(\mathrm{mg} \mathrm{L}^{-1}\right)$. O resultado da mortalidade dos organismos nos controles foi inferior a $10 \%$ como requerido para validade do ensaio. 


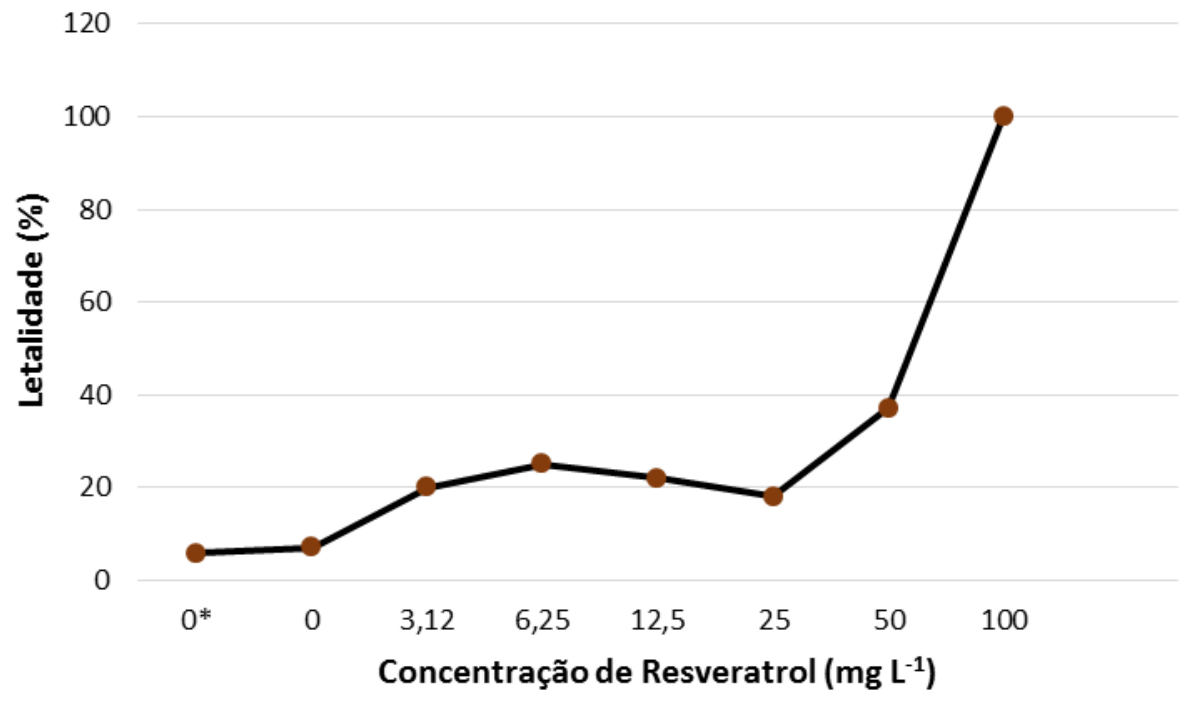

FIGURA 34 - Curva de letalidade do peixe Danio rerio no estágio embriolarval em função das concentrações do resveratrol após $168 \mathrm{~h}$ de exposição. "0*" refere-se ao controle solvente.

Este ensaio avaliou a CL50/168h, concentração que causa efeito letal em $50 \%$ dos organismos após $168 \mathrm{~h}$ de exposição ao resveratrol.

O valor da CL50 e do intervalo de confiança do ensaio de ecotoxicidade aguda no estágio embriolarval do peixe Danio rerio foi obtido pelo programa estatístico Trimmed Spearman-Karber. Na TAB. 10 é apresentado o valor da CL50 e o intervalo de confiança.

TABELA 10 - Valor da CL50 e intervalo de confiança para o ensaio de ecotoxicidade aguda do resveratrol no peixe Danio rerio no estágio embriolarval.

\begin{tabular}{ccc}
\hline Ensaio & CL50 (mg L-1) & $\begin{array}{c}\text { Intervalo de confiança } \\
\left(\mathbf{m g ~ L}^{-1}\right)\end{array}$ \\
\hline 1 & 50,87 & $(39,22-65,97)$ \\
\hline
\end{tabular}

A CL50/168h (50,87 $\left.\mathrm{mg} \mathrm{L}^{-1}\right)$ obtida neste ensaio é menor que a CL50/96h (75,33 $\mathrm{mg} \mathrm{L}^{-1}$ ) obtida no ensaio anterior (5.5). A diferença dos resultados pode ser devido ao tempo de exposição ao resveratrol. No ensaio anterior, os embriões foram expostos ao resveratrol por $96 \mathrm{~h}$ e neste ensaio foram expostos ao composto por $168 \mathrm{~h}$. Pode-se inferir que quanto maior o tempo de 
exposição ao resveratrol maior a taxa de letalidade dos organismos, o que justifica os nossos resultados.

Em $24 \mathrm{~h}$ do ensaio, os embriões no controle e nas concentrações de resveratrol (3,12 a $\left.100 \mathrm{mg} \mathrm{L}^{-1}\right)$ apresentaram desenvolvimento normal como descrito por Kimmel et al. (1995). Embriões apresentaram cabeça, o corpo e a cauda bem desenvolvidos, além dos batimentos cardíacos, pigmentação dos olhos e do corpo, formação de somitos e desprendimento da cauda (FIG. 35).

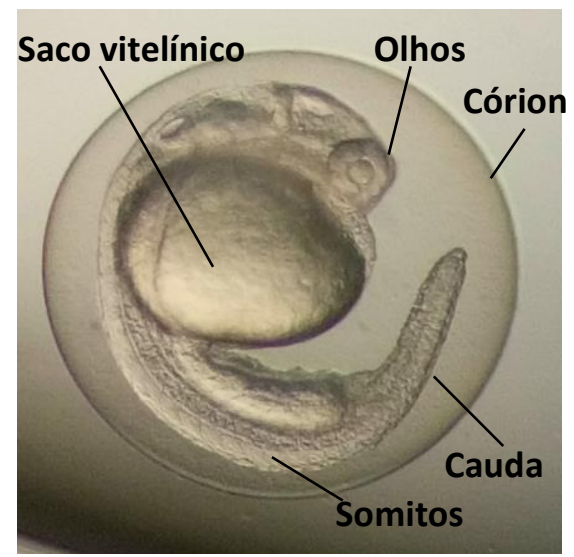

FIGURA 35 - Controle embrião de Danio rerio no período de $24 \mathrm{~h}$ com desenvolvimento normal. Fonte: O Autor, 2017.

Após $48 \mathrm{~h}$, na concentração de $100 \mathrm{mg} \mathrm{L}^{-1}$ de resveratrol, observamos em alguns embriões a falta de pigmentação dos olhos e do corpo (FIG. 36) e batimento cardíaco lento. 

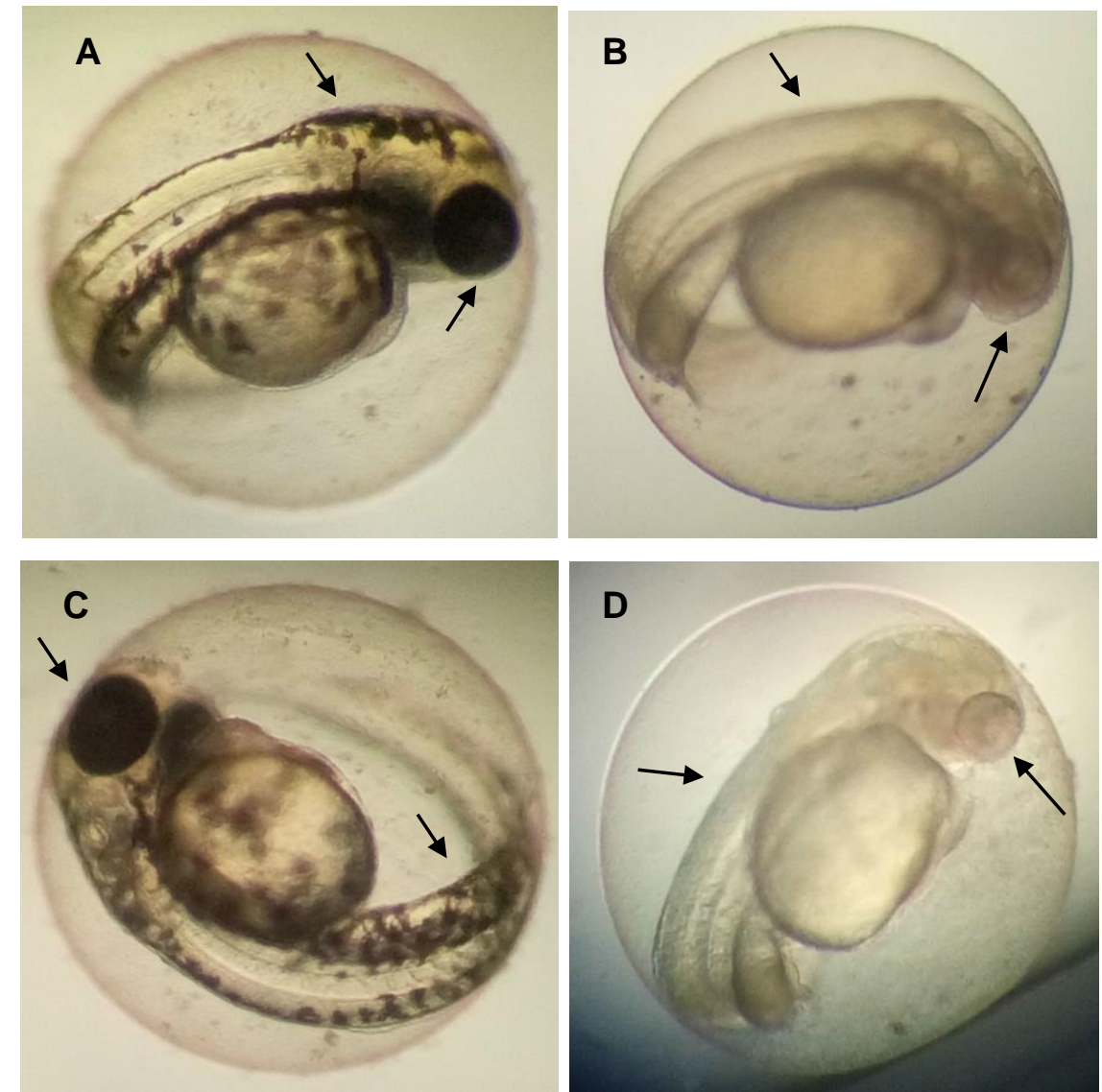

FIGURA 36 - (A) Controle no período de 48 h com pigmentação dos olhos e do corpo (setas pretas); (C) Embrião no período de $48 \mathrm{~h}$, na concentração de 6,25 $\mathrm{mg} \mathrm{L}^{-1}$, com pigmentação dos olhos e do corpo (setas pretas); (B e D) Embriões no período de $48 \mathrm{~h}$, na concentração de $100 \mathrm{mg} \mathrm{L}^{-1}$, sem pigmentação dos olhos e do corpo (setas pretas). Fonte: O Autor, 2017.

Após $72 \mathrm{~h}$, as larvas que eclodiram no controle e nas concentrações de resveratrol $\left(3,12\right.$ a $100 \mathrm{mg} \mathrm{\textrm {L } ^ { - 1 } )}$ apresentaram desenvolvimento normal como descrito por Braunbeck e Lammer (2006) (FIG. 37).

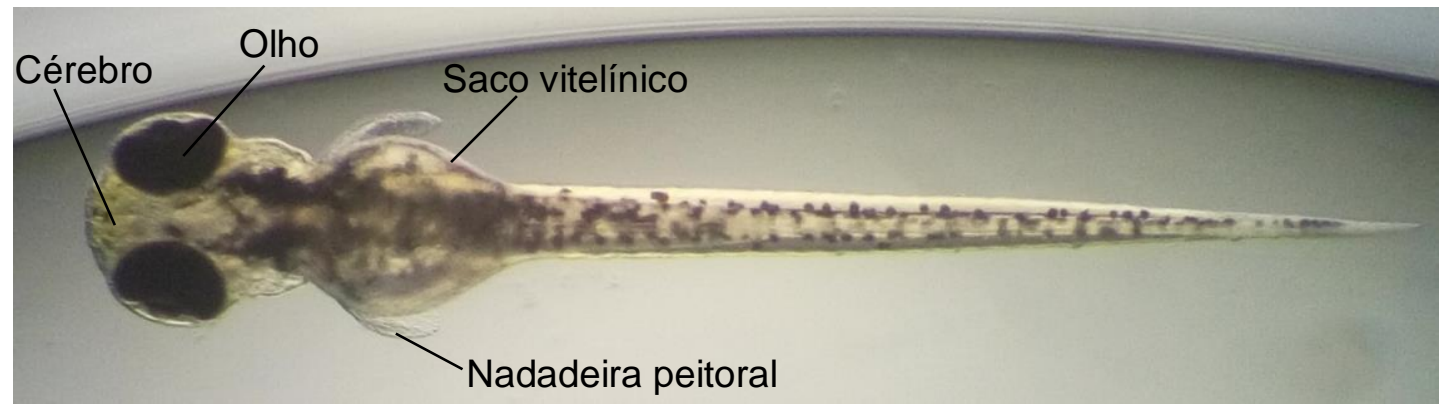

FIGURA 37 - Controle larva de Danio rerio no período de $72 \mathrm{~h}$ com desenvolvimento normal. Fonte: O Autor, 2017. 
Na concentração de $50 \mathrm{mg} \mathrm{L}^{-1}$ de resveratrol, após 96, 120 e 144 h, as larvas apresentaram deformidades e no período de $168 \mathrm{~h}$ a letalidade desses organismos foi verificada. As deformidades constatadas foram: edema do pericárdio, edema do saco vitelínico (FIG. 38) e coluna vertebral torta.
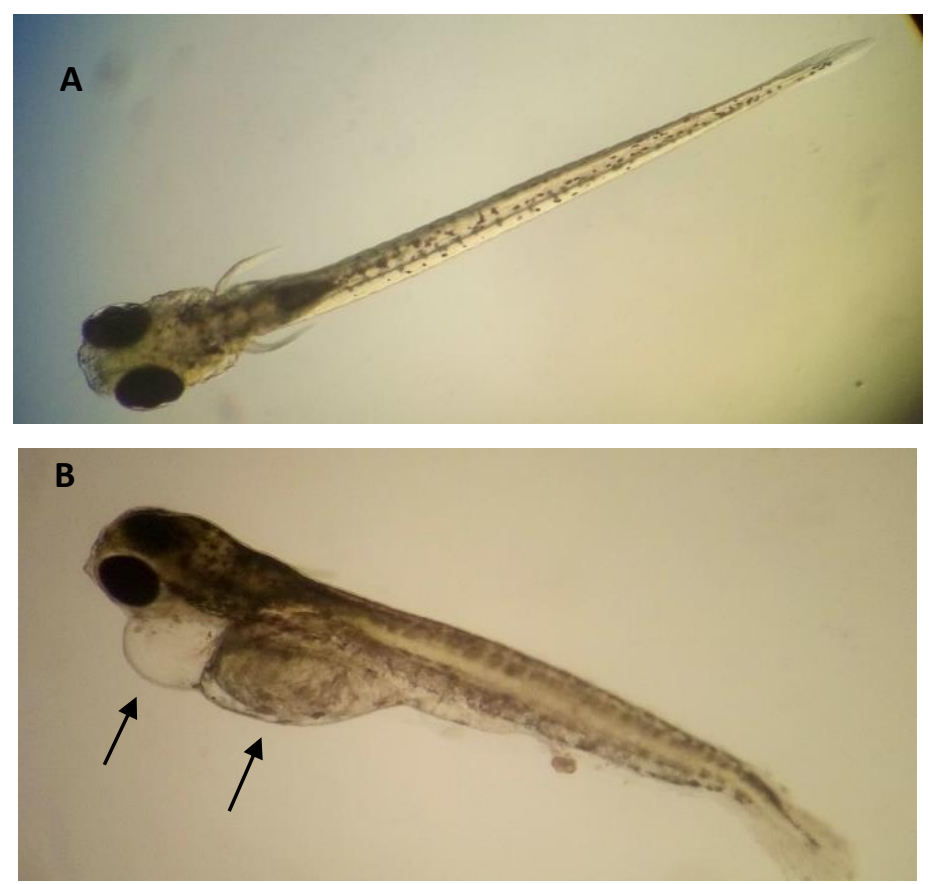

FIGURA 38 - Deformidades nas larvas de Danio rerio após exposição ao resveratrol (50 mg L-1) no período de $144 \mathrm{~h}$ : (A) Controle; (B) Larva com edema do pericárdio e do saco vitelínico (setas pretas). Fonte: O Autor, 2017.

Após 96 e 120 h, observamos letalidade dos embriões que não eclodiram na concentração de $100 \mathrm{mg} \mathrm{L}^{-1}$ de resveratrol (FIG. 39) e as larvas sobreviventes apresentaram deformidades ocorrendo a letalidade no período de $120 \mathrm{~h}$. As deformidades constatadas foram iguais as encontradas nas larvas expostas a concentração de $50 \mathrm{mg} \mathrm{L}^{-1}$ 

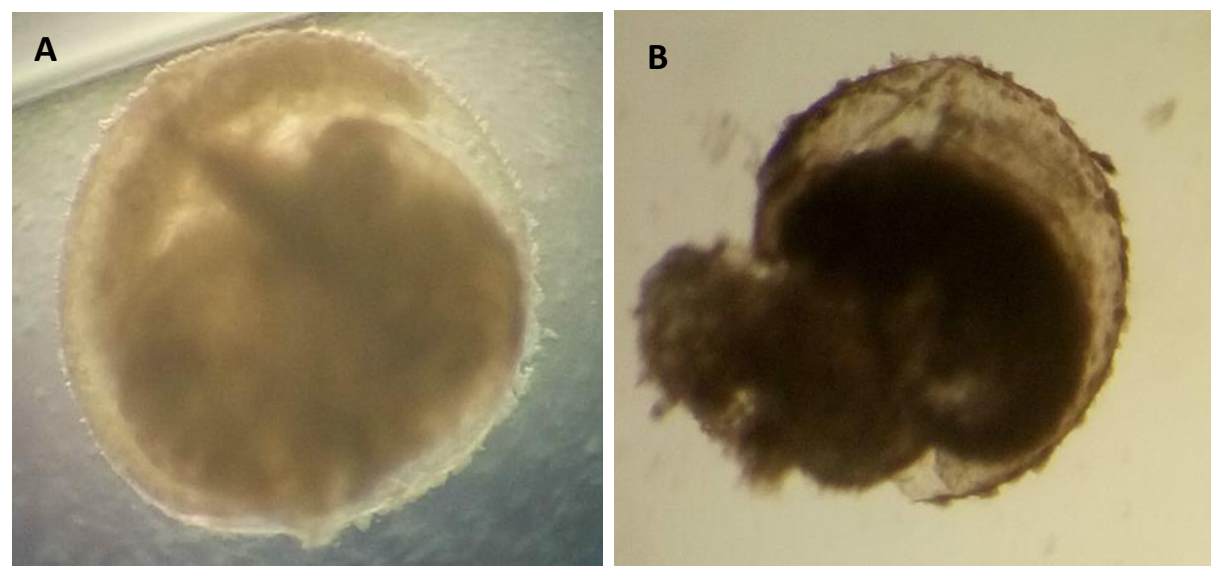

FIGURA 39 - (A) Embrião morto na concentração de $100 \mathrm{mg} \mathrm{L}^{-1}$ no período de $96 \mathrm{~h}$; (B) Embrião morto na concentração de $100 \mathrm{mg} \mathrm{L}^{-1}$ no período de $120 \mathrm{~h}$. Fonte: O Autor, 2017.

\subsection{Ensaio de biomarcadores enzimáticos de Danio rerio no estágio embriolarval}

Os ensaios de biomarcadores enzimáticos na ecotoxicologia estão se tornando cada vez mais comuns, e são considerados ferramentas para avaliar os efeitos da contaminação ambiental (Nunes et al., 2006), pois permitem explorar a resposta biológica do organismo através de alterações bioquímicas, celulares, histológicas, fisiológicas e comportamentais relacionadas e assim, determinar a intensidade de um efeito tóxico (Pitanga, 2011; Oliveira, 2014). A colinesterase (ChE) e a lactato desidrogenase (LDH) são biomarcadores muito usados no monitoramento da qualidade dos ecossistemas aquáticos (Domingues et al., 2007; Monteiro et al., 2006; Vieira et al., 2008).

A análise estatística deste ensaio foi realizada pelo software SigmaPlot. Posteriormente, os dados foram submetidos ao método de análise de variância (ANOVA) para verificar se o resveratrol mostrou diferenças estatisticamente significativas sobre os organismos em comparação com o controle com nível de significância de $p<0,05$. 


\subsubsection{Quantificação de proteínas}

O resultado da quantificação de proteínas no ensaio de biomarcadores enzimáticos no estágio embriolarval do Danio rerio está apresentado no gráfico da FIG. 40.

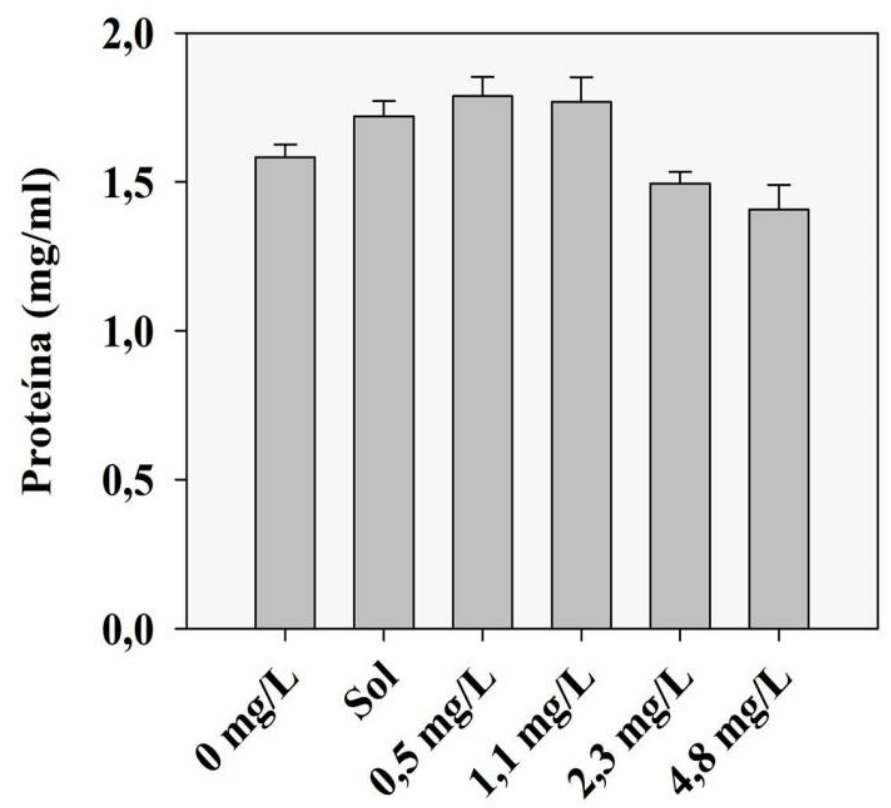

\section{Resveratrol (mg/L)}

FIGURA 40 - Resultado da quantificação de proteínas no ensaio de biomarcadores enzimáticos no estágio embriolarval do peixe Danio rerio, após 96 $\mathrm{h}$ de exposição ao resveratrol.

A quantificação de proteínas é necessária para padronizar os resultados dos ensaios de biomarcadores enzimáticos, porém a proteína por si só é um indicativo da saúde dos organismos. Apesar destes resultados não serem estatisticamente significativos (FIG. 40.), foi observado que nas concentrações mais baixas de resveratrol $\left(0,5\right.$ e $\left.1,1 \mathrm{mg} \mathrm{L}^{-1}\right)$, houve aumento da quantidade de proteína, ou seja, o composto induziu até certo ponto o crescimento dos organismos, e nas concentrações mais altas $\left(2,3\right.$ e 4,8 $\left.\mathrm{mg} \mathrm{L}^{-1}\right)$ houve diminuição da quantidade de proteína, representando crescimento menor comparados ao controle. 


\subsubsection{Atividade da enzima lactato desidrogenase (LDH)}

O resultado da análise da atividade da enzima lactato desidrogenase (LDH) do peixe Danio rerio no estágio embriolarval está apresentado no gráfico da FIG. 41.

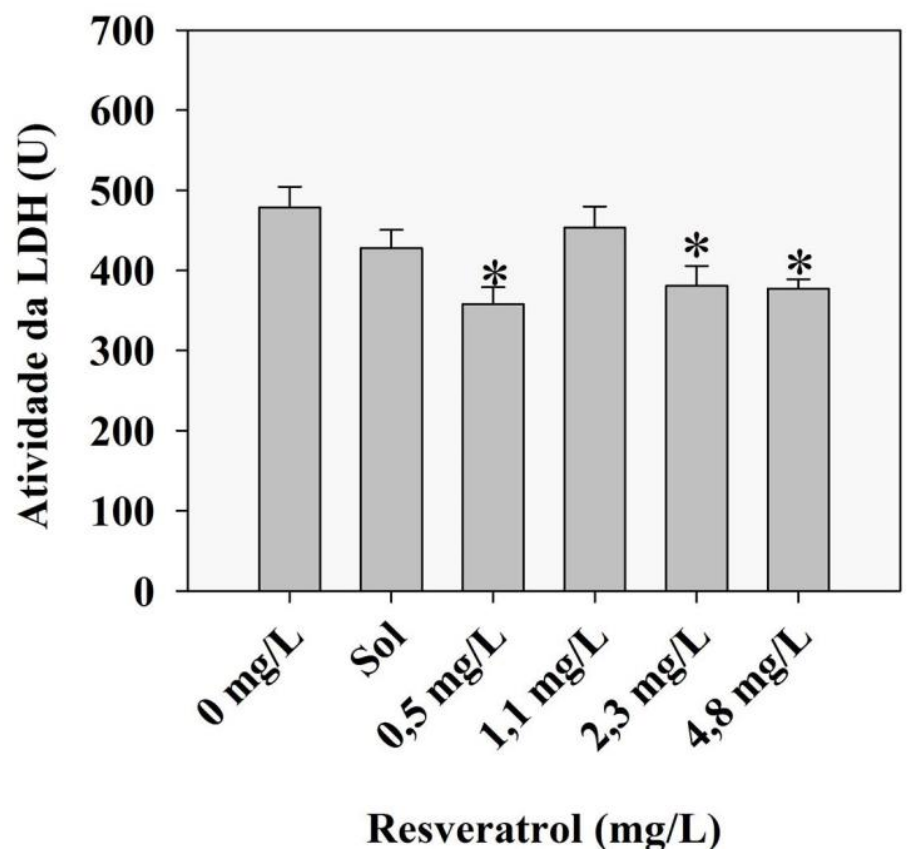

FIGURA 41 - Resultado da atividade da enzima lactato desidrogenase (LDH) do peixe Danio rerio no estágio embriolarval, após $96 \mathrm{~h}$ de exposição ao resveratrol. * Diferença estatisticamente significativa em relação ao controle (ANOVA p > $0,05)$.

A análise de peixes Danio rerio no estágio embriolarval expostos ao resveratrol durante $96 \mathrm{~h}$ evidenciou alterações na atividade da LDH. O gráfico da FIG. 41 mostra uma diminuição significativa da atividade enzimática da LDH nos organismos expostos as diferentes concentrações do resveratrol, em relação ao controle, exceto na concentração de $1,1 \mathrm{mg} \mathrm{L}^{-1}$.

A LDH é uma enzima do metabolismo energético, que reduz o substrato piruvato e oxida o NADH, originando o NAD+ (Marquezi, 2006). É uma enzima chave na produção de energia por via anaeróbica, responsável pela catalisação da interconversão do piruvato ao lactato, representando um papel importante no desenvolvimento embrionário (Robles et al., 2004). Pelo fato desta enzima ser induzida a baixos níveis de oxigênio, ela também é uma ferramenta importante na avaliação do estado respiratório dos organismos aquáticos (Neves, 2012; Silva, 2015). A LDH tem mostrado ser uma boa indicadora de estresse para 
peixes, sendo esta enzima sugerida como uma ferramenta para deteç̧ão de risco ambiental (Almeida et al., 2002; Osman et al., 2007; Vieira et al., 2008; Saravanan et al., 2011).

No ensaio realizado, o resveratrol nas concentrações de 0,$5 ; 2,3$ e 4,8 $\mathrm{mg} \mathrm{L}^{-1}$ inibiu a atividade da enzima $\mathrm{LDH}$, ou seja, os organismos expostos a essas concentrações apresentaram baixo metabolismo energético. Resveratrol na concentração de $1,1 \mathrm{mg} \mathrm{L}^{-1}$ não apresentou interferência na atividade da $\mathrm{LDH}$, em relação ao controle.

De acordo com Brito (2016), o antibiótico amoxicilina, nas concentrações de 1,5 a $12,5 \mathrm{mg} \mathrm{L}^{-1}$, inibiu a atividade da enzima LDH em larvas de Danio rerio expostas a este fármaco por $168 \mathrm{~h}$. A atividade da LDH das larvas do peixe Puntius conchonius (Barbo rosado) foi inibida em altas concentrações de mercúrio (Gill et al., 1990). Muitas espécies de peixes expostas a metais pesados sofrem uma diminuição da atividade da LDH. Alguns exemplos são as larvas do peixe Clarias gariepinus (peixe-gato africano) exposto ao nitrato de chumbo (Osman et al., 2007) e o peixe Oreochromis niloticus (Tilápia-do-nilo) exposto ao cádmio (Almeida et al., 2002).

No estudo de Tsai et al. (2007) o resveratrol diminuiu a LDH no plasma de ratos submetidos a isquemia cerebral.

\subsubsection{Atividade da enzima colinesterase (ChE)}

O resultado da análise de peixes Danio rerio no estágio embriolarval expostos ao resveratrol, por $96 \mathrm{~h}$ evidenciou alterações na atividade da enzima colinesterase (ChE), apresentado no gráfico da FIG. 42. Foi possível observar uma diminuição estatisticamente significativa da atividade da enzima ChE comparada ao controle, nas concentrações 2,3 e 4,8 $\mathrm{mg} \mathrm{L}^{-1}$ de resveratrol. 


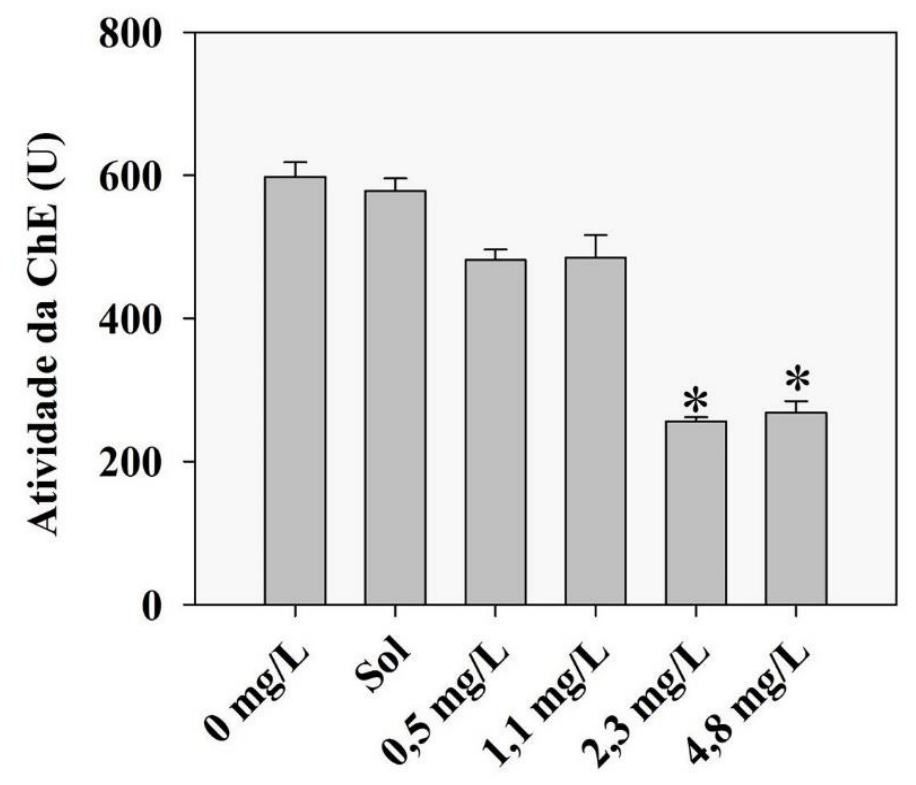

Resveratrol (mg/L)

FIGURA 42 - Resultado da análise da atividade da enzima colinesterase (ChE) do peixe Danio rerio no estágio embriolarval, após $96 \mathrm{~h}$ de exposição ao resveratrol. * Diferença estatisticamente significativa em relação ao controle (ANOVA $p>0,05$ ).

A ChE é uma enzima importante para a neurotransmissão, sendo responsável pela degradação do neurotransmissor acetilcolina nas sinapses colinérgicas. A inibição da ChE gera um acúmulo de Acetilcolina, provocando um colapso do sistema nervoso central, causando perda do controle muscular, convulsões e morte por parada cardiorrespiratória (Petronilho et al., 2011).

A inibição da colinesterase é associada geralmente a compostos organofosforados e carbamatos, encontrado nos agrotóxicos utilizados (Watson et al., 2014). Alguns fármacos e metais também influenciam na atividade da colinesterase (Rang, 2001). Exemplos podem ser encontrados na literatura, como o trabalho de Costa et al. (2007), onde a atividade da ChE do peixe Hoplias malabaricus (Traíra) foi inibida pela exposição dietética ao metilmercúrio, e o trabalho de Silva e Pathiratne (2008), onde a atividade da ChE do peixe Oreochromis niloticus (Tilápia-do-nilo) foi inibida por cádmio tanto in vivo como in vitro.

Neste ensaio, o resveratrol apresentou atividade anticolinérgica significativa nas concentrações de 2,3 e 4,8 $\mathrm{mg} \mathrm{L}^{-1}$. Para Pushpalatha et al. (2013) o resveratrol é um inibidor da colinesterase, e de acordo com Schmatz et al. (2009), 
a atividade da colinesterase em ratos saudáveis, que receberam resveratrol por 30 dias (10 mg/kg e $20 \mathrm{mg} / \mathrm{kg}$ ), diminuiu de forma significativa comparada ao controle. A ChE é alvo de algumas toxinas, incluindo inseticidas, veneno de serpentes e armas químicas. Contudo, os inibidores da atividade da ChE podem ser usados no tratamento de doenças neurodegenerativas, como o mal de Alzheimer.

Segundo Behra et al. (2002), a atividade da colinesterase em Danio rerio no estágio embriolarval indica que esta enzima é muito importante no desenvolvimento neuronal e muscular, portanto, a sua alteração pode estar ligada a efeitos como, por exemplo, larvas com coluna vertebral torta, deformidade que foi verificada no nosso trabalho. 


\section{CONCLUSÕES}

$\checkmark$ Este trabalho proporcionou dados inéditos sobre a toxicidade do resveratrol no estágio embriolarval de peixes da espécie Danio rerio.

$\checkmark$ A análise do resveratrol por cromatografia líquida de alta pressão (HPLC), evidenciou que o resveratrol utilizado no presente estudo estava de acordo com as características dadas pelo fornecedor, e após $24 \mathrm{~h}$ de exposição a luz fluorescente o resveratrol se manteve estável. Por esse método não foi observado degradação do resveratrol e nem a conversão da forma trans para cis-resveratrol após $24 \mathrm{~h}$ de exposição a luz fluorescente. Portanto, a forma trans-resveratrol é a forma do composto que causou toxicidade nos embriões e larvas de Danio rerio.

$\checkmark$ O índice de citotoxicidade $\left(\mathrm{IC}_{50}\right)$, concentração do resveratrol que causou a morte de $50 \%$ das células de mamíferos foi cerca de $39 \mathrm{mg} \mathrm{L}^{-1}$.

$\checkmark$ A concentração que causa efeito na letalidade de 50\% (CL50/168h) das larvas do peixe Danio rerio após $168 \mathrm{~h}$ de exposição ao resveratrol foi de $51,37 \mathrm{mg} \mathrm{L}^{-1}$.

$\checkmark$ A concentração que causa efeito na letalidade de 50\% (CL50/96h) dos peixes Danio rerio no estágio embriolarval após $96 \mathrm{~h}$ de exposição ao resveratrol foi de $75,33 \mathrm{mg} \mathrm{L}^{-1}$.

$\checkmark$ A concentração que causa efeito na letalidade de 50\% (CL50/168h) dos peixes Danio rerio no estágio embriolarval após $168 \mathrm{~h}$ de exposição ao resveratrol foi de $50,87 \mathrm{mg} \mathrm{L}^{-1}$.

$\checkmark$ A fase larval de Danio rerio é mais sensível que a fase embrionária. 
$\checkmark$ Quanto maior o tempo de exposição ao resveratrol, maior é a taxa de letalidade dos peixes Danio rerio no estágio embriolarval.

$\checkmark$ Nas maiores concentrações de resveratrol foram observadas deformidades nos embriões e nas larvas de Danio rerio, e com o passar das horas a letalidade dos organismos foi verificada. As deformidades encontradas foram semelhantes em todos os ensaios realizados e em estudos de toxicidade de fármacos e metais pesados.

$\checkmark$ Em relação a taxa de eclosão das larvas, pode ser verificado que o processo de eclosão dos organismos é dependente da concentração do resveratrol. Provavelmente o resveratrol seja capaz de induzir ou inibir a atividade da enzima corionase, responsável pelo processo de eclosão dos organismos.

Os resultados do ensaio de biomarcadores enzimáticos são inicias, portanto é necessário que sejam mais estudados. O resveratrol, nas concentrações de 0,5 e 1,1 $\mathrm{mg} \mathrm{L}^{-1}$ teve influência no crescimento de Danio rerio no estágio embriolarval. $O$ resveratrol inibiu a atividade da enzima lactato desidrogenase (LDH) em todas as concentrações utilizadas, exceto na de $1,1 \mathrm{mg} \mathrm{L}^{-1}$, e inibiu a atividade da enzima colinesterase (ChE) nas concentrações de 2,3 e 4,8 $\mathrm{mg} \mathrm{L}^{-1}$. 


\section{REFERÊNCIAS BIBLIOGRÁFICAS}

1 ABESSA, D.M.S. Avaliação da qualidade de sedimentos do sistema estuarino de Santos, SP, Brasil. 2002. Tese (Doutorado) - Universidade de São Paulo, São Paulo.

2 ACQUAVIVA, R.; RUSSO, A.; CAMPISI, A.; SORRENTI, V.; DI GIACOMO, C.; BARCELLONA, M.L.; AVITABILE, M.; VANELLA, A. Antioxidant activity and protective effect on DNA cleavage of resveratrol. Journal of Food Science., v.67, p.137-141, 2002.

3 AFONSO, M.S.; FERREIA, S.; DOMINGUES, F.C.; SILVA, F. Resveratrol production in bioreactor: Assessment of cell physiological states and plasmid segregational stability. Biotechnology Reports., v. 5, p. 7-13, 2015.

4 AGGARWAL, B.B.; BHARDWAJ, A.; AGGARWAL, R.S.; SEERAM, N.P.; SHISHODIA, S.; TAKADA, Y. Role of resveratrol in prevention and therapy of cancer: preclinical and clinical studies. Anticancer Res., v. 24, p. 27832840, 2004.

5 AKANDE, M.G.; ORN, S.; NORRGREN, L. Evaluation of the toxic effects of clozapine in zebra fish (Danio rerio) embryos with the fish embryo toxicity test. International Journal on Pharmaceutical and Biomedical Research., v. 1, p. 90-94, 2010.

6 ALBINATI, A.C L.; MOREIRA, E.L.T.; ALBINATI, R.C.B.; CARVALHO, J.V.; DE LIRA, A.D.; SANTOS, G.B.; VIDAL, L.V.O. Biomarcadores histológicos - toxicidade crônica pelo Roundup em piauçu (Leporinus macrocephalus). Arq Bras Med Vet e Zootec., v. 61, p. 621-627, 2009.

7 ALI, S., AALDERS, J. \& RICHARDSON, M.K. Teratological effects of a panel of sixty water-soluble toxicants on zebrafish development. Zebrafish., v. 11, p. 129-141, 2014.

8 ALMEIDA, J.A.; DINIZ, Y.S.; MARQUES, S.F.G.; FAINE, L.A.; RIBAS, B.O.; BURNEIKO, R.C.; NOVELLI, E.L.B. The use of the oxidative stress responses as biomarkers in Nile tilapia (Oreochromis niloticus) exposed to in vivo cadmium contamination. Environment International., v. 27, p. 673679, 2002.

9 AMRI, A.; CHAUMEIL, J.C.; SFAR, S.; CHARRUEAU, C. Administration of resveratrol: What formulation solutions to bioavailability limitations. $\boldsymbol{J}$ Control Release., v.158, p.182-193, 2012. 
10 ANISIMOVA, N.YU.; KISELEVSKY, M.V.; SOSNOV, A.V.; SADOVNIKON, S.V.; STANKOV, I.N.; GAKH, A.A. Trans-, cis-, and dihydro-resveratrol: a comparative study Chemistry. Chem Cent J., v. 5, p. 1-6, 2011.

11 ARAGÃO, M. A.; ARAÚJO, R.P.A. 2006. Métodos de Ensaios de Toxicidade com Organismos Aquáticos. Cap. 6, p: 117 - 152. 2006. In: ZAGATO, P.A. e BERTOLETTI, E. 2006. Ecotoxicologia aquática princípios e aplicações. ZAGATTO e BERTOLETTI (org.) São Carlos: Rima; 2006.

12 ASHARANI, P.V.; WU, Y, L.; GONG, Z.; VALIYAVEETTIL, S. Toxicity of silver nanoparticles in zebrafish models. Nanotechnology., v. 19, p. 1-8, 2008.

13 ASSOCIAÇÃO BRASILEIRA DE NORMAS TÉCNICAS (ABNT NBR 15088). Ecotoxicologia aquática, Toxicidade aguda, Método de ensaio com peixes: in ABNT, 2011.

14 ASSOCIAÇÃO BRASILEIRA DE NORMAS TÉCNICAS (ABNT NBR 15499). Ecotoxicologia aquática, Toxicidade crônica de curta duração, Método de ensaio com peixes: in ABNT, 2007.

15 AZEVEDO, F.A.; CHASIN, A.A.M. As bases toxicológicas da ecotoxicologia. São Carlos, Rima, 2003.

16 BACHUR, C. K.; BACHUR, J. A.; VEIGA, E. V.; NOGUEIRA, M. S. Suplementação dietética com resveratrol na promoção da saúde: uma revisão sistemática. Rev. Bras. Nutr. Clín., v. 24, p. 23-28, 2009.

17 BAI, W.; TIAN, W.; ZHANG, Z.; HE, H.; MA, Y.; LIU, N.; CHAI, Z. Effects of copper nanoparticles on the development of zebrafish embryos. Journal of Nanoscience and Nanotechnology., v. 10, p. 1-7, 2010.

18 BAR-LLAN, O.; ALBRECHT, R.M.; FAKO, V.E.; FURGESON, D.Y. Toxicity assessment of multisized gold and silver nanoparticles in zebrafish embryos. Small., v. 5, p. 1879-1910, 2009.

19 BEHRA, M.; COUSIN, X.; BERTRAND, C.; VONESCH, J.; BIELLMANN, D.; CHATONNET, A.; STRÄHLE, U. Acetylcholinesterase is required for neuronal and muscular development in the zebrafish embryo. Nat Neurosci., v. 5, p. 111-118, 2002.

20 BÉLIVEAU, R.; GINGRAS, D. Os alimentos contra o cancer: a prevenção e o tratamento do cancer pela alimentação. Petrópolis, RJ: Editora Vozes, 2007. 
21 BERTOLETTI, E. Determinação da ecotoxicidade crônica para Danio rerio. J. Braz. Soc of Ecotoxicol., v. 4, p. 1-7, 2009.

22 BERTOLETTI, E. Estimativa de efeitos tóxicos crônicos com Danio rerio (Pisces, Cyprinidae). 2000. Tese (Doutorado) - Universidade de São Paulo, São Paulo.

23 BERTOLETTI, E. Toxicidade e Concentração de agentes tóxicos em efluentes industriais. Revista Ciência e Cultura., v. 43, p. 271-277, 1990.

24 BITTERMAN, J.L.; CHUNG, J.H.; Metabolic effects of resveratrol: addresing the controversies. Cellular and Molecular Life Sciences., v. 72, p. 14731488, 2015.

25 BOOCOCK, D.J.; FAUST, G.E. Phase I dose escalation pharmacokinetic study in healthy volunteers of resveratrol, a potential cancer chemopreventive agent. Cancer Epidemiol Biomarkers Prev., v. 16, p. 1246-1252, 2007.

26 BRADFORD, M. A rapid and sensitive method for the quantification of microgram quantities of protein utilizing the principle of protein-dye binding. Analytical Biochemistry., v. 72, p. 248-254, 1976.

27 BRASIL. CONAMA. Resolução no 430, de 13 de maio de 2011. Dispõe sobre as condições e padrões de lançamento de efluentes, complementa e altera a Resolução n 3ㄱ, de 17 de março de 2005, do Conselho Nacional do Meio Ambiente- CONAMA. Diário Oficial da União: República Federativa do Brasil, Poder Executivo, Brasília, DF, 16 maio de 2011. p. 89.

28 BRAUNBECK, T.; LAMMER, E. Fish embryo toxicity assays. German Federal Environment Agency. UBA contract number 20385 422. p. 2-40. 2006.

29 BRENTANO, D. M. Desenvolvimento e aplicação do teste de toxicidade crônica com Daphnia magna: Avaliação de efluentes tratatos de um aterro sanitário. 2006. Dissertação (Mestrado) - Universidade Federal de Santa Catarina, Florianópolis.

30 BRITO, L.B. Avaliação ecotoxicológica do antibiótico amoxicilina considerando sua presença no ambiente aquático. 2016. Dissertação (Mestrado) - Universidade Federal de Goiás, Goiânia.

31 BUGIAK, B. J. The aryl hydrocarbon receptor and the cardiovascular system in zebrafish (Danio rerio). 2009. Dissertação (Mestrado) University of Saskatchewan, Saskatchewan. 
32 CAIRNS, J.J.; NIEDERLEHNER, B.R. Ecological Toxicity Testing: Scale, Complexity, and Relevance. Boca Raton, Lewis Publishers, 1995.

33 CARERI, M.; CORRADINI, C.; ELVIRI, L.; NICOLETTI, I.; ZAGNONI, I. Direct HPLC analysis of quercetin and trans-resveratrol in red wine, grape, and winemaking by products. Journal of Agricultural and Food Chemistry., v. 51, p. 5226-5231, 2003.

34 CASTRO, A.A.A.S. Avaliação ecotoxicológica de efluentes industriais utilizando Danio rerio Hamilton-Buchanan, 1822 (Teleoestei, Cyprinidae). 2008. Dissertação (Mestrado) - Universidade Federal do Rio Grande do Norte, Natal.

35 CHANG, LI.; XIAOFEI, XU.; ZHIHAO, TAO.; XIU, J.W.; YUANJIANG, PAN. Resveratrol dimers, nutritional componentes in grape wine, are selective ROS scavengers and weak Nrf2 activators. Food Chemistry., v. 173, p. 218-223, 2015.

36 CHAVES, M.M.; FLEXAS, J.; PINHEIRO, C. Photosynthesis under drought and salt stress: regulation mechanisms from whole plant to cell. Annals of Botany., v.103, p.551-560, 2009.

37 CHENG, S.H.; WING, K.W.A.; HUNG, S.C.; SHIU, S.W.R. Cellular and molecular basis of cadmium-induced deformities in zebrafish embryos. Environ Toxicol Chem., v. 19, p. 3024-3031, 2000.

38 CHUKWUMAH, Y.C.; WALKER, L.T.; VERGHESE, M.; OGUTU, S. Effect of frequency and duration of ultrasonication on the extraction efficiency of selected isoflavones and trans-resveratrol from peanuts (Arachis hypogaea). Ultrasonics Sonochemistry., v. 16, p. 293-299, 2009.

39 CLAIRBORNE, A. Catalase activity. In: Greenwald, R.A. (Ed), CRC Handbook of Methods in Oxygen Radical Research, p. 283-284, 1985.

40 COELHO, E.B. Mecanismos de formação de edemas. Revista Medicina Ribeirão Preto., v. 37, p. 189-198, 2004.

41 COSTA, C. R.; OLIVI, P.; BOTTA, C. M. R.; ESPINDOLA, E. L. G. A toxicidade em ambientes aquáticos: discussão e métodos de avaliação. Quím. Nova., v. 31, p. 1820-1830, 2008.

42 COSTA, A.J.R.; MELA, M.A.H.C.; PELLETIER, E.; RANDI, M.A.; RIBEIRO, O.C.A. Enzymatic inhibition and morphological changes in Hoplias malabaricus from dietary exposure to lead(II) or methylmercury. Ecotoxicol. Environ. Saf., v. 67, p. 82-88, 2007. 
43 COTTART, C.H.; NIVET-ANTOINE, V.; BEAUDEX, J.L. Review of recente data on the metabolism, biological effects, and toxicity of resveratrol in humans. Mol Nutr Food Res., v. 58, p. 7-21, 2014.

44 COTTART, C. H.;NIVET-ANTOINE, V.;LAGUILLIER-MORIZOT, C.BEAUDEUX, J. L. Resveratrol bioavailability and toxicity in humans. Mol Nutr Food Res., v. 54, p. 7-16, 2010.

45 CROWELL, J.P.; KORYTKO, P.J.; MORRISEY, R.L.; BOOTH, T.D.; LEVINE, B.S. Resveratrol-associated renal toxicity. Toxicol Sci., v. 82, p. 614-619, 2004.

46 DAVE, G.; XIU, R. Toxicity of mercure, copper, nickel, lead, and cobalt to embryos and larvae of zebrafish, Brachydanio rerio. Archives of Environmental Contamination and Toxicology., v. 21, p. 126-134, 1991.

47 DEJANA, E.; LASSERVE, E.B.; WEINSTEIN, B.M. The control of vascular integrity by endothelial cell junctions: molecular basis and pathological implications. Developmental Cell., v. 16, p. 209-221, 2009.

48 DIAMANTINO, T.C.; ALMEIDA, E.; SOARES, A.M.V.M.; GUILHERMINO, L. Lactate dehydrogenase activity as an effect criterion in toxicity tests with Daphnia magna. Straus. Chemosphere., v.45, p. 553-560, 2001.

49 DOCHERTY, J.J.; SMITH, J.S.; FU, M.M.; STONER, T.; BOOTH, T. Effect of topically applied resveratrol on cutaneous herpes simplex virus infections in hairless mice. Antiviral Research., v. 61, p. 19-26, 2004.

50 DOMINGUES, D. F.; BERTOLETTI, E. Seleção, manutenção e cultivo de organismos aquáticos. In: ZAGATTO, P. A.; BERTOLETTI, E.

Ecotoxicologia aquática - princípios e aplicações. São Carlos: Rima, 2006. p. 153-184.

51 DOMINGUES, I.; GUILHERMINO, L.; SOARES, A.M.V.M.; NOGUEIRA, A.J.A. Assessing dimethoate contamination in temperate and tropical climates: Potential use of biomarkers in bioassays with two chironomid species. Chemosphere., v.69, p.145-154, 2007.

52 DOUILLET-BREUIL, A.C.; JEANDET, P.; ADRIAN, M.; BESSIS, R. Changes in the phytoalexin content of various Vitis spp. in response to ultraviolet C elicitation. J Agric Food Chem., v.47, p. 4456-4461, 1999. 
53 DU, F.Y.; XIAO, X.H.; LI, G.K. Application of ionic liquids in the microwaveassisted extraction of trans-resveratrol from Rhizma Polygoni Cuspidati. Journal of Chromatography A., v. 1140, p. 56-62, 2007.

54 ELLMAN, G.L.; COURTNEY, K.D.; ANDRES, J.R.; FEATHERSTONE, R.M. A new and rapid colorimetrie determination of acetylcholinesterase activity. Biochem. Pharmacol., v.7, p. 88-95, 1961.

55 FABIÃO, C. O vinho na Lusitânia: reflexões em torno de um problema arqueológico. Revista Portuguesa de Arqueologia., v. 1, p. 169-198, 1998.

56 FACCO, E.M.P.; FOGAÇA, A.O.; DAUDT, E.; GODOY, H.T. Quantificação de 5-metiltetrahidrofolato no processamento e conservação de vinhos de uvas viníferas e híbridas. Ciência e Tecnologia Alimentar., v. 27, p. 874$877,2007$.

57 FERNÁNDEZ-MAR, M.I.; MATEOS, R.; GARCÍA-PARRILLA, M.C.; PUERTAS, B.; CANTOS-VILLA, E. Bioactive compounds in wine: Resveratrol, hydroxytyrosol and melatonin: A review. Food Chem., v.130, p.797-813, 2012.

58 FRACÁCIO, R. Utilização de bioensaios ecotoxicológicos com Danio rerio (Cypriniformes, Cyprinidae) e análises limnológicas para a avaliação ambiental dos reservatórios do médio e baixo Rio Tietê (SP). 2001. Dissertação (Mestrado)-Universidade de São Paulo, São Carlos.

59 FRANCIOSO, A.; MASTROMARINO, P.; RESTIGNOLI, R.; BOFFI, A.; d'ERME, M.; MOSCA, L. Improved stability of trans-resveratrol in aqueous solutions by carboxymethylated $(1,3 / 1,6)-\beta$-D-glucan. J Agric Food Chem., v. 62 , p. 1520-1525, 2014.

60 FRASCO, M.F; GUILHERMINO, L. Effects of dimethoate and betanaphthoflavone on selected biomarkers of Poecilia reticulata. Fish Physiol Biocherm., v.26, p. 149-156, 2002.

61 FREITAS, A.A.; DETONI, A.M.; CLEMENTE, E.; OLIVEIRA, C.C. Determinação de resveratrol e características químicas em sucos de uvas produzidos em sistemas orgânicos e convencional. Revista Ceres., v. 57, n. 1, p. 1-5, 2010.

62 FRÉMONT, L. Minireview: Biological effects of resveratrol. Life Sciences., v. 66, p. 663-673, 2000. 
63 FUIMAN, L.A. Special considerations of fish eggs and larval. In: FUIMAN, L.A.; WERNER, R.G. (eds). Fishery Science: The unique contributions of early life stage. Blacwell Science, p.1-32, 2002.

64 GHERARDI-GOLDSTEIN, E.B.E.; ZAGATTO, P.A.; ARAÚJO, R.P.A.; RAMOS, M.L.L.C. Procedimentos para utilização de testes de toxicidade no controle de efluentes líquidos. CETESB: Companhia de Tecnologia de Saneamento Ambiental São Paulo, SP. 1990.

65 GILLESPIE, N.D.; LENZ, T.L. Resveratrol: potential benefits on aging and heart disease. American Journal of lifestyle medicine., v.6, p. 390-392, 2012.

66 GILL. T.S.; TEWARI, H.; PANDE, J. Use of the fish enzyme system in monitoring water quality: effects of mercury on tissue enzymes. Comp. Biochem. Physiol., v. 97, p. 287-292, 1990.

67 GOLDBERG, D.M.; YAN, J.; NG, E.; DIAMANDIS, E.P.; KARUMANCHIRI, A.; SOLEAS, G.; WATERHOUSE, A.L. Direct injection gas chromatographic mass spectrometric assay for trans-resveratrol. Analytical Chemistry., v. 66, p. 3959-3963, 1994.

68 GOMES, M.V.T.; SATO, Y. Avaliação da contaminação por metais pesados em peixes do rio São Francisco à jusante da represa de Três Marias, Minas Gerais, Brasil. Saúde \& Amb. Rev., v.6, p. 24-30, 2011.

69 GOULART, M.; CALLISTO, M. Bioindicadores de qualidade de água como ferramenta em estudos de impacto ambiental. Revista da FAPAM, v. 2, p. 1-3, 2003.

70 GRUNWALD, D.J.; EISEN, J.S. Headwater of the zebrafish-emergence of a new model vertebrate. Nat Ver Genet., v. 3, p. 717-724, 2002.

71 GUILHERMINO, L.; LOPES, M.C.; CARVALHO, A.P.; SOARES, A.M.V.M. Acetylcholinesterase activity in juvenile Daphnia magna Strauss. Bull Environ Contam Tox., v. 57, p. 979-985, 1996.

72 GÜLÇIN, I. Antioxidant properties of resveratrol: A structure-activity insight. Innov Food Sci Emerg., v.11, p. 210-218, 2010.

73 GUO, S. Linking genes to brain, behavior and neurological diseases: what can we learn from zebrafish?. Genes Brain Behav., v. 3, p. 63-74, 2004. 
74 HABIG W.; PABST M.J. ANA JAKOBY W.B. Glutathione-S-Transferases. The first enzymatic step in mercapturic acid formation. The Journal of Biological Chemistry., v.22, p. 7130-7139, 1974.

75 HALLARE, A.V.; SCHIRLING, M.; LUCKENBACH, T.; KOHLER, H.R.; TRIEBSKORN, R. Combined effects of temperature and cadmium on developmental parameters and biomarker responses in zebrafish (Danio rerio) embryos. Journal of Thermal Biology., v. 30, p. 7-17, 2005.

76 HASSAN-KHABBAR, S.; COTTART, C.H.; WENDUM, D.; VIBERT, F.; CLOT, J.P.; SAVOURET, J.F., CONTI, M.; NIVET-ANTOINE, V. Postischemic treatment by trans-resveratrol in rat liver ischemiareperfusion: a possible strategy in liver surgery. Liver Transpl., v. 14, p. 451-459, 2008.

77 HEREDIA, A.; DAVIS, C.; REDFIELD, R. Synergistic inhibition of HIV-1 in activated and resting peripheral blodd mononuclear cells, monocyte-derived macrophages, and selected drug-resistant isolates with nucleoside analogues combined with a natural product, resveratrol. Journal of Acquired Immune Deficiency Syndromes., v. 25, p. 246-255, 2000.

78 HILL, A.J.; TERAOKA, H.; HEIDEMAN, W.; PETERSON, R.E. Zebrafish as a model vertebrate for investigating chemical toxicity. Toxicological Sciences., v. 86, p. 6-19, 2005.

79 HOSHINO, J.; PARK, E. J.; KONDRATYUK, T. P.; MARLER, L.; PEZZUTO, J. M.; VAN BREEMEN, R. B.; MO, S. Y.; LI, Y. C.; CUSHMAN, M. Selective Synthesis and Biological Evaluation of Sulfate-Conjugated Resveratrol Metabolites. Journal of Medicinal Chemistry., v. 53, p. 5033-5043, 2010.

80 HUANG, S.Y.; FENG, C.W.; HUNG, H.C.; CHAKRABORTY, C.; CHEN, C.H.; CHEN, W.F.; JEAN, Y.H.; WANG, H.M.D.; SUNG, C.S.; SUN, Y.M.; WU, C.Y.; LIU, W.; HASIAO, C.D.; WEN, Z.H. A novel zebrafish model to provide mechanistic insights into the inflammatory events in carrageenan induced abdominal edema. Plos one., v. 9, p. 1-11, 2014.

81 IKARI, F.L; BOIANI, N.F.; PIETRO, T.C. Adequação da metodologia do ensaio de toxicidade com o embrião do peixe Danio rerio utilizando-se o sulfato de cobre como substância de referência. 2013. Monografia (Graduação) - Centro Universitário São Camilo, São Paulo.

82 INTERNATIONAL ORGANIZATION FOR STANDARDIZATION (ISSO document 10 993-5). Biological evaluation of medical devices, Part 5, Tests for cytotoxicity: in vitro methods, 2009. 
83 JANG, M.; CAI, L.; UDEANI, G.O.; SLOWING, K.V.; THOMAS, C.F.; BEECHER, C.W.;FONG, H.H.; FARNSWORTH, N.R.; KINGHORN A.D.; MEHTA, R.G.; MOON, R.C.; PEZZUTO, J. M. Cancer chemopreventive activity of resveratrol, a natural product derived from grapes. Science., v. 275, p. 218-220, 1997.

84 JEANDET, P.; DOUILLET-BREUIL, A. C.; BESSIS, R.; DEBORD, S.; SBAGHI, M.; ADRIAN, M. Phytoalexins from the Vitaceae: biosynthesis, phytoalexin gene expression in transgenic plants, antifungal activity, and metabolism. J. Agric. Food Chem., v. 50, p. 2731-2741, 2002.

85 JENKINS, G. Molecular mechanisms of skin ageing. Mech Ageing Dev., v. 123, p. 801-810, 2002.

86 JESUS, F.T.; OLIVEIRA, R.; SILVA, A.; CATARINO, A.L.; SOARES, A.M.V.M.; NOGUEIRA, A.J.A.; DOMINGUES, I. Lethal and sub lethal effects of the biocide chlorhexidine on aquatic organisms. Ecotoxicology., v. 22, p. 1348-1358, 2013.

87 JEZIERSKA, B.; LUGOWSKA, K.; WITESKA, M. The effects of heavy metals on embryonic development of fish (a review). Fish Physiol Biochem., v. 35, p. 625-640, 2009.

88 KENDALL, R.J.A.T.A., BAKER, R.J.; BENS, C.M;. CARR, J.A.; CHIODO, L.A.; DICKERSON, R.L.; DIXON, K.R.; FRAME, L.T.; HOOPER, M.J.; MARTIN, C.F.; MCMURRY, S.T.; PATINO, R.; SMITH, E.E.; THEODORAKIS, W. Casarett and doull's toxicology - the basis science of poisons. 6 ed. New York, MacGraw-Hill, 2001.

89 KIMMEL, C.B.; BALLARD, W.W.; KIMMEL S.R.; ULLMANN, B.; SCHILLING, T.F. Stages of embryonic development of zebrafish. Developmental Dynamics., v. 203, p. 253-310, 1995.

90 LANCON, A.; HANET, N.; JANNIN, B.; DELMAS, D.; HEYDEL, J. M.; LIZARD, G.; CHAGNON, M. C.; ARTUR, Y.LATRUFFE, N. Resveratrol in human hepatoma HepG2 cells: Metabolism and inducibility of detoxifying enzymes. Drug Metabolism and Disposition., v. 35, p. 699-703, 2007.

91 LANG, F.; QIN, Z.; LI, F.; ZHANG, H.; FANG, Z.; HAO, E. Apoptotic cell death induced by resveratrol is partially mediated by the autophagy pathway in human ovarian cancer cells. Plos One Journal Pone., v. 10, p. 1-17, 2015. 
92 LEONARD, S. S.; XIA, C.; JIANG, B. H.; STINEFELT, B.; KLANDORF, H.; HARRIS, G. K.; SHI, X. Resveratrol scavenges reactive oxygen species and effects radical-induced cellular responses. Biochem Biophys Res Commun., v. 309, p. 1017-1026, 2003.

93 LI, K.; WU, J.; JIANG, L.; SHEN, LI.; LI, J.; HE, Z.; WEI, P.; LV, Z.; HE, M. Developmental toxicity of 2,4-dichlorophenoxyacetic acid in zebrafish embryos. Chemosphere., v. 171, p. 40-48, 2017.

94 LUTTE, A. H. Avaliação do metabolismo da adenosina em um modelo de sindrome alcoólica fetal em zebrafish (Danio rerio). 2015. Dissertação (Mestrado) - Pontífica Universidade Católica do Rio Grande do Sul, Porto Alegre.

95 MAGALHÃES, D. P.; FERRÃO FILHO, A. S. A ecotoxicologia como ferramenta no biomonitoramento de ecossistemas aquáticos. Oecol. Bras., v. 12, p. 355-381, 2008.

96 MAGALHÃES, V.D. Efeito radiomodificador do resvetarol em cultura de células de rabdomiossarcoma humano (RD) aplicando o teste do cometa. 2012. Dissertação (Mestrado) - Instituto de Pesquisas Energéticas e Nucleares, São Paulo.

97 MAHADY, G.B.; PENDLAND, S.L.; CHADWICK, L.R. Resveratrol and red wine extracts inhibit the growth of CagA + strains of Helicobacter pylori in vitro. The American Journal of Gastroenterology., v. 98, p. 1440-1441, 2003.

98 MARQUEZI, M.L. Bases metabólicas do conceito limiar anaeróbio. Revista Mackenzie de Educação Física e Esporte., v. 5, p. 53-64, 2006.

99 MARTINI, G.A. Avaliação da citotoxicidade do dietiltoluamida (DEET) em mexilhões Perna perna (Linnaeus, 1758) irradiados e não irradiados com radiação gama de ${ }^{60}$ Co. 2013. Dissertação (Mestrado) Instituto de Pesquisas Energéticas e Nucleares, São Paulo.

100 McKIM, J.M. Evaluation of tests with early life stages of fish for predicting long - term toxicity. J. Fish. Res. Board. Can., v. 34, p. 1148 1154, 1977.

101 MISCHIATTI, K.L. Obtenção de derivados do Resveratrol por biotransformações e avaliação das atividades biológicas. 2012.

Dissertação (Mestrado) - Universidade Federal do Paraná, Curitiba. 
102 MOKNI, M.; ELKAHOUI, S.; LIMAN, F.; AMRI, M.; AOUANI, E. Effect of resveratrol on antioxidant enzyme activities in the brain of healthy rat. Neurochem Res., v.32, p. 981-987. 2007.

103 MONTEIRO, M.; QUINTANEIRO, C.; PASTORINHO, M.; PEREIRA, M.L.; MORGADO, F.; GUILHERMINO, L.; SOARES, A.M.V.M. Acute effects of 3,4-dichloroaniline on biomarkers and spleen histology of the common goby Pomatoschistus microps. Chemosphere., v. 62, p. 1333-1339, 2006.

104 MORAES, V.; LOCATELLI, C. Vinho: uma revisão sobre a composição química e benefícios à saude. Revista Evidência., v. 10, p. 57-68, 2010.

105 MORENO, C.S. Avaliação dos efeitos da radiação ionizante e do Resveratrol na cultura de células tumorais de pulmão. 2016. Tese (Doutorado) - Instituto de Pesquisas Energéticas e Nucleares, São Paulo.

106 MORENO, C. S. Estudo do efeito radioprotetor do resveratrol. 2009. Dissertação (Mestrado) - Instituto de Pesquisas Energéticas e Nucleares, São Paulo.

107 MUKHERJEE, S.; DUDLEY, J. I.; DAS, D. K. Dose-dependency of resveratrol in providing health benefits. Dose Response., v. 8, p. 478-500, 2010.

108 MULLER, E.B.; LIN, S.; NISBET, R.M. Quantitative adverse outcome pathway analysis of hatching in zebrafish with $\mathrm{CuO}$ nanoparticles. Environmental Science \& Technology., v. 49, p. 11817-11824, 2015.

109 NADERALI, E.K. Obesity and cardiovascular dysfunction: a role for resveratrol? Obes. Res. Clin. Pract., v. 3, p. 45-52, 2009.

110 NEMEN, D.; SENNA, E.L. Preparação e caracetrização de suspensões coloidais de nanocarreadores lipídicos contendo resveratrol destinados à administração cutânea. Quim. Nova., v. 34, p. 408-413, 2011.

111 NEVES, H.M.P. Avaliação ecotoxicológica da Barrina de Esmoriz, utilizando uma análise integrada de biomarcadores enzimáticos e histopatológicos. 2012. Dissertação (Mestrado), Faculdade de Ciência e Tecnologia, Porto.

112 NUNES, B.; CARVALHO, F.; GUILHERMINO, L. Effects of widely used pharmaceuticals and detergent on oxidative stress biomarkers of the crustacean Artemia parthenogenetica. Chemosphere., v.62, p. 581-594, 2006. 
113 OECD. GUIDELINE FOR THE TESTING OF CHEMICALS. Fish embryo acute toxicity (FET) test, n. 236, julho 2013.

114 OLAS, B., WACHOWICZ, B.; SALUK-JUSZCZAK, J.; ZIELINSKI, T. Effect of resveratrol, a natural polyphenolic compound, on platelet activation induced by endotoxin or thrombin. Thromb. Res., v.107, p.141-145, 2002.

115 OLIVEIRA, J.M.M.; GALHANO, V.; HENRIQUES, I.; SOARES, A.M.V.M.; LOUREIRO, S. Basagran induces developmental malformations and changes the bacterial community of zebrafish embryos. Environmental Pollution., v. 221, p. 52-63, 2017.

116 OLIVEIRA, L.L.D. Biomarcadores enzimáticos e testes ecotoxicológicos na avaliação da toxicidade de fármacos em invertebrados aquaticos. 2014. Tese (Doutorado) - Universidade de São Paulo, São Carlos.

117 OLIVEIRA, R.; DOMINGUES, I.; GRISOLIA, C.K.; SOARES, A.M.V.M. Effects of triclosan on zebrafish early-life stages and adults. Environ Sci Pollut Res., v. 16, p. 679-688, 2009.

118 OLIVEIRA, R.; McDONOUGH, S.; LADEWIG, J.C.L.; SOARES, A.M.V.M.; NOGUEIRA, A.J.A.; DOMINGUES, I. Effects of oxytetracycline and amoxicillin on development and biomarkers activities of zebrafish (Danio rerio). Environmental Toxicology and Pharmacology., v. 36, p. 903912, 2013.

119 ORTUÑO, J.; COVAS, M.I.; FARRE, M.; PUJADAS, M.; FITO, M.; KHYMENETS, O.; ANDRES-LACUEVA, C.; ROSET, P.; JOGLAR, J.; LAMUELA-RAVENTÓS, R. M.; TORRE, R. Matrix effects on the bioavailability of resveratrol in humans. Food Chemistry., v. 120, p. 11231130, 2010.

120 OSMAN, A.G.M.; WUERTZ, S.; MEKKAWY, I.A.; EXNER, H.J.; KIRSCHBAUM, F. Lead induced malformations in embryos of the African Catfish Clarias gariepinus (Burchell, 1822). Environmental Toxicology., v. 22, p. 375-389, 2007.

121 PANKRATZ, T.M. Environmental engineering dictionary and directory. Thomas M. Pankratz. Lewis Publishers, Boca Raton; Florida. 2001.

122 PAN, Q.H.; WANG, L.; LI, J.M. Amounts and subcellular localization of stilbene synthase in response of grape berries to UV irradiation. Plant Science., v.176, p. 360-366, 2009. 
123 PAULO, L. A. S. Determinação dos teores de resveratrol em vinhos tintos com denominação de origem controlada beira interior $e$ avaliação das suas propriedades antimicrobianas. 2011. Tese (Doutorado) - Universidade da Beira Interior, Covilhã.

124 PENNA, N.G.; HECKTHEUER, L.H.R. Vinho e saúde: uma revisão. Infarma., v. 16, p. 64-67, 2004.

125 PERVAIZ, S. Chemotherapeutic potential of the chemopreventive phytoalexin resveratrol. Drug Resistance Updates., v. 7, p. 333-344, 2004.

126 PETRONILHO, E.C.; PINTO, A.C.; VILLAR, J.D.F. Acetilcolinsterase: Alzheimer e guerra química. Revista Militar de Ciências e Tecnologia., v. 18, p. 3-12, 2011.

127 PEZET, R.; GINDRO, K.; VIRET, O.; SPRING, J.L. Glycosylation and oxidative dimerization of resveratrol are respectively associated to sensitivity and resistance of grapevine cultivars to downy mildew.

Physiological and Molecular Plant Pathology., v. 65, p. 297-303, 2004.

128 PITANGA, F. L. The effect of sodium hypochlorite in different aquatic organisms. 2011. Dissertação (Mestrado) -Universidade de Aveiro, Aveiro.

129 PYTEL, R.F.; SILVA, L.V.N.; NUNES, A.S.; GESZTESI, J.; COSTA, A. Estudo in vivo de atividade anti-radicalar por quantificação de peróxidos cutâneos. Anais Brasileiros de Dermatologia., v. 80, supl. 3, p. S323S328, 2005.

130 PLAA, G.L. Present status: toxic substances in the environment. Can $\mathbf{J}$ Physiol Pharmacol., v. 60, p. 1010-1016, 1982.

131 PUSCEDDU, F.H. Avaliação do risco ambiental de sedimentos contaminados com Triclosan, Ibuprofeno e 17a-Etinilestradiol empregando invertebrados marinhos bentônicos. 2016. Tese (Doutorado) - Instituto de Pesquisas Energéticas e Nucleares, São Paulo.

132 PUSHPALATHA, B.; VENUMADHAV, N.; SWATHI, M.; RAJU, A.B. Neuroprotective effect os resveratrol against scopolamine-induced cognitive impairment and oxidative stress in rats. Arch Biol Sci Belgrade., v. 65, p. 1381-1386, 2013.

133 RAND, G.M.E.; PETROCELLI, S.R. Fundamentals of Aquatic Toxicology. Washington, Hemisphere, 1985. 
134 RAND, G.M.; WELLS, P.G.; MACCARTY, L.S. Fundamentals of Aquatic Toxicology: Effects, environmental fate and risk assessment. 2.ed. Washington, DC, Taylor e Francis, 1125p. 1995.

135 RANG, H. P.; DALE, M. M.; RITTER, J. M.; Drogas que Inibem a Cholinesterase. $4 a$ edição, Guanabara Koogan, 2001,110-115.

136 RATNA, W. N.; SIMONELLI, J. A. The action of dietary phytochemicals quercetin, catechin, resveratrol and naringenin on estrogen-mediated gene expression. Life Sciences., v. 70, p. 1577-1589, 2002.

137 REZENDE, V.B. Desenvolvimento de modelos animais alternativos para avaliação dos efeitos comportamentais e metabólicos de antipsicóticos. 2013. Tese (Doutorado) - Universidade Federal de Minas Gerais, Belo Horizonte.

138 RIBO, J.M. Interlaboratory comparision studies of the luminescente bactéria toxicity bioassay. Environ. Toxicol. Water Qual., v. 12, p. 283294, 1997.

139 ROBLES, V.; CABRITA, E.; PAZ, P.; CUÑADO, S.; ANEL, L.; HERRÁEZ, M.P. Effect of a vitrification protocol on the lactate dehydrogenase and glucose-6- phosphatase dehydrogenase activities and the hatching rates of Zebrafish (Danio rerio) and turbot (Scophthantalmus maximus) embryos. Theriogenology., v. 61, p. 1367-1379, 2004.

140 ROGERO, S.O.; LUGÃO, A.B.; IKEDA, T.I.; CRUZ, A.S. Teste in vitro de Citotoxicidade: Estudo comparativo entre duas metodologias. Materials Research., v. 6, p. 317-319, 2003.

141 ROMERO-PÉREZ, A.I.; LAMUELA-RAVENTÓS, R.M.; ANDRÉSLACUEVA, C.; LA TORRE-BORONAT, M.C. Method for the quantitative extraction of resveratrol and piceid isomers in grape berry skins. Effect of powdery mildew on the stilbene content. J Agric Food Chem., v.49, p.210-215, 2001.

142 RUBINGER, C. F. Seleção de métodos biológicos para a avaliação toxicologia de efluentes industriais. 2009. Tese (Doutorado) Universidade Federal de Minas Gerais, Belo Horizonte.

143 SAKATA, Y.; ZHUANG, H.; KWANSA, H.; KOEHLER, R.C.; DORÉ, S. Resveratrol protects against experimental stroke: Putative neuroprotective role of heme oxygenase 1. Experimental Neurology., v. 224, p. 325-329, 2010. 
144 SANT'ANNA, M. C. B. Zebrafish (Danio rerio) como modelo para estudo da toxicidade induzida pelo ferro. 2009. Dissertação (Mestrado) - Pontifícia Universidade Católica do Rio Grande do Sul, Porto Alegre.

145 SARAVANAN, M.; KARTHIKA, S.; MALARVIZHI, A.; RAMESH, M. Ecotoxicological impacts of clofibric acid and diclofenac in common carp (Cyprinus carpio) fingerlings: Hematological, biochemical, ionoregulatory and enzymological responses. Journal of Hazardous Materials., v. 195, p. 188-194, 2011.

146 SAUTTER, C. K. Avaliação da presença de resvetrarol em suco de uva. 2003. Dissertação (Mestrado) - Universidade Federal de Santa Maria, Santa Maria.

147 SAUTTER, C.K.; DENARDIN, S.; ALVES, A.O.; MALLMANN, C.A.; PENNA, N.G.; HECKTHEUER, L.H. Determinação de resveratrol em sucos de uva no Brasil. Ciência e Tecnologia de Alimentos., v. 25, p. 437-442, 2005.

148 SCHMATZ, R.; MAZZANTI, C.M.; SPANEVELLO, R.; STEFANELLO, N.; GUTIERRES, J.; CORRÊA, M.; ROSA, M.M.; RUBIN, M.A.; SCHETINGER, M.R.C.; MORSCH, V.M. Resveratrol prevents memory deficits and the increase in acetylcholinesterase activity in streptozotocin induced diabetic rats. European Journal of Pharmacology., v. 610, p. 42-48, 2009.

149 SCHNEIDER, H.; FRITZKY, L.; WILLIAMS, J.; HEUMANN, C.; YOCHUM, M.; PATTAR, K.; NOPPERT, G.; MOCK, V.; HAWLEY, E. Cloning and expression of a zebrafish 5-HT(2C) receptor gene. Gene., v. 502, p. 10817, 2012.

150 SCHÖPPNER, A.; KINDI, H. Purification and properties of a stilbene synthase from induced cell suspension cultures of peanut. J. Biol Chem., v. 259 , p. 6806-6811, 1984.

151 SCOPE - Scientific Committee on Problems of the Environment. Report 12: Principles of Ecotoxicology. 1978. Edited by G.C. Butler, published on behalf of the Scientific Comitte on Problems of the Environment (SCOPE) of the International Council of Scientific Unions (ICSU) by John Wiley e Sons. Chicherster, New York, Brisbane, Toronto. Disponível em: < http://globalecology.stanford.edu/SCOPE/SCOPE 12/SCOPE 12.html> em 25 de março de 2017. 
152 SGAMBATO, A.; ARDITO, R.; FARAGLIA, B.; BONINSEGNA, A.; WOLF, F.I.; CITTADINI, A. Resveratrol, a natural phenolic compound, inhibits cell proliferation and prevents oxidative DNA damage. Mutation Reserch., v. 496, p. 171-180, 2001.

153 SILVA, K.T.; PATHIRATNE, A. In vitro and in vivo effects of cadmium on cholinesterases in Nile tilapia fingerlings: implications for biomonitoring aquatic pollution. Ecotoxicology., v. 17, p. 725-731, 2008.

154 SILVA, S. R. Quantificação de substâncias com atividade estrogênica e caracterização da toxicidade embriolarval em zebrafish (Danio rerio) nos efluentes das Estações de Tratamento de Esgotos Sul e Norte e no Lago Paranoá. 2015. Dissertação (Mestrado) -Universidade de Brasília, Brasília.

155 SINHA, K.; CHAUDHARY, G.; GUPTAM Y.K. Protective effect of resveratrol against oxidative stress in middle cerevral artery occlusion model of stroke in rats. Life Science., v. 71, p. 655-665, 2002.

156 SOLEAS, G.J.; DIAMANDIS, E.P.; GOLDBERG, D.M. Resveratrol: a molecule whose time has come? And gone? Clinical Biochemistry., v. 30, p. 91-113, 1997.

157 SOUSA, E. C.P.M. Toxicologia Marinha: Histórico. In: NASCIMENTO, I. A.; SOUSA, E. C. P. M.; NIPPER, M. Métodos em ecotoxicologia marinha: Aplicações no Brasil. São Paulo, Artes Gráficas e Industria, p. 9-12. 2002.

158 SOUTO, A.A.; CARNEIRO, M.C.; SEFERIN, M.; SENNA, M.J.H.; CONZ, A.; GOBBI, K. Determination of trans-resveratrol concentrations in Brazilian red wines by HPLC. Journal of Food Composition and Analysis., v. 14, p. 441-445, 2001.

159 SPENCE, R. GERLACH, G.; LAWRENCE, C.; SMITH, C.The behaviour and ecology of the zebrafish, Danio rerio. Biol Rev Camb Philos Soc., v. 83, p. 13-34, 2008.

160 SUVARCHALA, G.; PHILIP, G.H. Toxicity of 3,5,6-trichloro-2-pyridinol tested at multiple stages of zebrafish (Danio rerio) development. Environ Sci Pollut Res., v. 23, p. 15515-15523, 2016.

161 SZKUDELSKA, K.; SZKUDELSKI, T. Resveratrol, obesity and diabetes. European Journal of Pharmacology., v. 635, p. 1-8, 2010. 
162 TAIZ, L.; ZEIGER, E. Fisiologia vegetal. 3. ed. Porto Alegre, Artmed, 2004.

163 TESOLIN, G.A.S.; MARSON, M.M.; JONSSON, C.L.; NOGUEIRA, A.J.A.; FRANCO, D.A.S.; ALMEIDA, S.D.B.; MATALLO, M.B.; MOURA, M.A.M. Avaliação da toxicidade de herbicidas usados em cana-de-açucar para 0 Paulistinha (Danio rerio). O Mundo da Saúde., v. 38, p. 86-97, 2014.

164 TOKUNAGA, S.; WOODIN, B.R.; STEGEMAN, J.J. Plant lignan secoisolariciresinol suppresses pericardial edema caused by dioxin-like compounds in developing zebrafish: Implications for suppression of morphological abnormalities. Food and Chemical Toxicology., v. 96, p. 160-166, 2016.

165 TRELA, B.C.; WATERHOUSE, A.L. Resveratrol: Isomeric Molar Absorptivities and Stability. J. Agric. Food Chem., v.44, p.1253-1257, 1996.

166 TRUHAUT, R. Ecotoxicology: objectives, principles and perspectives. Ecotoxicol Environ Saf., v.1, p. 151-173, 1977.

167 TSAI, S.K.; HUNG, L.M.; FU, Y.T.; CHENG, H.; NIEN, M.W.; LIU, H.Y.; ZHANG, F.B.; HUANG, S.S. Resveratrol neuroprotective effects during focal cerebral ischemia injury via nitric oxide mechanism in rats. $J$ Vasc Surg., v. 46, p. 346-353, 2007.

168 UDENIGWE, C.C.; RAMPRASATH, V.R.; ALUKO, R.E.; JONES, P.J. Potential of resveratrol in anticancer and anti-inflammatory therapy. Nutr Rev., v. 66, p. 445-454, 2008.

169 VALLVERDÚ-QUERALT, A.; BOIX, N.; PIQUÉ, E.; GÓMEZ-CATALAN, J.; MEDINA-REMON, A.; SASOT, G.; MERCADER- MARTÍ, M.; LLOBET, J.M.; LAMUELA-RAVENTOS, R. Identification of phenolic compounds in red wine extract samples and zebrafish embryos by HPLC-ESI-LTQOrbitrap-MS. Food Chemistry., v. 181, p. 146-151, 2015.

170 VANETTEN, H. D.; MANSFIELD, J. W.; BAILEY, J. A.; FARMER, E. E. Two classes of plant antibiotics: phytoalexins versus "phytoanticipins". Plant Cell., v. 6, p. 1191-1192, 1994.

171 VASANTHI, H.R.; PARAMESWARI, R.P.; DELEIRIS, J.; DAS, D.K. Health benefits of wine and alcohol from neuroprotection to heart health. Front. Biosci., v. 4, p. 1505-1512, 2012. 
172 VASSAULT, A. Lactate Dehydrogenase. In: Bergmeyer HO (ed) Methods of enzymatic analysis, enzymes: oxyreductases transferases. Academic, New York, p. 118-126, 1983.

173 VEIGA, L. F.; VITAL, N. Testes de toxicidade aguda com o microcrustáceo Artemia sp. In: NASCIMENTO, I. A.; SOUSA, E. C. P. M.; NIPPER, M. Métodos em ecotoxicologia marinha: aplicações no Brasil. São Paulo, Artes Gráficas e Indústria, p. 111-112. 2002.

174 VIEIRA, L.R.; SOUSA, A.; FRASCO, M.F.; LIMA, I.; MORGADO, F.; GUILHERMINO, L. Acute effects of Benzo[a]pyrene, anthracene and a fuel oil on biomarkers of the common goby Pomatoschistus microps. Sci Total Environ., v. 395, p. 87-100, 2008.

175 VITRAC, X.; DESMOULIÈRE, A.; BROUILLAUD, B.; KRISA, S.; DEFFIEUX, G.; BARTHE, N.; ROSENBAUM, J.; MÉRILLON, J. M. Distribution of $\left[{ }^{14} \mathrm{C}\right]$ - trans-resveratrol, a cancer chemopreventive polyphenol, in mouse tissues after oral administration. Life Sciences., v. 72, p. 2219-2233, 2003.

176 VUONG, T.V.; FRANCO, C.; ZHANG, W. Treatment strategies for high resveratrol induction in Vitis vinífera L. cell suspension culture.

Biotechnology Reports., v.1-2, p.15-21, 2014.

177 WALLE, T. Bioavailability of resveratrol. Ann N Y Acad Sci., v. 1215, p. 915, 2011.

178 WALLE, T.; HSIEH, F.; DELEGGE, M.H.; OATIS, J.E.; WALLE, U.K. High absorption but very low biovailability of oral resveratrol in humans. Drug Metabolism and Disposition., v. 32, p. 1377-1382, 2004.

179 WANG, D.; XU, Y.; LIU, W. Tissue distribution and excretion of resveratrol in rat after oral administration of Polygonum cuspidatum extract (PCE).

Phytomedicine., v. 15, p. 859-866, 2008.

180 WANG, Q.; YU, S.; SIMONYA, A.; ROTTINGHAUS, G.; SUN, G.Y.; SUN, A.Y. Resveratrol protects against neurotoxicity induced by kainic acid. Neurochemical Research., v. 29, p. 2105-2112, 2004.

181 WATSON, F.L.; SCHMIDT, H.; TURMAN, Z.K.; HOLE, N.; GARCIA, H.; GREGG, J.; TILGHMAN, J.; FRADINGER, E.A. Organophosphate pesticides induce morphological abnormalities and decrease locomotor activity and heart rate in Danio rerio and Xenopus laevis. Environmental Toxicology and Chemistry., v. 33, p. 1337-1345, 2014. 
182 WIEDER, T.; PROKOP, A.; BAGCI, B.; ESSMANN, F.; BERNICKE, D.; SCHUZE-OSTHOFF, K.; DÖRKEN, B.; SCHMALZ, H.G.; DANIEL, P.T.; HENZE, G. Piceatannol, a hydroxulated analog of the chemopreventive agent resveratrol, is a potent inducer of apoptpsis in the lymphoma cell line BJAB and in primary, leukemic lymphoblast. Leukemia., v. 15, p. 1735-1742, 2001.

183 WORLD HEALTH ORGANIZATION. Global status report on alcohol and health 2014. Geneva: WHO, 2014. Disponível em:< http://apps.who.int/iris/bittstream/10665/112736/1/9789240692763_eng.pd f>. Acesso em: 03/04/2017.

184 WORLD HEALTH ORGANIZATION. Global status report on alcohol 2004. Geneva: WHO, 2004. Disponível em:<

http://www.who.int/susbtance_abuse/publications/global_status_report_20 04_overview.pdf>. Acesso em: 03/04/2017.

185 YIN, J.; YANG, J.N.; ZHANG, F.; MIAO, P.; LIN, Y.; CHEN, M. Individual and joint toxic effects of cadmium sulfate and $\alpha$ - naphthoflavone on the development of zebrafish embryo. Journal of Zhejiang UniversityScience B (Biomedicine \& Biotechnology)., v. 15, p. 766-775, 2014.

186 YU, L.; SUN, Z. J.; WU, S.L.; PAN, C.E. Effect of resveratrol on cell cycle proteins in murine transplantable liver cancer. World Journal of Gastroenterology., v. 9, p. 2341-2343, 2003.

187 YU, M.H., TSUNODA, H.; TSUNODA, M. Environmental toxicology: biological and health effects of pollutants. 2.ed. Boca Raton, Florida, 2005.

188 ZAGATTO, P. A.; BERTOLETTI, E. Ecotoxicologia aquática princípios e aplicações. São Carlos: Rima, 2006.

189 ZHANG, C.; WILLETT, C.; FREMGEN, T. Zebrafish: an animal model for toxicological studies. Current Protocols in Toxicology., v. 17, p. 1711718, 2003.

190 ZHANG, L.; LI, Q.; CHEN, L.; ZHANG, A.; HE, J.; WEN, Z.; WU, L. Toxicity of surface water from Huangpu River to luminous bacteria (Vibrio qinghaiensis SP. Q67) and zebrafish (Danio rerio) embryos.

Ecotoxicology and Environmental Safety., v. 112, p. 137-143, 2015.

191 ZHOU, S.; DONG, Q.; LI, S.; GUO, J.; WANG, X.; ZHU, G. Developmental toxicity of cartap on zebrafish embryos. Aquatic Toxicology., v. 95, n. 4, p. 339-346, 2009. 